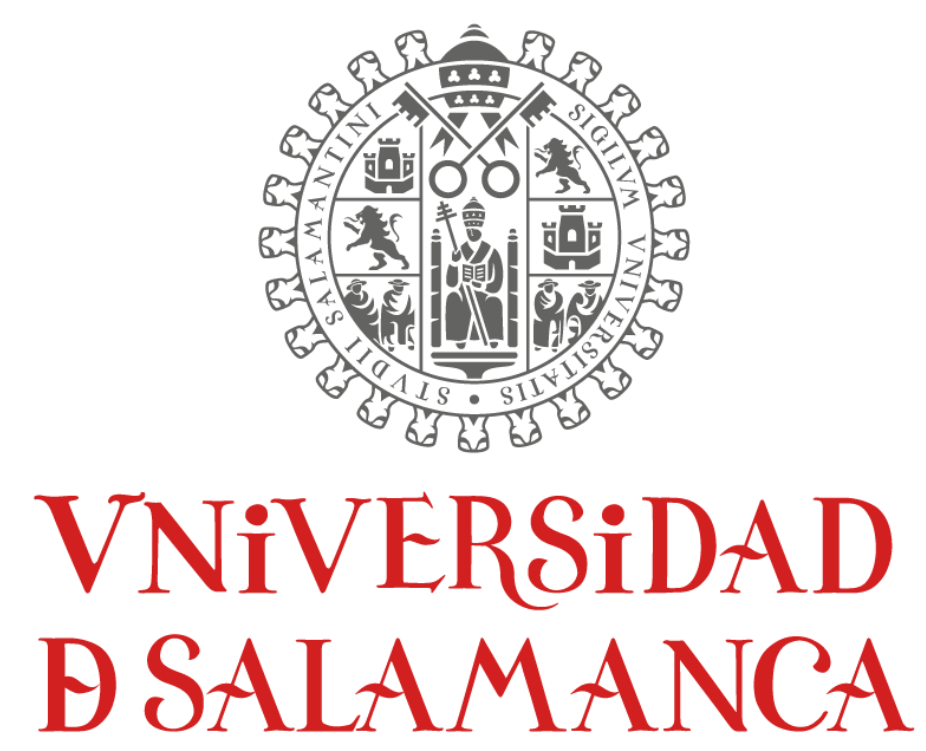

CAMPUS DE EXCELENCIA INTERNACIONAL

FACULTAD DE ENFERMERÍA Y FISIOTERAPIA

TESIS DOCTORAL

INFLUENCIA DEL PROGRAMA DE REVITALIZACIÓN GERIÁTRICA EN

LA COGNICIÓN Y SU POSIBLE RELACIÓN CON LA LONGITUD

TELOMÉRICA EN EL ENVEJECIMIENTO FISIOLÓGICO.

JUAN LUIS SÁNCHEZ GONZÁLEZ 


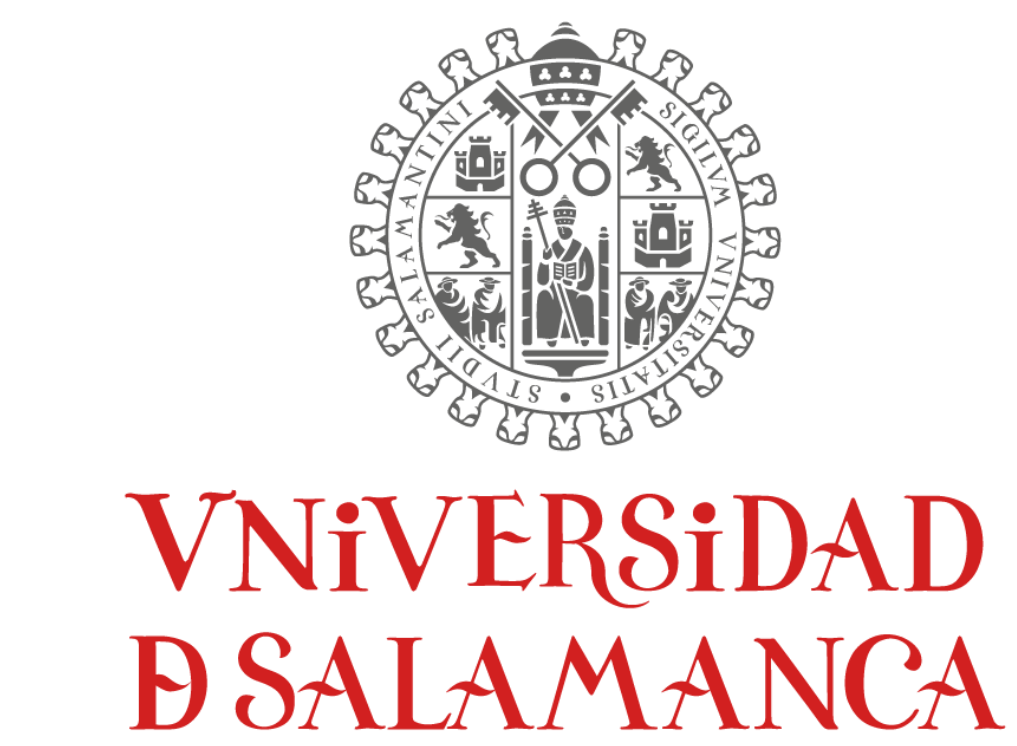

CAMPUS DE EXCELENCIA INTERNACIONAL

TESIS DOCTORAL

INFLUENCIA DEL PROGRAMA DE REVITALIZACIÓN GERIÁTRICA EN

LA COGNICIÓN Y SU POSIBLE RELACIÓN CON LA LONGITUD TELOMÉRICA EN EL ENVEJECIMIENTO FISIOLÓGICO.

\section{PRESENTADA POR:}

Juan Luis Sánchez González

DIRIGIDA POR:

José Ignacio Calvo Arenillas

Juan Luis Sánchez Rodríguez

Salamanca, 2020 
Dr. D. José Ignacio Calvo Arenillas, Catedrático de la Universidad.

Dr. D, Juan Luis Sánchez Rodríguez, Profesor Titular de Universidad.

\section{CERTIFICA:}

Que Don Juan Luis Sánchez González ha realizado bajo su dirección el estudio titulado “ Influencia del programa de revitalización geriátrica en la cognición y su posible relación con la longitud telomérica en el envejecimiento fisiológico", que reúne todos los requisitos para que el autor pueda optar con él al Grado de Doctor por la Universidad de Salamanca.

Y para que conste, firma en Salamanca, Enero del 2020

Los Directores:

D. José Ignacio Calvo Arenillas

D, Juan Luis Sánchez Rodríguez 
Dedicada a mi padre, Juan Luis 


\section{ÍNDICE}

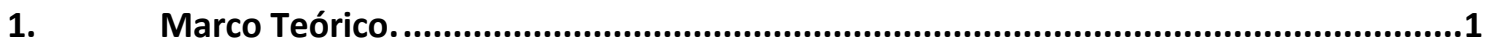

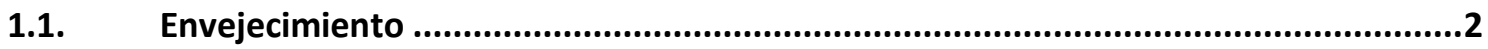

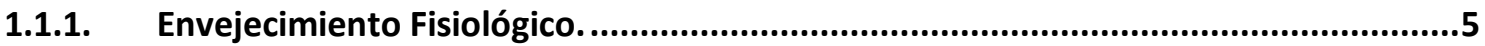

1.1.1.1. Cambios cognitivos en el envejecimiento fisiológico .................................................6

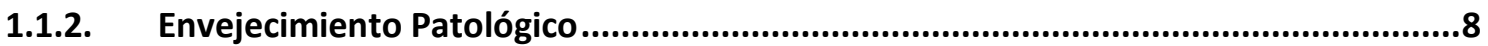

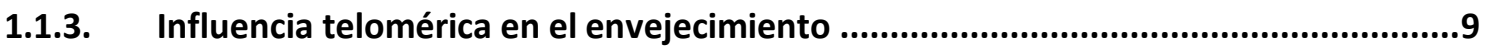

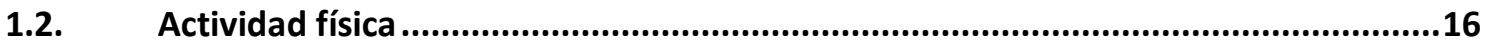

1.2.1. Actividad física recomendada en los adultos mayores ............................................17

1.3. Ejercicio físico ............................................................................................................17

1.3.1. Ejercicio Terapéutico................................................................................................18

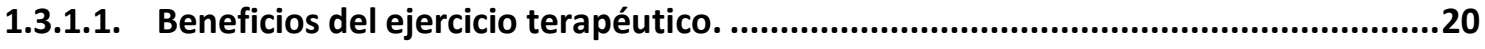

1.3.2. Influencia del ejercicio físico en la cognición............................................................22

1.3.3. Influencia del ejercicio físico en la longitud telomérica ..........................................23

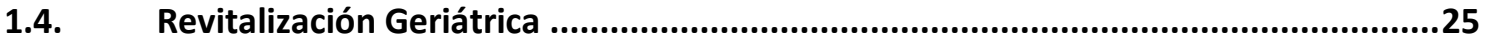

1.4.1. Programa de Revitalización Geriátrica de la Universidad de Salamanca ...................25

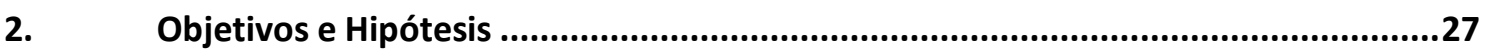

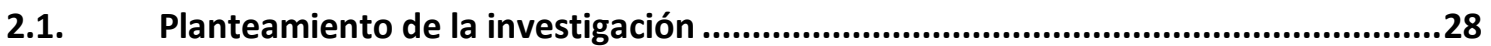

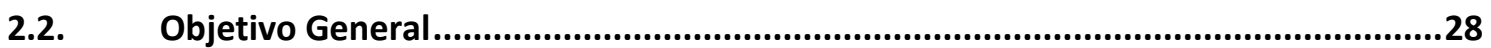

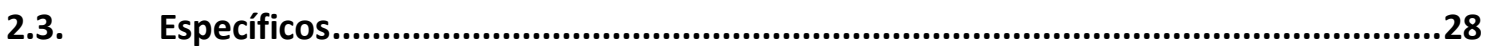

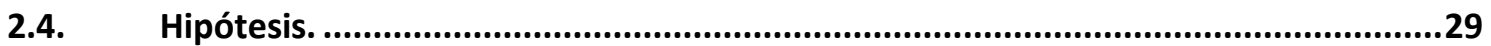

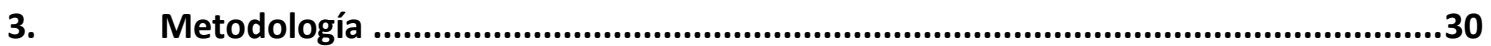

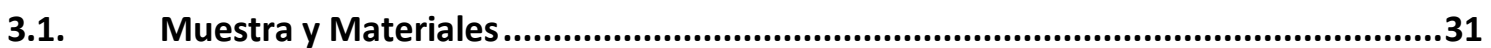

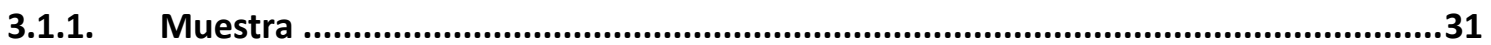

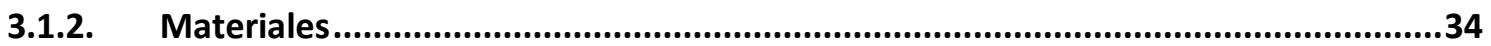

3.1.2.1. Instrumentos de evaluación de las funciones cognitivas........................................34

3.1.2.2. Instrumentos de evaluación/cuantificación de la telomerasa y longitud relativa del

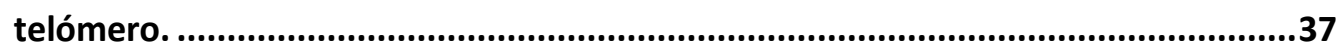

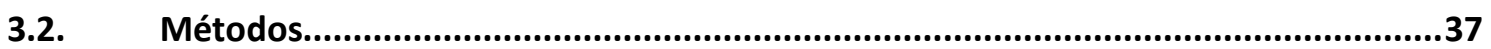

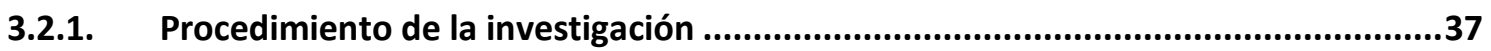

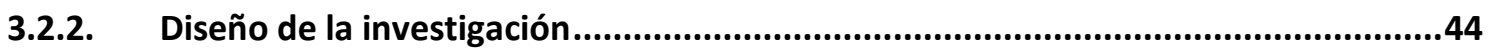

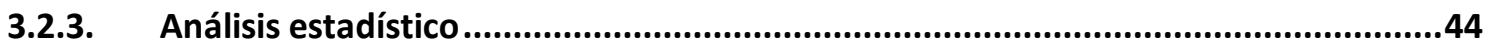

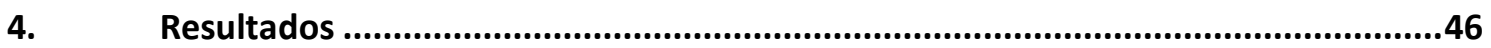

4.1. Estadísticos descriptivos y distribución de los sujetos en ambos grupos .................47

4.2. Influencia del Programa de Revitalización sobre las funciones cognitivas evaluadas. 
4.3. Influencia de la intervención en la actividad de la telomerasa.

4.4. Influencia del crecimiento de la actividad de la telomerasa en el rendimiento de las funciones cognitivas....................................................................................................63

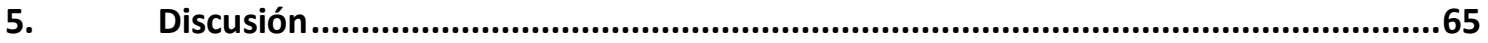

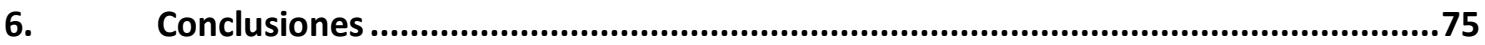

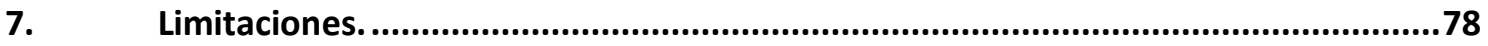

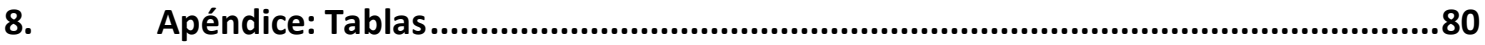

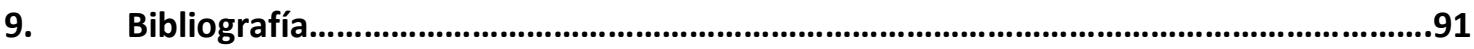

10. Anexo 


\section{JUSTIFICACIÓN}

Varios han sido los motivos para la realización de este trabajo de investigación. Actualmente vivimos una situación demográfica marcada por una disminución de la tasa de mortalidad, que trae consigo un aumento de la esperanza de vida y un aumento en el número de individuos mayores de 65 años, que se refleja en un envejecimiento de la población. Este envejecimiento produce un aumento en la incidencia de las enfermedades ligadas a la edad, entre las que se incluyen los procesos neurodegenerativos. Este tipo de enfermedades generan un gran impacto social y económico ya que provocan gran dependencia y gasto sanitario. Es por ello, que las políticas sociales y sanitarias, deben ir orientadas a la prevención primaria de este tipo de patologías a través de programas sociales de ejercicio físico, educación sanitaria, promoción de hábitos de vida saludables etc...

Desde el Área de Fisioterapia de la Universidad de Salamanca en colaboración con el Ayuntamiento de la ciudad, se lleva realizando desde hace varios años un Programa de Revitalización Geriátrica (PRG) siendo uno de sus objetivos principales la prevención de enfermedades ligadas a la edad, mediante la promoción de hábitos de vida saludables como la educación sanitaria, lo que se traduciría en una disminución en el grado de dependencia de los sujetos con este tipo de patologías. Durante los últimos años de mis estudios para alcanzar el Grado en Fisioterapia, mostré un marcado interés en el ámbito de la investigación, es por ello, que opté y posteriormente obtuve una plaza de personal investigador (PI) en dicho Programa, al finalizar mis estudios. Ese mismo año, realicé el Máster Universitario en Intervención a Personas con Enfermedad de Alzheimer, donde defendí mi Trabajo Fin de Máster con un objetivo principal, que consistía en estudiar el posible impacto que tenía el PRG en las funciones cognitivas de los participantes. Concluimos que las personas que participaron en el Programa de Revitalización Geriátrica presentaron una mejoría significativa en las variables cognitivas estudiadas: memoria, velocidad de procesamiento, rapidez perceptivo-motora, atención, funciones ejecutivas, así como en la calidad de vida percibida por los participantes.

La pregunta obligada, en relación a los resultados obtenidos, consistía en determinar el motivo por el cual y desde un punto de vista fisiológico, el Programa de Revitalización Geriátrica podría ser una herramienta útil de cara a la mejora de las funciones cognitivas de adultos mayores que se traduciría en una mejora en su calidad de vida. 
Consultada la bibliografía existente, autores como Elizabeth Blackburn junto a sus colaboradores, descubrieron el papel de la enzima Telomerasa. Observaron que dicha enzima se encargaba de la formación de unas proteínas llamadas telómeros. Con el paso de los años lograron descubrir que tanto la enzima telomerasa como los telómeros eran los principales biomarcadores responsables del envejecimiento. Viendo estos resultados, y los obtenidos por nosotros, nos surgió la pregunta de si la metodología empleada en el Programa de Revitalización Geriátrica podría tener influencia directa en la enzima telomerasa y en la longitud telomérica que justificaría la mejora en la cognición de los sujetos adultos.

Por los motivos expuestos y desde el Programa de Doctorado: Salud, Discapacidad, Dependencia y Bienestar, decidimos seguir esta línea de investigación mediante la realización de la Tesis Doctoral, titulada "INFLUENCIA DEL EJERCICIO FÍSICO EN LA COGNICIÓN Y SU POSIBLE RELACIÓN CON LA ACTIVIDAD TELOMÉRICA EN EL ENVEJECIMIENTO FISIOLÓGICO” 


\section{INTRODUCCIÓN}




\section{Marco Teórico.}

\subsection{Envejecimiento}

Resulta evidente el cambio de la pirámide poblacional en los países desarrollados. Según el Instituto Nacional de Estadística (INE), a 1 de Enero de 2018 España se situaba en 46.659 .302 habitantes, aumentando 132.263 personas más con respecto al año 2017. Si estudiamos el crecimiento poblacional por grupos de edad, podemos observar un aumento importante, en el grupo de mayores de 60 años. Los mayores incrementos con respecto al año 2017 se producen en los siguientes intervalos: 60-64 (con 76.685 personas más); 70-74 (con un incremento de 71.049 personas) y 85-89 (con un aumento de 35.377 personas).

Gracias a las nuevas políticas sanitarias y a los avances en el ámbito de la salud se está propiciando un aumento en la esperanza de vida y una disminución de la tasa de mortalidad, provocándose una inversión en la pirámide de población (mayor población envejecida). Esta situación provoca un aumento de las enfermedades crónicas ligadas a la edad, cuya prevalencia va unida a este envejecimiento de la población.

En este contexto nace la necesidad de crear y desarrollar políticas sanitarias que permitan un aumento de la calidad de vida en este grupo de población. Esta necesidad, hace que aumente el interés por el estudio del envejecimiento desde múltiples disciplinas. Teniendo en cuenta la definición de salud que dio la OMS en 1946:“estado de completo bienestar físico, mental y social, y no solamente la ausencia de afecciones o enfermedades" puede decirse que la salud es uno de los principales indicadores básicos de calidad de vida de cualquier población. El estudio del estado cognitivo en el envejecimiento, así como de los cambios neuroanatómicos y neurofisiológicos que subyacen a dicho estado cognitivo, es de especial relevancia en la sociedad actual.

El aumento de las enfermedades crónicas ligadas a la edad genera gran preocupación tanto en el ámbito social como en el ámbito sanitario. Quizás una de las enfermedades que más preocupación genera sean las demencias. En los años 90, Thomas, Pesce y Cassuto (Thomas, 1990) determinaron un incremento de las demencias en personas mayores de 65 años (incremento del 0,1\%), un 1\% en personas entre los 65 y 74 años y más del $10 \%$ en personas mayores de 85 años. Estos datos han ido aumentando conforme han ido pasando los años, tal es el caso que se estima una prevalencia del $8 \%$ en España, es decir, 800.000 personas y para el año 2050 los datos son alarmantes pues 
se espera 2.000.000 de personas afectadas (ONU, 2009) Otro de los principales problemas que presentan las demencias, se centra, en que sólo la mitad de ellas están diagnosticadas, realizándose en fases muy avanzadas de la enfermedad, lo que determina la aplicación tardía, tanto de los tratamientos farmacológicos y no farmacológicos utilizados en estos procesos.

Como ya hemos comentado anteriormente, la población residente en España se sitúa, según las cifras de población en 46.659.302 millones de habitantes, de los cuales aproximadamente 8,6 millones son personas mayores de 65 años, constituyendo el 18,5\% de la población total. Castilla y León, Asturias, Galicia, País Vasco, Aragón y Cantabria son las comunidades autónomas más envejecidas con mayor porcentaje de personas que supera el 20\% (INE, 2018).

Existen un gran número de teorías que tratan de explicar el porqué del envejecimiento humano, diferenciándose dos grandes grupos (Hernández \& González, 2013):

- Teorías no estocásticas o deterministas: engloban aquellos fenómenos que se describen mediante un número determinado de variables concretas y conocidas, que se desarrollan de la misma manera en cada reproducción del fenómeno estudiado. No recurren a ningún cálculo de probabilidades. Son innatas, están programadas en el genoma del individuo.

- Teorías estocásticas o ambientales: se fundamentan en la acumulación casual de sucesos nocivos, debido a la exposición de factores exógenos adversos y, por otra parte, fenómenos que implican una serie de variables aleatorias que hacen este fenómeno sea producto del azar, y se tenga que recurrir a cálculos de probabilidades, para ser estudiado.

A continuación, explicamos algunas de las teorías más conocidas sobre el envejecimiento:

Teoría evolucionista: considera que la estructura anatómica y química del cuerpo humano es el producto de las presiones evolucionistas para conseguir una óptima capacidad reproductiva y no para durar eternamente (López-Pousa, 2006).

Teoría del entrecruzamiento: se refiere a que hay enlaces entre moléculas, siendo las causantes de las enfermedades y la aceleración del envejecimiento (Hernández et al, 2013).n 
Teorías genéticas: engloban a todas las teorías que tratan de explicar que el envejecimiento está dictado por factores genéticos, aun cuando no se ha encontrado algún gen que lo determine (Hernández et al, 2013) (López-Pousa, 2006).

Teoría del error catastrófico de Orgel: postula que con el paso de la edad surgen errores en la síntesis de proteínas, de otra manera, la producción de proteínas por las células es de mala calidad, causando cada vez más errores hasta llegar a una catástrofe en el equilibrio homeostático dando como consecuencia la muerte celular

Teoría de los radicales libres de Denham Harman: considera a los radicales libres como los agentes causales de este proceso y sus manifestaciones. Los radicales libres son subproductos de la actividad metabólica celular, que tienen tanto una función fisiológica como tóxica para la célula. La toxicidad depende de su cantidad y de los mecanismos celulares antioxidantes, por lo que, esta teoría supone un desequilibrio inherente al sistema, por el que la producción de radicales libres supera a los mecanismos de defensa antioxidante (López-Pousa, 2006).

Teoría mitocondrial: sugiere que la alteración de las mitocondrias y sus consecuencias en la producción de energía dentro de la célula puede explicar el deterioro metabólico con el paso del tiempo (López-Pousa, 2006).

Teoría de los telómeros y telomerasas: los telómeros son regiones extremo del DNA, que no son codificables y funcionan como estabilidad estructural de los cromosomas, en la división celular y el tiempo de vida de algunas células. Dichos telómeros se acortan cada vez que una célula se divide, este acortamiento hace que se reduzca el número de mitosis según la estirpe celular, de tal manera que cada célula nueva que nace "es un poco más vieja" que su progenitora, asimismo tiene menos capacidad de volver a reproducirse (Hernández et al, 2013). Esta teoría será explicada detalladamente más adelante.

Cada una de estas teorías, lejos de contradecirse, reflejan una parte o múltiples facetas del problema. De hecho, algunas de ellas se encuentran ligadas entre sí por procesos metabólicos comunes y participan por lo tanto en el desarrollo del envejecimiento

En función de las definiciones vistas anteriormente podemos ver que el envejecimiento puede evolucionar de dos formas, por una parte, hacia un envejecimiento fisiológico y por otra, hacia un envejecimiento patológico. 


\subsubsection{Envejecimiento Fisiológico.}

Se entiende como envejecimiento fisiológico o envejecimiento normal al envejecimiento que experimenta la mayoría de la población, en el que no existen patologías neurodegenerativas y el deterioro cognitivo que se experimenta es atribuible a los cambios que experimenta el cerebro sano al envejecer (López-Pousa, 2006)

El envejecimiento implica una serie de cambios morfológicos y fisiológicos en todos los sistemas. Nos centraremos en cinco sistemas específicos, cuyos cambios asociados al envejecimiento son de alta relevancia tanto por la elevada prevalencia como por las consecuencias funcionales que tiene:

- Envejecimiento renal: el envejecimiento provoca cambios estructurales y declinación de la función renal: engrosamiento de la pared arterial, esclerosis de las arterias glomerulares, disminución de los glomérulos funcionales por oclusión. Disminución del flujo plasmático renal, disminución de la capacidad de concentrar la orina en los túbulos renales (Salech\&Michea, 2012)

- Envejecimiento cardiovascular: Dentro del envejecimiento cardiovascular, podemos destacar un:

- Envejecimiento arterial: el aumento de la rigidez arterial es una de las características del envejecimiento pudiendo ser una etapa previa a la hipertensión arterial. La disfunción endotelial (Safar, 2010) es otro de los cambios en los vasos sanguíneos que se observan en el envejecimiento. La disfunción endotelial (Laso, 2015) está caracterizada por:

- Aumento de la permeabilidad vascular

- Expresión de moléculas de adhesión en el endotelio vascular

- Vasoconstricción arteriolar

- Remodelación vascular

Desde hace varias décadas se lleva investigando sobre el estudio del envejecimiento cognitivo normal. Dichas investigaciones han generado una gran cantidad de resultados, que han traído consigo numerosos debates. Gran parte de las diferencias entre los distintos autores están vinculadas a las diferentes metodologías de estudio, así como el escaso control de otras variables estrechamente relacionadas con el deterioro cognitivo 
en el envejecimiento normal (Véliz, Riffo \& Arancibia, 2010; Khan, Singer \&Vaughan 2017; Edifizi\& Schumacher, 2017)

\subsubsection{Cambios cognitivos en el envejecimiento fisiológico}

La evidencia clínica a lo largo de estos años indica que los individuos ancianos muestran con mayor frecuencia (en relación con otros grupos de edad) diversos cambios cognoscitivos.

Uno de los mayores problemas clínicos que plantea esta situación, es distinguir entre los cambios cognoscitivos propios del envejecimiento fisiológico, y aquellos cambios propios del envejecimiento patológico. Los cambios cognoscitivos asociados a la edad son leves y poco incapacitantes y se refieren sobre todo a las funciones mnésicas y a la rapidez de pensamiento y razonamiento. No obstante, se ha demostrado que las personas ancianas son capaces de utilizar estrategias para compensar estas deficiencias mediante mecanismos de plasticidad y compensación (López-Pousa, 2006)

Dentro de este envejecimiento fisiológico, hay funciones cognitivas que se afectan más que otras. A continuación, explicaremos cuales son los cambios cognitivos que ocurren en el envejecimiento normal en las distintas funciones cognitivas:

\section{Velocidad de procesamiento}

Autores como Salthouse (Salthouse, 1996)concluyen que la disminución de la velocidad de procesamiento durante el envejecimiento normal produce un efecto global en la cognición.

\section{Memoria}

Durante mucho tiempo se consideró la pérdida de memoria una condición sine qua non de demencia, es por ello que en las últimas décadas numerosos estudios han ido enfocados al estudio de la memoria y su relación en el envejecimiento, ya sea normal o patológico.

En 1962, Kral propuso el término “Olvido senescente benigno”(Benign Senescent Forgetfulnes). Con este término se refiere a aquellos ancianos neurológicamente normales que presentan quejas de memoria.

Crook (Crook, 1986) fue un poco más allá e introdujo el término "Deterioro de la memoria asociado a la edad(Age Associated Memory Impairment, AAMI) para referirse 
a aquellos individuos mayores de 50 años que presentan quejas de memoria y en quienes se observa una ejecución inferior a una desviación típica de la norma para un joven adulto, en cualquier test estandarizado de memoria. Dos años más tarde, Blackford y La Rue (Blackford \& La Rue, 1989) introdujeron algunas modificaciones en los criterios establecidos por Crook, proponiendo nuevos test de memoria con el fin de objetivar el deterioro mnésico descrito por la AAMI.

Por lo tanto, el AAMI es el mejor concepto que define el deterioro de memoria asociado al envejecimiento normal.

Dentro del constructo global de memoria, numerosas publicaciones de Nilsson y colaboradores $(2003 ; 2004)$ han llegado a la conclusión de que la mayor afectación reside en la memoria episódica cuando se trata de un proceso de envejecimiento fisiológico, en cambio cuando hablamos de envejecimiento patológico la memoria semántica sería la más afectada.

Autores como Clemente (2015) concluyen que el envejecimiento conlleva una pérdida cognitiva que refleja diversos cambios, los cuales provocan un descenso en memoria, velocidad de procesamiento, concentración, etc.

\section{Función visoperceptiva, visoespacial y visoconstructiva}

La influencia del envejecimiento fisiológico en estas funciones cognitivas parece ser de manera selectiva y específica y no de manera generalizada. (Iachini, Iavarone, Senese, Ruotolo, \& Ruggiero, 2009).

Las tareas visoperceptivas simples y pasivas no se afectan mucho por la edad (Bäckman, Wahlin, Small, Herlitz, Winblad, et al., 2004; Iachini et al., 2009) en cambio, sí se ha observado evidencia del efecto de la edad en la función visoespacial (Moffat, 2009).

En lo que respecta a las funciones visoconstructivas, existe cierta controversia sobre si la edad ejerce un efecto negativo en ella. Existen autores que defienden el impacto negativo de la edad en las tareas visoconstructivas (Ardila et al, 2000; Bläckman et al, 2004).Sin embargo, otros autores defienden la hipótesis de que las tareas visoconstructivas están altamente influenciadas por otros factores que son los que provocan su deterioro como por ejemplo la velocidad de procesamiento o los déficits sensoriales. (Anstey, Dain, Andrews \& Drobny 2002; Haaland, Price \& Larue, 2003). 


\section{Atención y funciones ejecutivas.}

Cuando hablamos de atención, estamos hablando de distintos tipos de procesos y sistemas. Podemos destacar los procesos destinados a crear y mantener un estado de alerta adecuado, los sistemas de orientación destinados a la selección de la información relevante del imput sensorial, y aquellos procesos más relacionados con el control de los recursos atencionales y relacionados con la función ejecutiva (Stuss, 2006). Autores como Kramer y Madden (2008) concluyen que la edad tiene una influencia importante en la disminución de las capacidades atencionales de las personas mayores como por ejemplo la realización de tareas de atención dividida o duales.

Denominamos funciones ejecutivas a aquellas funciones cognitivas orientadas hacia la planificación y organización de las acciones de acuerdo a un objetivo determinado, así como a la iniciación y seguimiento de las mismas y, a la habilidad para cambiar y adaptar esas acciones en función de las contingencias del medio (Correia, 2010). Al igual que el resto de las funciones observadas anteriormente, se puede observar que la edad tiene un efecto de interferencia en esta tarea (Van der Elst, Van Boxtel, Van breukelen \& Jolles, 2006; Clemente et al, 2015)

\subsubsection{Envejecimiento Patológico}

El incremento de la población envejecida ha ido paralelo a la aparición de enfermedades ligadas a la edad, sobre todo aquellas que afectan a pérdidas físicas y mentales, que surgen durante el proceso de envejecimiento.

Dentro de las llamadas enfermedades ligadas a la edad, las demencias son las patologías que generan más preocupación en el ámbito sociosanitario, por las consecuencias derivadas del padecimiento de las mismas, en todos los ámbitos biopsicosociales (Alberca \& López-Pousa, 2002)

La demencia se define como un síndrome caracterizado por la presencia de deterioro cognitivo persistente que interfiere con la capacidad del individuo para llevar a cabo sus actividades profesionales, sociales, es independiente de la presencia de cambios en el nivel de conciencia y es causada por una enfermedad que afecta al sistema nervioso central (Nitrini, Dozzi-brucki, 2012)

En España, en la población mayor de 60 años, el número de personas con demencia se duplicará para el año 2025 (Alberca \& López-Pousa, 2002) 
Según la OMS (2019) la causa más frecuente de demencia en la actualidad es la Enfermedad de Alzheimer (EA), de etiología multifactorial y que en este momento no tiene un tratamiento curativo efectivo

La EA es una patología neurodegenerativa que se caracteriza por la presencia de deterioro cognitivo y conductual y del funcionamiento global de inicio insidioso y curso progresivo de aparición en la edad adulta, principalmente en la vejez (Lanfranco, Manriquez-Navarro, Avello \& Canales-Johnson, 2012).Actualmente está considerada como la causa más frecuente de demencia neurodegenerativa en los países desarrollados y su prevalencia se incrementa con la edad, aproximadamente entre un $60 \%$ y $70 \%$ de los casos de demencia se corresponden con la Enfermedad de Alzheimer (OMS, 2019).

Es una entidad clínico-patológica definida por la asociación de una demencia lentamente progresiva y unos hallazgos histológicos consistentes en placas neuríticas y lesiones neurofibrilares corticales, en una cantidad que excede la que podría encontrarse en una persona no demente de la misma edad(Robles, Del Ser, Alom\& Peña-Casanova, 2002).

El diagnóstico clínico de la EA se realiza por exclusión de otras patologías utilizando los criterios establecidos en DSM-V, ICD-10 y NINCDS-ADRA (McKhan, Drachman \& Folstein, 1991; American Psyquiatric Association, 1994; OMS, 1994)

\subsubsection{Influencia telomérica en el envejecimiento}

Los telómeros de las especies de vida larga, como los seres humanos, se acortan con la edad y la presencia de estos telómeros con una longitud menor inducen a una pérdida de la viabilidad celular, que se ha relacionado con una alteración de la función tisular y con la pérdida de capacidades regenerativas, características del envejecimiento. Hoy en día sabemos que existen numerosas enfermedades y síntomas asociados a un acortamiento telomérico acelerado, como son enfermedades cardiovasculares, del sistema nervioso central (Alzheimer, Parkinson), cáncer, diabetes e infertilidad (Gallardo, 2012).

\section{¿Qué son los telómeros?}

Los telómeros son unas estructuras nucleoproteicas situadas en los extremos de los cromosomas eucarióticos, de importancia crítica tanto en el mantenimiento de la estabilidad genómica como en los procesos de supresión tumoral y envejecimiento (Zakian, 1995). 
La función protectora que desempeñan fue descrita de forma independiente por Muller (1938) y McClintock (1939) quienes observaron de manera individual, que los cromosomas portaban en sus extremos una estructura especial que les confería estabilidad. Müller acuñó el término de etimología griega "telómeros" para denominar a esas estructuras "telos" final y "meros" parte. Por lo tanto, cumplen un rol esencial en la preservación de la integridad cromosómica, protegiendo al DNA codificante de la acción enzimática y la degradación, contribuyendo al mantenimiento de la estabilidad cromosómica; median en importantes interacciones entre los cromosomas y la matriz nuclear, pudiendo además ejercer efectos sobre la transcripción de genes situados en regiones subteloméricas e interactúan con los mecanismos regulatorios del ciclo celular (Blackburn, 1991; Holt, Wright \& Shay, 1996; Armanios \& Blackburn, 2012; Reicherchet, Froy, Boner, Burg \& Daunt et al, 2017).

En la mayor parte de las células eucariotas, los telómeros consisten en repeticiones en tándem de una secuencia rica en guanina (TTAAGGG en todos los vertebrados) que se desarrollan en el extremo de los cromosomas , en dirección $5^{\prime} \rightarrow 3^{\prime}$, con la cadena complementaria, rica en citidina (C). Los telómeros de eucariotas son secuencias hexaméricas repetidas de DNA, potencialmente expansionables y no codificables. Aparecen en el extremo de los cromosomas lineales y son esenciales para el mantenimiento de la estabilidad cromosómica. Los telómeros van unidos al complejo multiproteicos helterina/telosoma que ejerce un papel fundamental en la regulación de la longitud telomérica y en su protección (Aubert \& Lansdorp, 2008)

Las secuencias teloméricas pueden variar entre las especies, pero cada organismo posee la misma secuencia repetitiva en todos sus telómeros. En humanos y en ratones dicha secuencia es TTAGGG, como puede observarse en la figura 1. En el momento del nacimiento, los telómeros de las células somáticas humanas contienen unos $15 \mathrm{~kb}$ del fragmento TTAGGG y los ratones tienen de 25 a $40 \mathrm{~kb}$. En ausencia de telomerasa, en cada división celular se pierden un promedio de 25 a 200 bases de los extremos teloméricos (Opresko \& Shay, 2017), Cuando este acortamiento ocurre entre 80 a 100 veces, la célula deja de dividirse, envejece y muere (Cascales-Angosto \& Álvarez, 2010). 


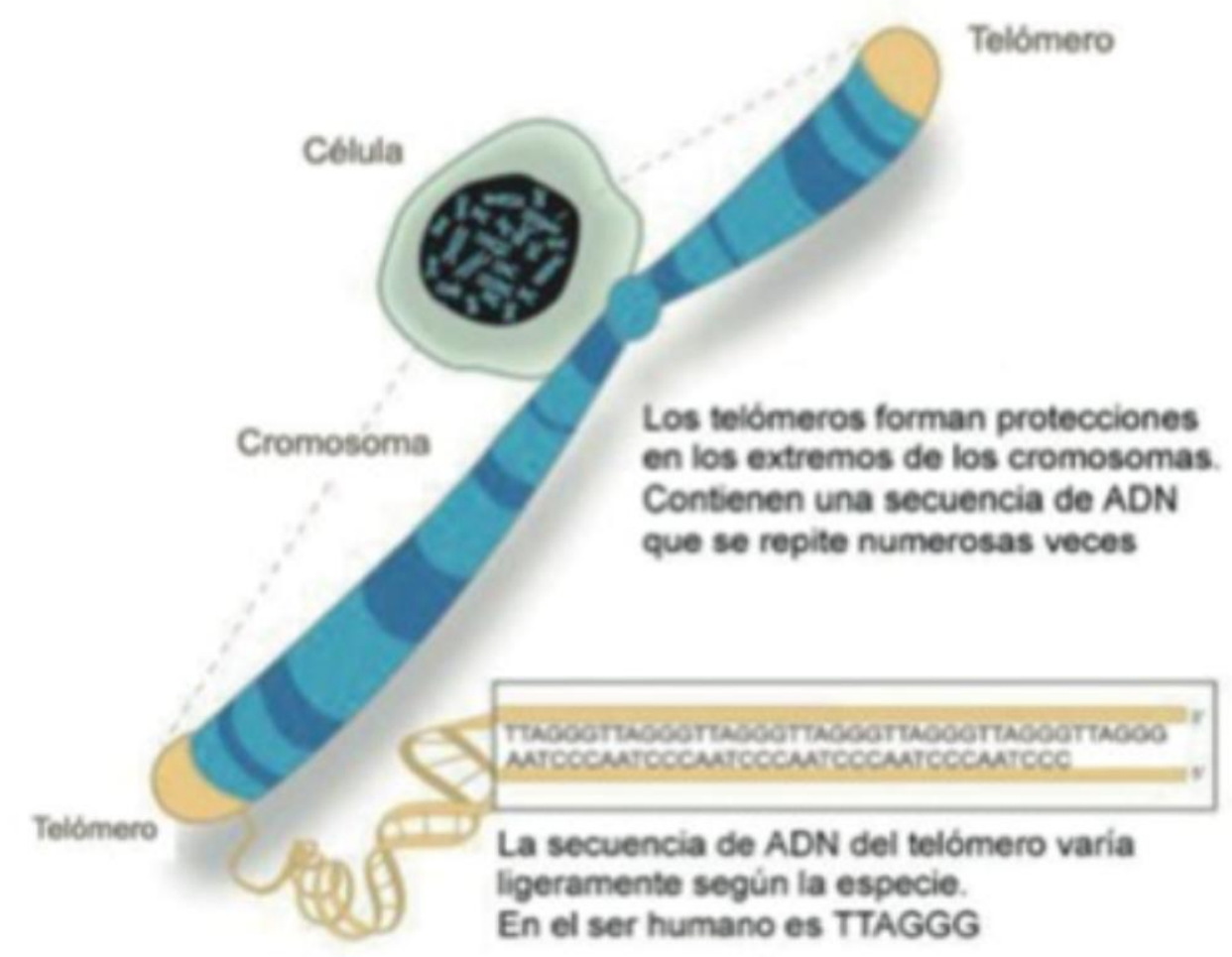

Figura 1. Secuencia de DNA del telómero.

La longitud de los telómeros es variable entre las distintas especies. Por ejemplo, en los linfocitos humanos el tamaño varía entre 2,5 y $15 \mathrm{k}$ pares de bases (kbp) (O’callaghanand, Fenech, 2011).

Las diferencias en la longitud media del telómero no afectan a la correcta función telomérica, a menos que los telómeros se acorten por debajo de una longitud crítica, lo cual impediría su correcta función y conduciría a una inestabilidad cromosómica (Counter, Avilion, Le Feuvre, Stewart, Creide r\& Harley, 1992; Slijepcevic \& Bryant, 1998).

Dicha inestabilidad cromosómica estaría relacionada con un aumento en la probabilidad de producir errores capaces de generar cambios genéticos de importancia para el proceso de desarrollo neoplásico, tales como amplificación génica y pérdida de heterocigosidad (Srinivas, Rachakonda, Hielscher, Calderazzo \& Rudnai et al, 2019).

Al no existir un mecanismo compensatorio, los telómeros en cada división celular se acortan progresivamente debido al problema de la replicación de los extremos de DNA 
lineal, dicho problema fue descubierto por Watson en 1972. Además, existen otros factores como la acción de las nucleasas y la de los radicales libres (ROS) que contribuyen al acortamiento telomérico con cada ciclo celular (Ramírez, Carracedo, Jiménez, Canela, Herrera, Aljama \& Blasco 2003;Kawanishi\&Oikawa, 2004; Sfeir, Chai, Shay \& Wright, 2005), especialmente, se ha demostrado que los radicales libres de oxígeno influyen en el segmento central de guanina 5'-GGG-3' (Arsenis, You, Ogawa, Tinsley \& Zuo, 2017). En la especie humana, como en la mayor parte de las especies de vida larga, los telómeros de todas las células se acortan en mayor o menor medida con la edad, llegando a una longitud crítica tras un determinado número de divisiones celulares (Harley et al., 1990; Opresko \& Shay, 2017).

Este acortamiento de los telómeros se puede acelerar por factores que inducen estrés oxidativo e inflamación (Wolkowitz, Mellon, Epel, Lin, Dhabhar et al, 2011) procesos cancerígenos (Ma, Zhou, Wei, Liu, Pooley et al, 2011), consumir tabaco (Huzen, Wong, van Veldhuissen, Samani, Zwinderman et al, 2013),trastornos psicológicos (Zhang, $\mathrm{Hu}$, Li, Li, Smerin et al, 2014), nivel socioeconómico más bajo (Shiels, McGlynn, MacIntyre, Jhonson, Batty et al, 2011), enfermedades cardiovasculares (Fyhrquist\& Saijonmaa, 2012), diabetes (Zhao, Miao, Wang, Ding, Wang et al, 2013), factores ambientales como la contaminación ambiental (Grahame \& Schlesinger, 2012) o la exposición al humo de tabaco (Theall, McKasson, Mabile, Dunaway \& Drury, 2013). Los telómeros críticamente cortos inducen una pérdida de viabilidad celular, que está relacionada con la pérdida de potencial regenerativo de los diferentes tejidos (Flores, Benetti \& Blasco, 2006; von Zglinicki, Pilger \& Sitte, 2000)

De esta manera, el acortamiento de los telómeros con cada división celular convierte a la longitud telomérica en un "reloj molecular" del envejecimiento del organismo (Blackburn, 2001; Collins \& Mitchel, 2002) y por lo tanto en un importante biomarcador de la edad biológica con múltiples aplicaciones clínicas. Figura 2. 


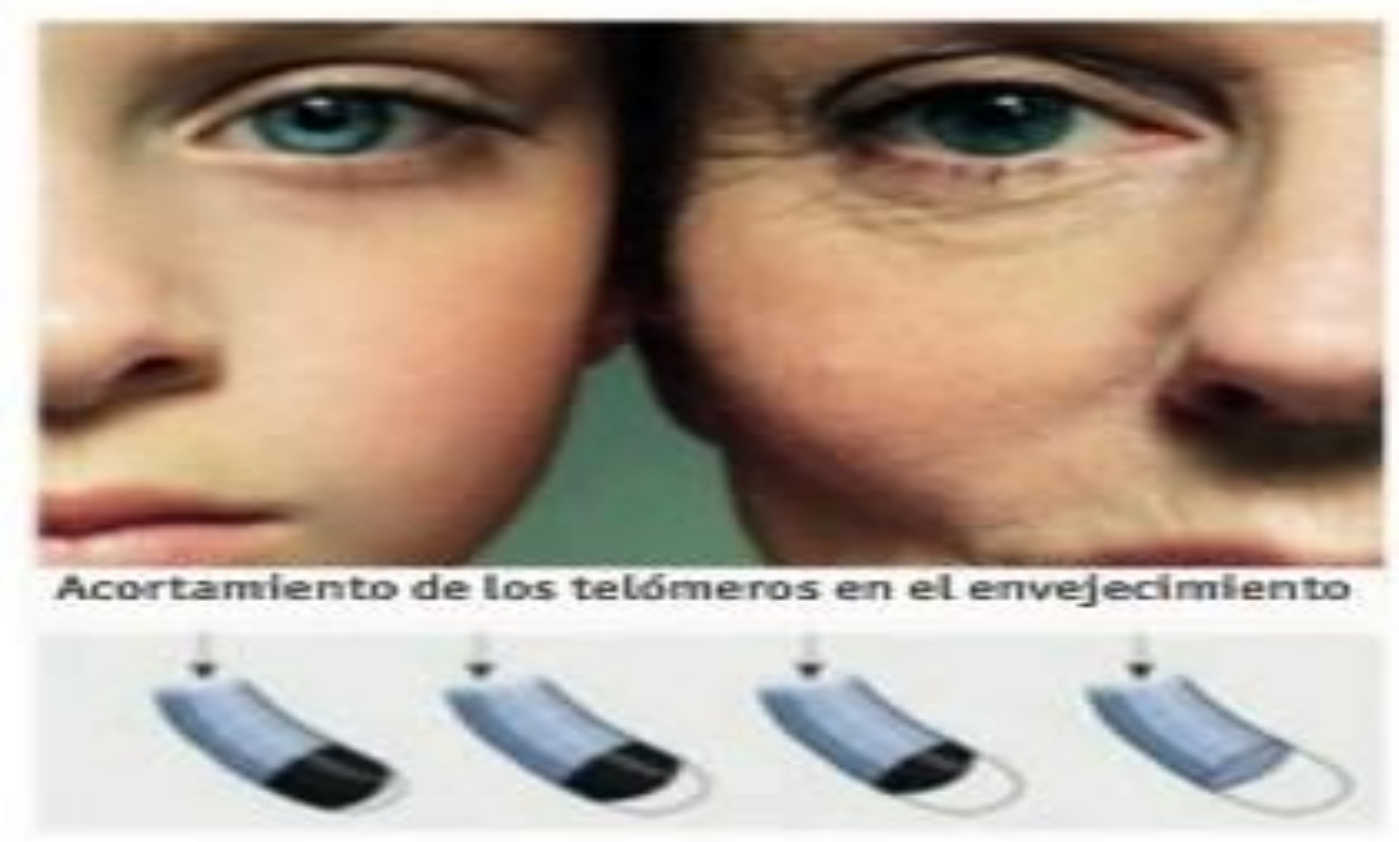

Figura 2. Acortamiento de los telómeros en el envejecimiento

Teniendo en cuenta estudios transversales de edad vs longitud telomérica en la población general muestran que el acortamiento de los telómeros en la edad adulta joven se enlentece en los linfocitos y se vuelve más rápido, aproximadamente 60 pares de bases por año en la edad avanzada (Iwawa, Ohyashiki, Ohyashiki, Hayashi, Yahata et al, 1998; Rufer, Brummendorf, Kolvraa, Bischoff, Christensen, Wadsworth et al, 1999; Whittemore, Vera, Martínez-Nevado, Sanpera, Blasco, 2019).

Sin embargo, son necesarios más estudios longitudinales para establecer una correcta tasa de pérdida de longitud de telómeros más precisa. En un estudio realizado por Vera y colaboradores (2012) observaron que los telómeros de ratones eran mucho más largos que los que presentaban los humanos en edades tempranas y, además, exhibían una tasa mucho más rápida de acortamiento con la edad, por lo tanto, para observar una disminución de la longitud telomérica, deberían tener más edad.

Canela y colaboradores (2007) establecieron que la longitud media de telómeros de una población masculina y femenina disminuyó con la edad a una tasa general similar de 7172 pares de bases por año, además, observaron que dicha tasa de acortamiento era más pronunciada en el sexo masculino que en el femenino, por tanto para observar cambios en la longitud relativa del telómero habría que esperar más tiempo en una población femenina que en una masculina en edades comprendidas entre los 60 y 80 años. 
Otros autores como Hastie o Slagboom y sus colaboradores (1990; 1994) determinaron que la tasa promedio de acortamiento de los telómeros por año en estudios de población humana variaba desde los 31 pares de bases a los 72 pares de bases por año, un rango mucho más amplio que el establecido por Canela. Otros estudios como el de Svenson y colaboradores (2011) observaron fluctuaciones (ganancias y pérdidas) en la longitud telomérica durante un periodo de 12 meses.

\section{LA TELOMERASA}

El principal mecanismo para mantener la longitud de los telómeros es la telomerasa, una ribonucleoproteína que alarga los telómeros en aquellas células que la expresan (Figura 3). La telomerasa se activa durante la embriogénesis. De hecho, espermatozoide y ovocitos maduros no tienen actividad telomerasa, y es justo después de la fecundación y a lo largo de toda la gestación cuando se detectan altos niveles de actividad telomerasa, persistiendo durante gran parte del desarrollo fetal y protegiendo a los telómeros de un acortamiento significativo en este periodo de elevada tasa de expansión celular (Wright, Jones, Mayer, Oehnninger \& Lanzendorf, 2001). La actividad telomerasa, no obstante, se silencia tras el nacimiento en la mayor parte de los tejidos somáticos y como consecuencia, el nacimiento marca el inicio del acortamiento telomérico en la mayor parte de los tejidos a lo largo de la vida. Los tejidos proliferativos de alto potencial regenerativo como son la medula ósea, la piel y el tracto intestinal, así como los linfocitos activados, expresan una actividad telomerasa moderada (Forsyth, Wright \& Shay, 2002).

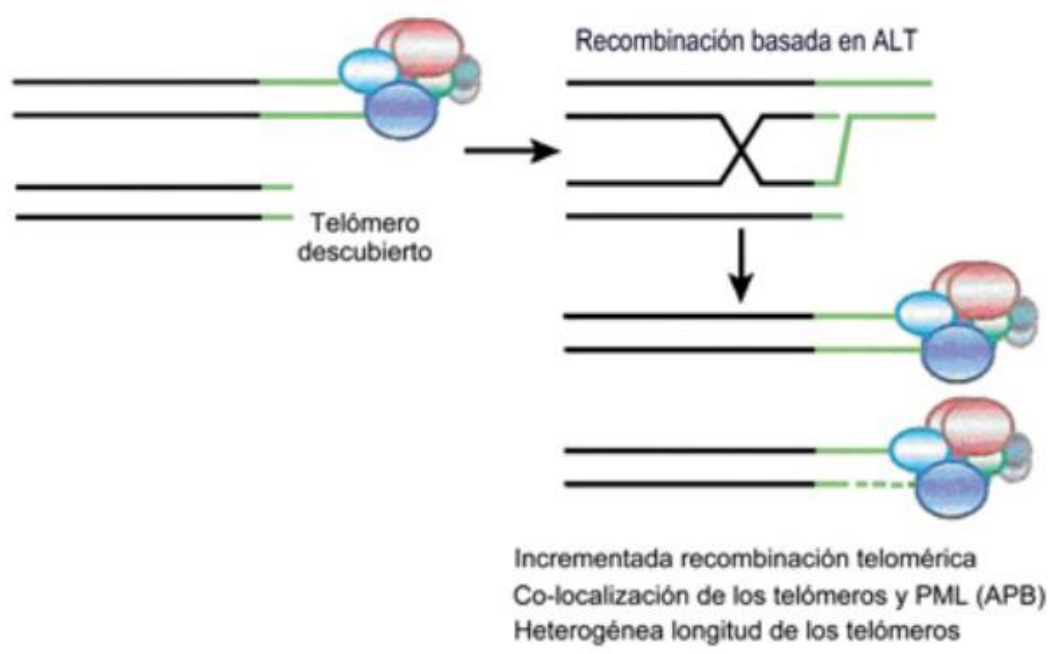

Figura 3. Funcionamiento de la telomerasa. 
Como ya hemos comentado la función principal de la enzima telomerasa es la de mantener la integridad telomérica, elongando los extremos cromosómicos erosionados a expensas de un componente de ARN que contiene un dominio que es complementario a la secuencia de DNA telomérico. Ese dominio permite alinear la enzima con el sustrato y provee de un templado para la adición de novo de deoxinucleotidos a las secuencias teloméricas. Por retrotranscripción, la telomerasa genera una copia de DNA de su propia copia de RNA, la cual es entonces fusionada al extremo 3’del telómero. La extensión de los telómeros por la telomerasa es requerida para llegar a la contracción normal que ocurre después de cada replicación de DNA (Sawyer, Roloson, Bell, Thomas, Teo \& Chadduck, 1996).

Se detectó actividad de telomerasa en las fases G1, S y G2 del ciclo celular, observándose una represión cuando las células entran en G0 debido a la carencia de factores de crecimiento, inhibición por contacto de la división celular, inducción de la senescencia por reversión en una línea celular inmortalizada o por diferenciación (Holt, Wright \& Shay,1996).

Por tanto, la deserción de la telomerasa se reconoce como un biomarcador de las características distintivas del envejecimiento (López-Otin, Blasco, Partridge, Serrano \& Kroemer, 2013)

\section{ENVEJECIMIENTO Y TELÓMEROS}

La senescencia celular es un proceso irreversible de declinación de la proliferación en relación con la edad. Es un proceso activo, genéticamente programado que responde a una inducción dada por el acortamiento telomérico, generando una señal semejante a la producida por el daño en el DNA. Por el contrario, la quiescencia es un proceso reversible que mediante una estimulación adecuada puede resultar en la continuación de la proliferación (Sedivy, 1998). El acortamiento de los telómeros se observa en todos los tejidos humanos a medida que transcurre la edad (Aubert, \& Lansdorp 2008). En individuos normales se detectó una disminución de la longitud telomérica con el avance de la edad, observándose variaciones entre distintos tipos celulares desde 15000-20000 pb en células germinales, 10000 pb en adultos jóvenes y 5000-7000 pb en células de ancianos (Shay, Werbin\& Wright, 1996). En humanos, la tasa de pérdida de teloméros es de 20 a 40 pb / año durante una vida útil de 75 años (Unryn, Cook \& Riabowol, 2005). 
En células somáticas en activa división, los telómeros pueden llegar a un acortamiento tal que cese la capacidad proliferativa por disminución de la longitud telomérica a niveles críticos (aproximadamente $2.5 \mathrm{~Kb}$ ) (Haber, 1995) situación definida como punto límite de Hayflick (1965). Esta situación nos lleva a pensar que la longitud telomérica sirve como un reloj biológico regulando la vida de las células normales.

\subsection{Actividad física}

Según la Organización Mundial de la Salud (OMS), se define actividad física como cualquier movimiento corporal producido por los músculos esqueléticos, con el consiguiente consumo de energía. Ello incluye las actividades realizadas al trabajar, jugar y viajar, las tareas domésticas y las actividades recreativas. (OMS, 2018)

La intensidad de la actividad física refleja la velocidad a la que se realiza la actividad, o a la magnitud del esfuerzo requerido para realizar un ejercicio o actividad. La intensidad varía de una persona a otra, depende de lo ejercitado que esté cada uno y de su forma física.

\section{Actividad física moderada (aproximadamente 3-6 MET)}

Requiere un esfuerzo moderado, que acelera de forma perceptible el ritmo cardiaco. Por ejemplo:

- Caminar a paso rápido

- Bailar

- Jardinería

- Tareas domésticas

- Caza y recolección

- Participación activa en juegos y deportes con niños y paseos con animales domésticos

- Trabajos de construcción generales

- Desplazamiento de cargas moderadas

\section{Actividad física intensa (aproximadamente $<6$ MET)}

Requiere una gran cantidad de esfuerzo y provoca una respiración rápida y un aumento sustancial de la frecuencia cardiaca. Se consideran ejercicios vigorosos: 
- Correr

- Desplazamientos rápidos en bicicleta

- Aerobic

- Natación rápida

- Deportes y juegos competitivos

- Desplazamiento de cargas pesadas

*los MET son la razón entre el metabolismo de una persona durante la realización de un trabajo y su metabolismo basal. Un MET se define como el costo energético de estar sentado tranquilamente y es equivalente a un consumo de $1 \mathrm{kcal} / \mathrm{kg} / \mathrm{hora}$. Se calcula que, en comparación con esta situación, el consumo calórico es unas 3 a 6 veces mayor (3-6 MET) cuando se realiza una actividad de intensidad moderada, y más de 6 veces mayor $(<6 \mathrm{MET})$ cuando se realiza una actividad vigorosa.

\subsubsection{Actividad física recomendada en los adultos mayores}

La OMS recomienda:

- Practicar al menos 150 minutos semanales de actividad física moderada, o al menos 75 minutos semanales de actividad física intensa, o una combinación equivalente entre actividad moderada e intensa.

- Para obtener mayores beneficios para la salud estas personas deben llegar a 300 minutos semanales de actividad física moderada o su equivalente.

- Las personas con problemas de movilidad deben practicar actividad física para mejorar su equilibrio y prevenir caídas por lo menos 3 días a la semana.

- Conviene realizar las actividades de fortalecimiento muscular 2 o más días a la semana y de tal manera que se ejerciten grandes conjuntos musculares.

\subsection{Ejercicio físico}

Una vez definido el concepto de actividad física, es necesario tener claro que dicho concepto no es sinónimo de ejercicio físico. Caspersen, Powell y Christerson en el año 1985 definieron al ejercicio físico como aquella actividad física planificada, estructurada, repetitiva y dirigida hacia un fin, es decir, para la mejora o mantenimiento de uno o más de los componentes de la aptitud física (Caspersen, Powell \& Christenson, 1985). 
*Aptitud física: es el conjunto de atributos que las personas poseen o alcanzan relacionado con la habilidad para llevar a cabo actividades físicas.

\subsubsection{Ejercicio Terapéutico.}

Dentro del ejercicio físico es conveniente hablar del ejercicio terapéutico. Se define ejercicio terapéutico como la ejecución sistemática y planificada de movimientos corporales, posturas, actividades físicas con el propósito de que el paciente disponga de medios para: (American Physical Therapy Association, 2001)

- Corregir o prevenir alteraciones.

- Mejorar, reestablecer o potenciar el funcionamiento físico.

- Prevenir o reducir factores de riesgo para la salud.

- Optimizar el estado general de salud, el acondicionamiento físico o sensación de bienestar.

Los programas de ejercicio terapéutico son realizados por fisioterapeutas y se trata de programas individualizados según las necesidades de la persona.

A la hora de hablar de ejercicio terapéutico conviene hablar de todos los aspectos multidimensionales que abarca (Kisner \& Colby, 2010):

- Equilibrio: capacidad de alinear los segmentos corporales contra la gravedad para que el cuerpo (Centro de la masa) se mantenga o se desplace dentro de la base de sustentación disponible sin caer.

- Aptitud cardiorrespiratoria: capacidad de realizar movimientos corporales totales repetitivos de baja intensidad (Caminar, practicar aerobismo, andar en bicicleta, nadar) durante un lapso prolongado de tiempo.

- Coordinación: sincronización y secuenciación correctas de la activación muscular combinada con la contracción de intensidad apropiada del músculo que conduce al inicio efectivo, guiado y graduado del movimiento. Es la base del movimiento suave, preciso y eficiente, y se produce a nivel consciente o automático.

- Flexibilidad: capacidad de moverse libremente, sin restricciones; se usa en forma intercambiable con el término movilidad

- Movilidad: capacidad que tienen las estructuras o segmentos del cuerpo de moverse o ser movidos en orden para permitir que se produzca la amplitud de 
movimiento durante las actividades funcionales (amplitud de movimiento funcional).

- Rendimiento neuromuscular: capacidad del músculo de producir tensión y realizar trabajo físico. El rendimiento muscular exige fuerza, potencia y resistencia a la fatiga muscular.

- Control neuromuscular: interacción de los sistemas sensitivo y motor que permite que los músculos agonistas y antagonistas y también los estabilizadores y los neutralizadores anticipen o respondan a la información propioceptiva y cinestésica y, en consecuencia, trabajen en la secuencia correcta para generar movimientos coordinados.

- Control postural, estabilidad postural y equilibrio: términos de uso intercambiable con equilibrio estático o equilibrio dinámico.

- Estabilidad: capacidad propia del sistema neuromuscular por la cual, mediante acciones musculares sinérgicas, este sistema puede mantener segmentos proximales o distales del cuerpo en una posición estacionaria o controlar que haya una base de sustentación estable durante la realización de movimientos superpuestos. La estabilidad articular es el mantenimiento de la alineación correcta de los extremos óseos de una articulación por medio de componentes pasivos y dinámicos.

En la figura 4 quedan resumidos los principales aspectos multidimensionales del ejercicio terapéutico.

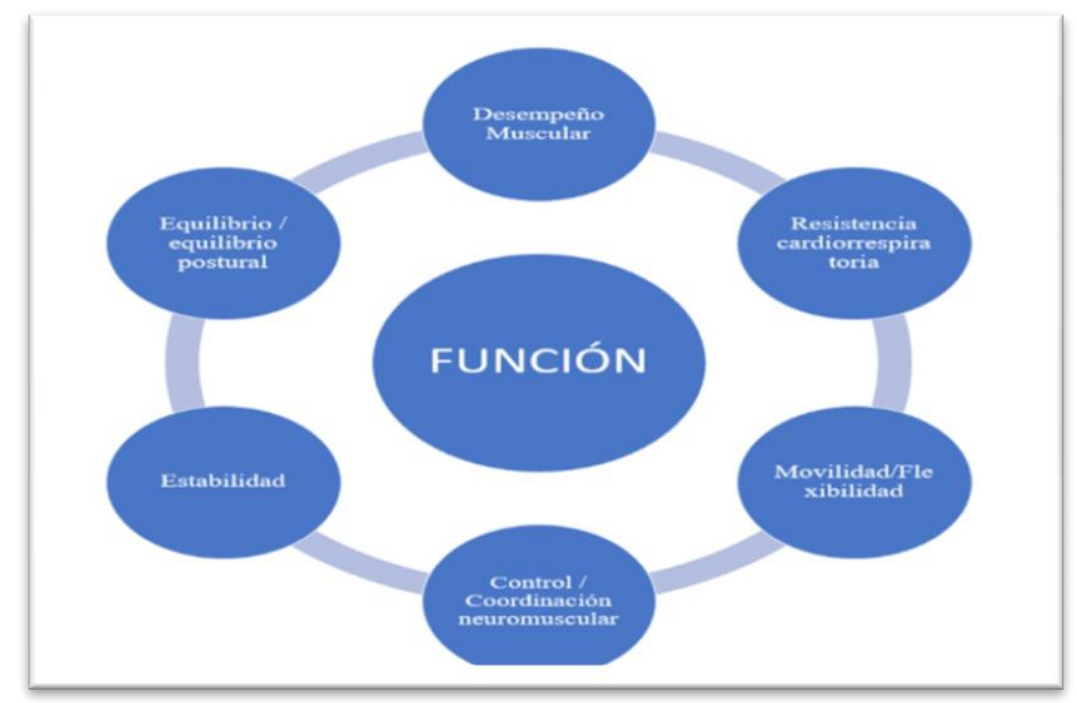

Figura 4. Aspectos multidimensionales que abarca el Ejercicio Terapéutico 
Entre las diferentes intervenciones del ejercicio terapéutico podemos señalar:

- Acondicionamiento y reacondicionamiento aeróbico.

- Ejercicios para mejorar el rendimiento muscular: entrenamiento de la fuerza, la potencia y la resistencia.

- Técnicas de estiramiento que incluyan procedimientos de elongación de los músculos y técnicas de movilización articular

- Control neuromuscular, técnicas de inhibición y facilitación y entrenamiento de la postura mediante atención sobre ésta

- Control de la postura, mecánica corporal y ejercicios de estabilización.

- Ejercicios para mejorar el equilibrio y entrenamiento de la agilidad.

- Ejercicios de relajación.

- Ejercicios respiratorios y entrenamiento de los músculos de la respiración.

- Entrenamiento funcional especifico de cada tarea.

\subsubsection{Beneficios del ejercicio terapéutico.}

La práctica de ejercicio terapéutico de forma regular reporta los siguientes beneficios (Kisner \& Colby, 2010):

- En el sistema musculo esquelético:

- Disminución del dolor.

○ Disminución de la debilidad muscular.

- Aumento de la amplitud de movimiento (restricción de la cápsula articular, restricción del tejido conjuntivo periarticular, acortamiento del músculo.

○ Mejora de la postura corporal.

- Equilibrio entre la longitud y la fuerza de los músculos.

- En el sistema neuromuscular:

○ Disminución del dolor.

- Mejora del equilibrio, estabilidad y control postural.

- Mejora en la coordinación y sincronización de los movimientos.

- Mejora en el tono muscular (hipotonía, hipertonía y distonías).

- Estrategias motrices funcionales eficaces.

- Aparato cardiovascular/respiratorio:

- Mejora de la capacidad aeróbica (Resistencia cardiorrespiratoria). 
- Disminución de las alteraciones de la circulación (linfática, venosa y arterial).

- Sistema tegumentario:

- Mejora en la hipomovilidad de la piel (por ejemplo: inmovilidad o formación de cicatrices adherentes)

Además de los beneficios citados anteriormente, conviene señalar también los múltiples beneficios de la práctica regular de ejercicio físico.

Existen múltiples evidencias de que la actividad física constituye un elemento de suma importancia en la prevención de muchas enfermedades crónicas, en la calidad de vida (Battaglia, Bellafiore, Alesi, Paoli \& Bianco et al, 2016) y debe ser una herramienta indispensable en la sanidad pública (Lee, Shiroma, Lobelo, Puska, Blair \& Katzmarzyk, 2012).

La inactividad física es responsable del 5,5\% de las muertes en el mundo y del $10 \%$ en Europa, $10 \%$ de los casos de cáncer de mama y colon, 10\% de las enfermedades cardiovasculares y el 7\% de la diabetes mellitus tipo 2 (Aragonés, Fernández \& Ley, 2016).

En la última recomendación sobre el estilo de vida del grupo de expertos del Grupo de Educación Sanitaria y Promoción de la salud (PAPPS) (Córdoba, Camarelles, Muñoz, Gómez, San José \& Ramírez, 2018) se establece el nivel de evidencia científica del ejercicio físico en las patologías más frecuentes, llegando a las siguientes conclusiones:

- Existencia de evidencia alta y recomendación fuerte a favor en:
- Resistencia a la insulina
○ Obesidad
- Diabetes tipo 2
- Hipertensión Arterial (HTA)
- Cardiopatía isquémica
○ Insuficiencia Cardiaca
- Claudicación intermitente
- Dislipemias
- Cáncer
- Osteoporosis
- Ictus cerebral 
- Existencia de evidencia moderada con recomendación fuerte a favor de:

○ Enfermedad Pulmonar Obstructiva Crónica

- Existencia de evidencia baja con recomendación fuerte a favor de:

○ Depresión

- Existencia de evidencia muy baja con recomendación fuerte a favor de:

○ Artrosis

La práctica de ejercicio físico está asociada con mejoras en múltiples aspectos de la salud humana. Entre los múltiples beneficios podemos destacar: mejoría en la capacidad de ejercicio, mejora de la función endotelial, de la presión arterial, reducción de la grasa abdominal (Schuler, Adams \& Goto, 2013; Piepoli, Hoes, Agewall, Albus, Brotons \& Catapano et al, 2016).

\subsubsection{Influencia del ejercicio físico en la cognición}

Numerosos autores han estudiado los efectos del ejercicio físico sobre las estructuras cerebrales, concretamente en áreas frontales (Oberlin, Vestynen, Burzynska, Voss \& Prakash et al, 2016). Por otra parte, el ejercicio físico produce menos atrofia relacionada con la edad en la corteza prefrontal y temporal (Colcombe, Erickson, Raz, Webb \& Cohen et al, 2003), produciendo aumentos significativos en volumen de materia gris y blanca en dichas áreas (Reiter, Nielson, Smith, Weiss, Alfini \& Smith et al, 2015). Colcombe y colaboradores (2006) demostraron que en un grupo de adultos mayores sanos, una intervención de 6 meses de entrenamiento aeróbico 3 veces por semana condujo a un aumento en el volumen de materia gris y un aumento de volumen del hipocampo (Erickson, Prakash, Voss, Chaddok, Hu \& Morris et al, 2009; Thomas, Dennis, Rawlings, Stagg, Matthews \& Morris et al, 2016), concretamente en la parte anterior del mismo. (Erickson, Voss, Prakash, Basak, Szabo \& Szabo et al, 2011).

Recientes investigaciones han concluido que los adultos mayores físicamente activos tienen altos niveles de neurotrofinas (proteínas que favorecen la supervivencia de las neuronas) y materia gris en la corteza prefrontal y cingulada (Flöel, Ruscheweyh, Krüger, Willemer, Winter, Völker \& Knecht et al, 2010).

Estudios observacionales prospectivos indican que los individuos que mantienen altos niveles de condición física muestran mejoras en la función neurocognitiva en relación con las personas inactivas (Yaffe, Barnes, Nevitt, Lui \& Covinsky, 2001; Podewils, 2005). 
Además, se ha demostrado que el ejercicio aeróbico provoca una mejor conexión entre el córtex prefrontal izquierdo y el derecho obteniéndose una mejora del funcionamiento de la red fronto-ejecutiva, ya que ambas áreas son cruciales para el funcionamiento de dicha red (Voss, Prakash, Erickson, Basak, Chaddok \& Kim, 2010).

Dada la evidencia visible que apoya los beneficios del ejercicio físico en la estructura del cerebro, no resulta sorprendente que haya también beneficios en la función cognitiva.

Brown y colaboradores (2010) identificaron fuertes asociaciones entre la aptitud física, función vascular y cognición. En su estudio de 42 mujeres se observó que aquellas que tenían mejor forma física tenían a su vez mejor actividad cerebrovascular y mejor constructo cognitivo.

Netz y colaboradores (2010) en un estudio de 38 adultos de 65,3 a 85,3 años observó que aquellos sujetos que tenían una aptitud física alta (a través de una prueba de esfuerzo graduada, progresiva y máxima) obtenían mejores resultados de la función ejecutiva evaluándose con una batería neuropsicológica computarizada, donde se observó una prevención significativa del deterioro cognitivo en edades avanzadas.

Autores como Hertzog (2009), Ku (2012) y Gow (2012) afirman que las funciones cognitivas pueden beneficiarse de un estilo de vida saludable, sobre todo con una buena actividad física regular.

Todos estos beneficios en la cognición a través del ejercicio físico se observan preferentemente en los adultos mayores y en los niños tal y como lo demuestran los estudios de intervención (Hötting \& Röder, 2013; Karr, Areshenkoff \& Rast, GarcíaBarrera, 2014; Cerrillo, García, Sánchez, Pardo, Santos \& Martínez, 2015; Kramer \& Colcombe, 2018).

\subsubsection{Influencia del ejercicio físico en la longitud telomérica}

Es bien sabido que la actividad física regular mejora la función cardiorrespiratoria, induce cierta pérdida de peso y reduce el riesgo de padecer enfermedad crónica temprana; sin embargo, se ha informado que el aumento del consumo de oxígeno durante el ejercicio aumenta el estrés oxidativo al inducir oxígeno activo (Kodja \& Hambrecht, 2005; Yun, 2019), por lo tanto, existe mucha controversia entre los autores entre el impacto del ejercicio físico y la longitud telomérica. 
Por un lado, se han observado efectos beneficiosos de la actividad física sobre la regeneración y la senescencia celular. Por ejemplo, el entrenamiento de resistencia a largo plazo se ha asociado con una mayor actividad de la enzima telomerasa y una reducción de la longitud telomérica en atletas jóvenes y de mediana edad en comparación con grupos poblacionales inactivos (Laufs, Werner, Link, Endres \& Waussmann et al, 2004; Werner, Furster, Widmann, Poss \& Roggia et al, 2009; Ornish, Lin, Chan, Epel \& Kemp et al, 2013; Haycook, Heydon, Kaptoge, Butterworth \& Thompson, 2014; Mundstock, Zatti, Louzada, Oliveira, Guma \& Paris et al, 2015)

Los niveles moderados de actividad física pueden reducir el acortamiento telomérico al inducir un fenotipo protector de los telómeros, previniendo enfermedades relacionadas con la edad (Mundstock et al, 2015). Autores como Du y colaboradores (2012) ratifican estos resultados pues concluyen quelas cantidades moderadas de ejercicio físico suelen asociarse con una buena salud y una mejor supervivencia en comparación con un estilo de vida sedentario.

Numerosos estudios publicados respaldan estos resultados, Mirabello y colaboradores (2009) concluyen que los estilos de vida saludables como el ejercicio físico tienden a asociarse con una mayor longitud telomérica. Cherkas y colaboradores (2008) estudiaron el impacto de estilos de vida sedentarios y hábitos de vida no saludables como fumar o tener un índice de masa corporal alto y concluyeron que todo ello provoca un aceleramiento en el proceso de envejecimiento y por ende, un aumento de la disminución de la longitud telomérica.

Además del ejercicio físico, otros factores relacionados con la salud, como puede ser la nutrición pueden afectar a la longitud telomérica (Ornish et al, 2013; Sjögren, Fisher, Kallings, Svenson, Roos \& hellenius, 2014).

No obstante, algunos estudios experimentales sobre los efectos protectores del entrenamiento de resistencia crónica en la longitud telomérica han mostrado resultados contradictorios (Werner et al, 2009; Rae, Vignaud, Butler, Thornell \& Sinclair et al, 2010; Østhus, Sgura, Berardinelli, 2012; Denham, Nelson \& O’Brien, 2013). Mathur y colaboradores (2013) observaron que no hay relación entre la actividad física y la longitud telomérica en una cohorte de atletas adultos sanos y una cohorte de controles sedentarios; sin embargo, LaRocca y colaboradores (2010) indican que la longitud telomérica se conserva en adultos mayores sanos que realizan ejercicio aeróbico 
vigoroso y se relaciona positivamente con la capacidad máxima de ejercicio aeróbico medida a través del volumen de oxígeno máximo (VO2 máximo).

Una de las posibles explicaciones a los resultados obtenidos por Mathur puede ser que la exposición aguda y exhaustiva al ejercicio de resistencia también se asocia con la generación acelerada de radicales libres de oxígeno (especies reactivas de oxígeno ROS) y el estrés oxidativo, pudiendo poner en peligro la salud y el bienestar, produciendo una disminución de la longitud telomérica (Mastaloudis, Leonard \&Traber, 2001; Mataloudis, Yu, O’Donnell, Frei, Dashwood \& Traber, 2004; Borghni, Giardini, Tonacci, Mastorci, Mercuri \& Mrakic et al, 2015).

En consonancia con estos estudios, un reciente metaanálisis realizado por Xiufang y colaboradores (2019), no encuentran una relación positiva entre el ejercicio aeróbico y una mayor longitud telomérica.

Dichas contradicciones entre unos autores y otros pueden atribuirse a las diferencias entre la intensidad y duración del ejercicio aeróbico, a la diversidad genética de los sujetos, al tamaño de la muestra, entre otras variables.

Por lo tanto, no hay suficientes estudios experimentales que establezcan claramente una asociación entre la actividad física y la longitud del telómero.

\subsection{Revitalización Geriátrica}

La revitalización geriátrica es la aplicación de la fisioterapia preventiva en personas mayores con el fin de mejorar su calidad de vida y mantener su bienestar físico (Calvo \& Sánchez, 2013).

\subsubsection{Programa de Revitalización Geriátrica de la Universidad de} Salamanca

Desde el año 1992, el Área de Fisioterapia de la Universidad de Salamanca, en colaboración con el Excelentísimo Ayuntamiento de Salamanca, lleva a cabo un Programa de Revitalización Geriátrica en el Municipio de Salamanca en el que participan actualmente cerca de 500 personas.

La revitalización geriátrica es la aplicación de la fisioterapia preventiva en personas mayores con el fin de mejorar su calidad de vida y mantener su bienestar físico. (Calvo, Sánchez, 2013). 
Los objetivos del PRG llevado a cabo en personas mayores son:

- Retrasar la aparición de los cambios fisiológicos propios del envejecimiento.

-Evitar la disminución de las capacidades que dichos cambios producen.

-Mantener un buen nivel de independencia funcional.

-Aumentar la calidad de vida de las personas mayores.

Actualmente participan en dicho programa, 10 PDI (Personal Docente Investigador) y 7 PI (Personal Investigador): 6 fisioterapeutas y 1 terapeuta ocupacional. 


\section{OBJETIVOS E HIPÓTESIS DE TRABAJO}




\section{Objetivos e Hipótesis}

\subsection{Planteamiento de la investigación}

La investigación desarrollada trata de conocer los efectos del Programa de Revitalización Geriátrica en el rendimiento neurocognitivo en el envejecimiento fisiológico, y su posible relación con la actividad de los telómeros.

Como hemos desarrollado en el marco teórico son varios los estudios que se han hecho eco de la posible influencia del ejercicio físico en la longitud telomérica, sin llegar a una conclusión clara, debido a las diferencias entre unos estudios y otros, es por ello que a través de este trabajo de investigación, queremos aportar resultados sobre el posible impacto que presenta el ejercicio físico en la longitud telomérica, a través del Programa de Revitalización Geriátrica.

\subsection{Objetivo General}

El objetivo general de este estudio es conocer el impacto del Programa de Revitalización Geriátrica sobre las funciones cognitivas en el proceso de envejecimiento de personas sanas mayores de 65 años y su posible influencia en la actividad telomérica.

\subsection{Específicos}

Como objetivos específicos planteamos los siguientes:

$>$ Conocer sobre qué funciones cognitivas específicas tiene más influencia el Programa de Revitalización Geriátrica.

- Saber si existe correlación entre el rendimiento neuropsicológico y la longitud de los telómeros en ambos grupos.

$>$ Saber si existe correlación entre el índice de masa corporal y la longitud de los telómeros en ambos grupos.

$>$ Conocer el impacto del Programa de Revitalización Geriátrica en la calidad de vida de los sujetos participantes.

> Ver si hay diferencias entre la longitud de los telómeros entre los participantes del Programa de Revitalización Geriátrica y los sujetos del grupo control tras la intervención y a los seis meses de ella.

- Ver si existen diferencias en el rendimiento neuropsicológico entre los participantes del Programa de Revitalización Geriátrica y los sujetos del grupo control tras la intervención. 


\subsection{Hipótesis.}

Hipótesis 1:La intervención a través del Programa de Revitalización Geriátrica producirá una mejora en las funciones cognitivas de los sujetos participantes en él, mostrando mejores puntuaciones post-intervención que el grupo control.

Hipótesis 2:Los sujetos participantes del Programa de Revitalización Geriátrica tendrán una mayor longitud de sus telómeros con respecto a los sujetos del grupo control.

Hipótesis 3:Los sujetos con mejores puntuaciones post-intervención en las variables cognitivas tendrán una mayor longitud telomérica.

Las hipótesis de este trabajo se fundamentan en una de las principales teorías del envejecimiento descritas anteriormente en el apartado del marco teórico: la teoría de la telomerasa. En un reciente metaanálisis (Xiufang et al, 2019) concluyeron que el ejercicio físico tuvo una influencia positiva sobre la longitud de los telómeros. Asimismo, en otro reciente metaanálisis (Kramer et al, 2018) se corrobora la importancia que tiene el ejercicio físico en las funciones cognitivas, produciendo una gran mejora en funciones como la memoria, la atención, la rapidez perceptivo-motora, la memoria visoespacial, la función ejecutiva, etc... Basándonos en estas evidencias externas, creemos que el Programa de Revitalización Geriátrica, al tratarse de un programa de ejercicio físico dirigido por fisioterapeutas, podría ser una herramienta útil en el proceso de envejecimiento normal. 
METODOLOGÍA 


\section{Metodología}

\subsection{Muestra y Materiales}

\subsubsection{Muestra}

Para la elección de la muestra se realizó un muestreo aleatorio por conglomerados, donde se eligieron 8 asociaciones de un total de 20que participanenel Programa de Revitalización Geriátrica y en cada una de ellas se seleccionaron de manera aleatoria los sujetos que estaban dispuestas a participar en el estudio, eligiendo 96 participantes en total.

En la figura 5 se refleja el flujo de ejecución utilizado que conecta los puntos de inicio y de fin del proceso.

Muestreo por conglomerados

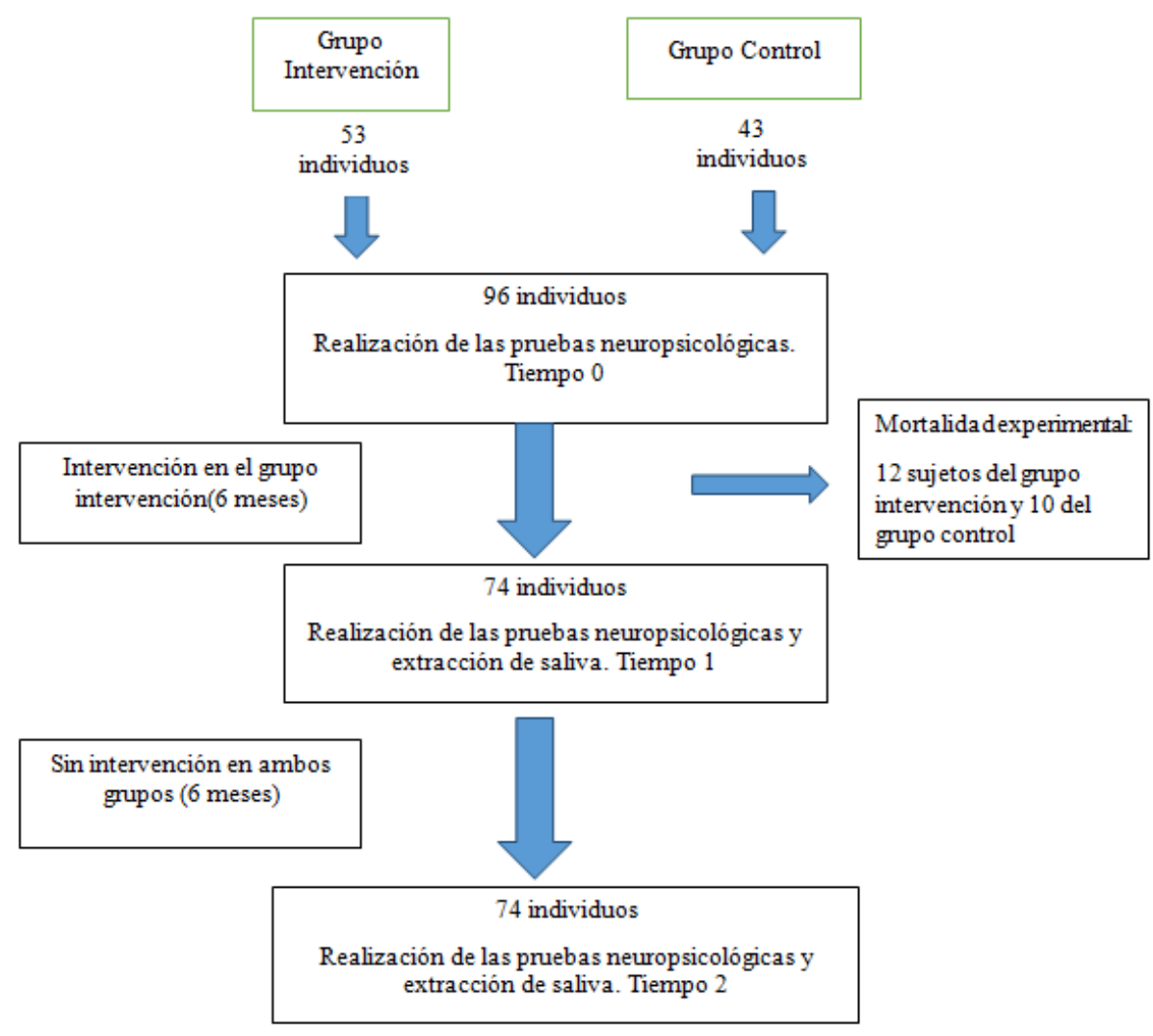

Figura 5. Flujo de ejecución. 
La muestra estaba formada por un total de 74 sujetos, que fue dividida en dos grupos. Grupo con intervención al que se denominará grupo experimental (GE), y grupo sin intervención al que se denominará grupo control (GC).

Los sujetos del GE pertenecían al Programa de Revitalización Geriátrica, y los sujetos del GC, participaban en otro tipo de programas/actividades ofertadas por el Ayuntamiento de Salamanca (Programa de Equilibrio, Programa de Reeducación Muscular, Programa de Ventilación, Psicomotricidad...).

Los sujetos del GE fueron sometidos a la práctica de ejercicio físico regular durante 6 meses, 3 días a la semana con una duración de 50 minutos por sesión, siendo unos 150 minutos de ejercicio físico a la semana.

Los sujetos del GC realizaban otro tipo de actividades como el programa de Equilibrio, el programa de Ventilación, el programa de Reeducación Muscular, es decir, realizaban actividades que no implicaban la práctica de ejercicio físico de manera regular. Realizaban una sesión a la semana de aproximadamente 50 minutos.

El Grupo de intervención estaba formada por un total de 41 sujetos del género femenino con una edad media de 72,70, El Grupo control estaba formado por un total de 33 sujetos del género femenino con una edad media de 71,21 años,

La bibliografía consultada, nos informa que existen numerosas enfermedades y síntomas asociados a un acortamiento telomérico acelerado, como son las enfermedades cardiovasculares, las patologías del sistema nervioso central (Alzheimer, Parkinson), procesos neoplásicos, diabetes, el consumo de tabaco o la exposición al humo, esta información nos ha permitido elaborar una serie de criterios de inclusión para ambos grupos de sujetos a la hora de formar la muestra de estudio.

Uno de esos criterios, consiste en pertenecer al género femenino. Como se observa en el apartado de la descripción de la muestra, únicamente está formada por mujeres, esta decisión fue tomada por los autores, con el motivo de controlar el mayor número posible de síntomas asociados a un acortamiento telomérico acelerado, al presentar las mujeres en este intervalo de edad, un menor número de malos hábitos de vida, en relación a los varones y que pudieran influir en la actividad telomérica.

Los criterios de inclusión para el GE en este estudio eran los siguientes:

Pertenecer al género femenino 
Edad comprendida entre los 65y 80 años

Ser participante del Programa de Revitalización Geriátrica

No padecer ningún tipo de enfermedad neurodegenerativa ni proceso neoplásico

No padecer enfermedades cardiovasculares

No padecer diabetes

No presentar patología psiquiátrica

No presentar defectos sensitivos o defectos campimétricos

No presentar antecedentes familiares de demencia

No tomar medicación especifica en relación a las patologías referenciadas.

Saber leer y escribir

Los criterios de inclusión para el grupo control en este estudio eran los siguientes:

Pertenecer al género femenino

Edad comprendida entre los 65y 80 años

No ser participante del Programa de Revitalización Geriátrica

No padecer ningún tipo de enfermedad neurodegenerativa ni proceso neoplásico

No padecer enfermedades cardiovasculares

No padecer diabetes

No presentar patología psiquiátrica

No presentar defectos sensitivos o defectos campimétricos

No presentar antecedentes familiares de demencia

No tomar medicación especifica en relación a las patologías referenciadas.

Saber leer y escribir 


\subsubsection{Materiales}

\subsubsection{Instrumentos de evaluación de las funciones cognitivas}

Para la valoración neuropsicológica de los sujetos de ambos grupos, se incluyeron una serie de pruebas que evaluaban las siguientes funciones cognitivas:

\subsection{Examen Cognoscitivo Mini-Mental}

Constituye el test cognitivo brevemás usado y con más estudios realizados. El autor de este test es Folstein, quien desarrollo este test de cribado en 1975. Existen múltiples versiones en España. Es un test de cribado o evaluación breve de capacidades cognitivas y está diferenciado en la evaluación de diferentes capacidades cognitivas. La puntuación máxima es de 30 puntos; se proporciona un punto cada vez que el sujeto contesta correctamente y0 puntos cuando lo hace de manera incorrecta. El puntode corte se encuentra en 24 puntos para personas escolarizadas, $<21$ en personas con escolaridad baja y $<18$ puntos en analfabetos. El tiempo de aplicación es de aproximadamente 10 min. (Lobo, Ezquerra \&Bugarda, 1979).

\subsection{Test de Retención Visual de Benton}

Evalúa procesamiento visoespacial, la memoria visual y las habilidades visoconstructivas, y la conceptualización visual y verbal. También es sensible a las alteraciones cognitivas asociadas al envejecimiento normal. Su aplicación y corrección es muy sencilla. La prueba consta de 10 láminas que contienen un conjunto de estímulos visuales de dificultad creciente que el sujeto debe reproducir, bien de memoria, bien copiándolos. Existen 3 formas paralelas (C, D y E) y 4 posibles modos de aplicación. La interpretación de la prueba se basa en una evaluación del número de reproducciones correctas y el número de errores cometidos, por lo que permite un análisis tanto cuantitativo como cualitativo de los resultados. (Benton \& Hamsher, 1983).

\subsection{Aprendizaje audio-verbal de Rey}

Permite evaluar el alcance de la memoria inmediata, proporciona una curva de aprendizaje, revela inclinaciones hacia patrones de interferencia retroactivos y proactivos, evalúa la confabulación existente en tareas de memoria y mide la retención después de una actividad mediadora. La lista consta de 15 palabras que no guardan relación entre sí. Se realiza una primera lectura de la lista a razón de una palabra por segundo y se pide al sujeto que intente recordar todas las que pueda. Cuando el 
examinado comienza a decirlas palabras que recuerda se anota el orden en el que las dice para así identificar el patrón de recuerdo. Luego se realiza una segunda lectura de la lista y se le recuerda al sujeto que debe decir todas las que recuerde, incluidas las dichas la primera vez, anotándose igualmente sus respuestas. Seguidamente se realiza el mismo procedimiento por tercera, cuarta y quinta vez. La puntuación que se otorga para cada ensayo es el número total de palabras recordadas. La puntuación totales la suma de los aciertos de los 5 ensayos. Así podemos obtener la denominada «curva de aprendizaje», que es la diferencia entre los aciertos del quinto y del primer ensayo.

A los 30 minutos se realiza la prueba de recuerdo demorado en la que se le pide que vuelva a decir las palabras que aún recuerda, procediendo igualmente a anotar sus respuestas (Rey, 1968).

\subsection{Test de Stroop}

Es una medida de la fluidez verbal y eficacia cognitiva. Mide la capacidad de inhibir estímulos que desencadenan respuestas automáticas y, por tanto, la capacidad para adaptarla percepción y acomodarse a demandas nuevas inhibiendo una respuesta habitual a favor de una inusual (flexibilidad cognitiva). La duración de la forma completa es de aproximadamente $5 \mathrm{~min}$ (45s de tiempo límite para cada lámina) y consta de 3 láminas. Cada lámina contiene 100 elementos distribuidos en 5 columnas de 20 elementos cada una. La primera lámina $(\mathrm{P})$ está formada por las palabras ROJO, VERDE y AZUL ordenadas al azar e impresas en tinta negra en una hoja A4. No se permite que la misma palabra aparezca 2 veces seguida en la misma columna. La segunda lámina (C) consiste en 100 estímulos, dispuestos de igual forma, conformados por equis $(\mathrm{XXXX)}$ (es decir, sin lectura posible) impresos en tinta azul, verde o roja. El mismo color no aparece 2 veces seguido en la misma columna. Los colores no siguen el mismo orden de las palabras de la primera lámina. El sujeto debe nombrar el color de la tinta utilizada. La tercera lámina (PC) contiene las palabras de la primera lámina impresas en los colores de la segunda, mezclado ítem por ítem; el primer ítem es el color del ítem 1 de la primera lámina impreso en la tinta del color del ítem 1 dela segunda lámina. No coincide en ningún caso el color de la tinta con el significado de la palabra. El sujeto debe nombrar el color de la tinta. El sujeto cuenta con $45 \mathrm{~s}$ en cada lámina para realizar la tarea propuesta. Los materiales utilizados son los siguientes: juego de 3 láminas, cronómetro, manual de aplicación y corrección. La lámina PC constituye un buen instrumento para la evaluación de funciones ejecutivas (inhibición 
de respuestas automáticas, flexibilidad cognitiva, control atencional, medida de la interferencia). Las láminas $\mathrm{P}$ y $\mathrm{C}$ permiten evaluar la velocidad para nombrar (C) y leer palabras $(\mathrm{P})$ de uso frecuente (ruta semántica de la lectura).En esta prueba se obtienen 3 puntuaciones principales: $\mathrm{P}$, que es el número de palabras leídas en la condición de no interferencia; $\mathrm{C}$, que es el número de elementos realizados en la condición control; y PC, que es el número de elementos realizados en la condición de interferencia. Para facilitarla comparación entre las puntuaciones directas se convierten en puntuaciones típicas $\mathrm{T}$ (con una media de 50 y una desviación típica de 10). Para considerar significativa una diferencia en puntuaciones, esta debe ser de al menos 10 puntos T. Los límites considerados normales se encuentran entre 35 y 65 puntos $\mathrm{T}$ en cualquiera de las puntuaciones. Con base en los resultados obtenidos en estas 3puntuaciones puede realizarse el cálculo de interferencia. (Stroop, 1935)

\subsection{Test del Trazo.}

Evalúa las habilidades de rastreo visual y exploración visoconceptual y visomotora. También evalúa la atención, la velocidad de búsqueda visual y la rapidez perceptivomotora. Es un test de lápiz y papel creado por Partington en 1938. La efectividad de esta

prueba para discriminar sujetos con daño cerebral del resto de la población fue ratificada en una gran cantidad de trabajos, y por ese motivo pasó a formar parte de las baterías de pruebas neuropsicológicas. La prueba consta 2 partes: Parte A: Consiste en unir con líneas 25 números ubicados dentro de círculos, distribuidos al azar en una hoja(números de 1 al 25).Parte B: Consiste en unir con líneas 12 números (del 1 al 12) y 12 letras (de la A a la L) dentro de círculos en orden alternativo. (Reitan, 1992).

\subsection{Escala de Vida WHOQOL-BREF}

La versión WHOQoL-BREF fue desarrollado para proveer un formulario de evaluación de la calidad de vida resumida, utilizando datos del proyecto oficial WHOQoL-100, conteniendo en total 26 preguntas. Para proveer una evaluación comprensiva, cada item de las 24 facetas contenidas en el WHOQoL-100 ha sido incluida en esta versión, y además 2 items de la calidad de vida en general y faceta de salud general han sido incluidas.

El WHOQoL-BREF produce una visión de calidad de vida y se puede separar en puntajes de cuatro dominios. Existen dos ítems que se examinan de forma separada: el ítem numero 1 pregunta por la percepción individual de su calidad de vida, y el ítem 
numero 2 pregunta acerca de la percepción individual de su salud. La separación en cuatro dominios separa 4 grupos de percepción individual de calidad de vida relacionado con ese dominio. El puntaje en cada ítem se expone en dirección positiva (es decir mayor puntaje equivale a mayor calidad de vida). El puntaje de cada ítem se agrupa con las del mismo dominio para calcular el puntaje total del dominio (Torres, Quezada, Rioseco \& Ducci, 2008)

3.1.2.2. Instrumentos de evaluación/ cuantificación de la telomerasa y longitud relativa del telómero.

En la tabla 1se reflejanlos instrumentos empleados para la evaluación/cuantificación de la telomerasa / longitud relativa del telómero.

Tabla 1: Herramientas de evaluación/ cuantificación de la telomerasa

\begin{tabular}{|l|l|}
\hline Extracción de saliva & Invasivesterile EUROTUBO \\
\hline Medición de la concentración de DNA & Nanodrop \\
\hline Dilución de las distintas concentraciones & Pipetas, eppendorfs, placas \\
\hline $\begin{array}{l}\text { Medición de la longitud relativa del } \\
\text { telómero }\end{array}$ & PROGRAMA PREGUNTAR EL \\
\hline $\begin{array}{l}\text { Kit del LaboratorioScienceCell Research } \\
\text { Laboratories }\end{array}$ & KIT Absolute Human Telomere Length \\
\hline
\end{tabular}

\subsection{Métodos}

\subsubsection{Procedimiento de la investigación}

Al inicio del estudio todos los sujetos participantes fueron informados del propósito del estudio y su intención de participar en el mismo se recoge mediante su consentimiento informado, de manera oral y escrita. (Anexo I)

Una vez firmado el consentimiento informado, se realizó una entrevista detallada con los datos de interés para el estudio, en ambos grupos de sujetos:

- Datos personales: nombre, apellidos, estado civil, domicilio, población, lugar de nacimiento y teléfono de contacto

- Datos personales neuropsicológicos: edad, sexo, nivel escolar (años de escolaridad), profesión y dominancia manual. 
- Datos neurológicos: defectos motores, defectos sensitivos o defectos campimétricos.

- Antecedentes personales de patologías y sus tratamientos.

- Antecedentes familiares de demencia

Todas las pruebas neuropsicológicas se realizaron en los meses de octubre (tiempo 0) y mayo (tiempo 1). Se realizó de manera individualizada en horario de tarde en la sala 3 de la Escuela de Enfermería y Fisioterapia. La duración aproximada con cada sujeto fue de 45-50 minutos.

Una vez realizada la primera evaluación, los sujetos del GE estuvieron durante 6 meses recibiendo sesiones de ejercicio aeróbico moderado. Los participantes recibieron 3 sesiones a la semana con una duración de 50 minutos cada sesión.

La sesión básica de revitalización geriátrica o ejercicio físico moderado consiste en lo siguiente:

- Calentamiento dinámico durante 4-5 minutos en el que se combinada movilidad articular dinámica y estática.

- Posteriormente se realizaban estiramientos de los principales grupos musculares.

- Ejercicios aeróbicos con los materiales disponibles (picas, pelotas, pesas, aros). Esta parte es la que más varía de una sesión a otra pero siempre con el objetivo de que el sujeto realizase ejercicio físico moderado.

- Ejercicio de fuerza muscular / resistencia

- Hidratación y nombramiento de los participantes para seguir un seguimiento exhaustivo de ellos

- Estiramiento de los principales grupos musculares.

- Enfriamiento-respiración.

Una vez acabados los 6 meses de seguimiento a través de las sesiones, los participantes se sometieron a una segunda evaluación neuropsicológica (Tiempo 1), tanto los sujetos del GE como los del GC.

Posteriormente a la segunda evaluación de las funciones cognitivas (Tiempo 1), a los participantes del estudio y a los 6 meses después (Tiempo 2) (sin intervención en ambos grupos), se le extrajo saliva mediante el "Invasivesterile EUROTUBO" del laboratorio DELTALAB. Una vez extraída la saliva de cada sujeto se llevaba dicho tubo al 
laboratorio del Instituto de Investigación Biomédica de Salamanca(IBSAL) en la tercera planta de la Facultad de Medicina donde se almacenó en los criocongeladores y posteriormente se analizó en el laboratorio del IBSAL de la Facultad de Medicina

En la figura 6, se detalla la cronología de la metodología empleada en este estudio.

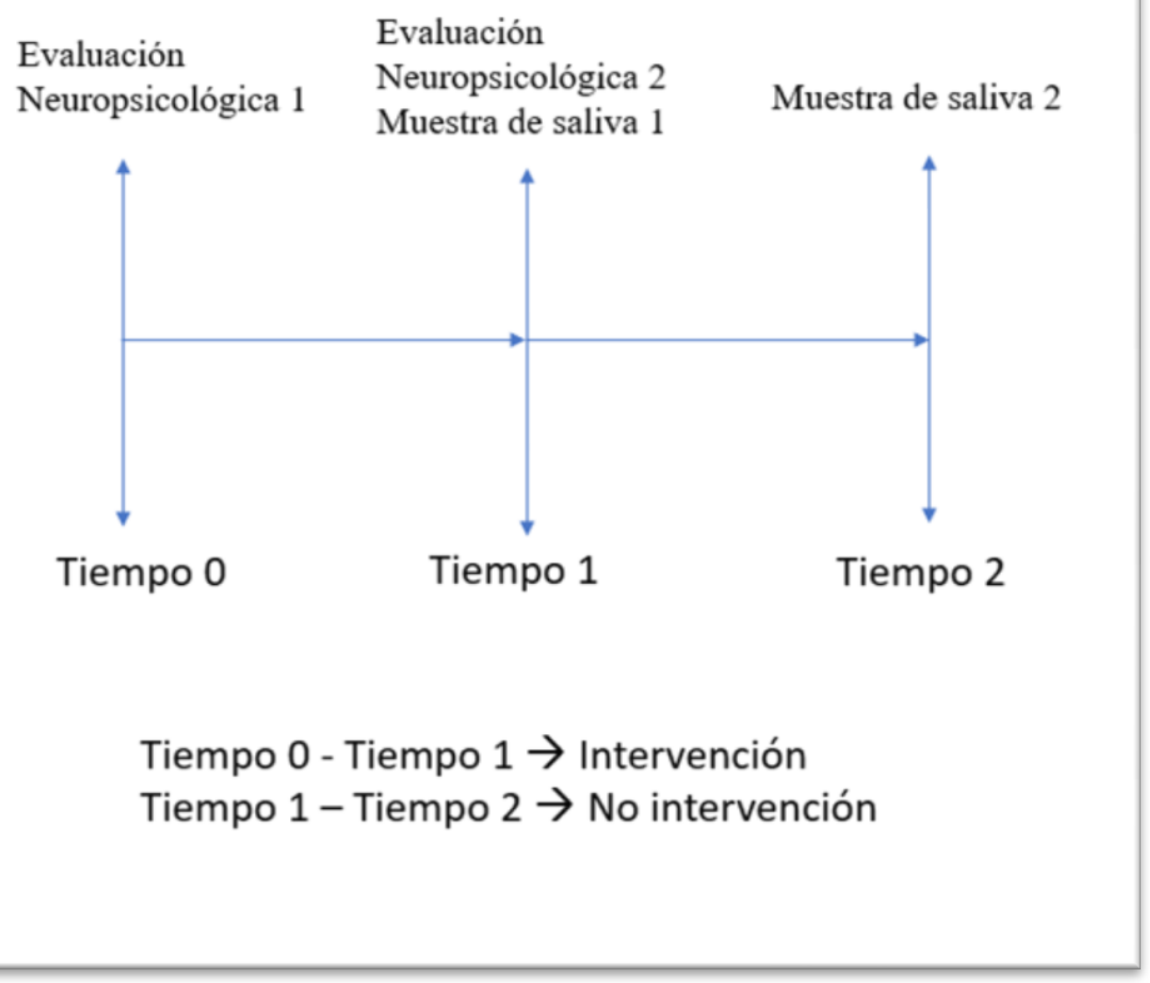

Figura 6: Cronología de la metodología utilizada en la investigación

Para la cuantificación de la enzima telomerasa y el cálculo de la longitud relativa del telómero se siguió el protocolo qPCR establecido por el laboratorio:

Primero se procedió a extraer el DNA de la saliva contenida en los bastoncillos:

Primer paso:

Coger un ependorf vacío por cada una de los bastoncillos y darles un código (el establecido por el laboratorio). Posteriormente se debe añadir:

- 600 microlitros de FORMACE (guardado a $4^{\circ} \mathrm{C}$ )

- 30 microlitros de EDTA 0,5 M

- 2 microlitros de Proteinasa K $20 \mathrm{mg} / \mathrm{ml}$ 
Encender el mechero y con unas tijeras esterilizadas cortar los algodones de las torundas y meter cada uno en su ependorf correspondiente. Pasar las tijeras por la llama entre saliva y saliva.

Dar un vortex a los ependorf.

Añadir 20 microlitros de SDS pH8 al 10\%

Dar una centrifugación corta (Spin)

Sellar los tapones de los ependorf con Parafilm para que no se borren los números y para que no entre agua del baño dentro de los tubos.

Dejar los ependorf en un baño a $55^{\circ} \mathrm{C} 2$ ó 3 noches

Segundo paso:

Ir a la campana de extracción. Echar 500 microlitros de Phenol-Cloroformo con una pipeta y centrifugar 5 minutos a 12.000 revoluciones por minuto (rpm). Coger con la pipeta la fase de arriba y pasar a otro ependorf numerado también (el mismo código).

Añadir 500 microlitros de CIAA con una pipeta en el ependorf que contiene la fase de arriba. Agitar por inversión suavemente el ependorf 8-10 veces y centrifugar 5 minutos a $12.000 \mathrm{rpm}$.

Coger de nuevo la fase de arriba y pasar a otro ependorf.

Echar 1000 microlitros de etanol absoluto $\left(\mathrm{a}-20^{\circ} \mathrm{C}\right)$ y agitar por inversión suavemente el ependorf 8-10 veces hasta que el DNA empiece a precipitar.

Centrifugar 15 minutos a $10.000 \mathrm{rmp}$ en una centrifugadora a $4^{\circ} \mathrm{C}$.

Decantar el etanol y añadir 100 microlitros de etanol al $10 \%\left(\mathrm{a}-20^{\circ} \mathrm{C}\right)$ y centrifugar 5 minutos a $10.000 \mathrm{rpm}$.

Decantar el etanol y dejar un día secando el ependorf con la tapa abierta.

Añadir 60 microlitros de agua destilada.

Posteriormente se debe hacer una dilución 1:5 y para ello se seguirán los siguientes pasos:

- Medir la concentración de DNA en el Nanodrop: 
○ Iniciar el programa (Ácidos Nucleicos)

- Comprobación rutinaria: pipetear 2 microlitros de Agua para limpiar y medir su absorbancia

○ Blanco: 1 microlitro de Agua

- Una vez puesto a punto el nanodrop se procedía a medir las muestras de todos los sujetos de manera individual. Se pipetea 1 microlitro de la muestra de saliva extraída al principio y se le da al botón de medir. El nanodrop nos da la concentración de DNA medida en nanogramo/microlitro de cada paciente. La ratio debe estar en 1,8 y 2,0 es decir, 200/280 nm. Entre muestras de cada paciente se debía de cambiar las puntas de las pipetas y limpiar el nanodrop.

- Una vez halladas las concentraciones de cada muestra debemos realizar una dilución 1:10 según la concentración. $\mathrm{Ci}$ x Vi $=\mathrm{Cf}$ x Vf

- Se vuelve a medir en el Nanodrop la concentración de las muestras (de las muestras $1 / 10$ diluidas)

- Preparar dilución para tener una concentración de 5 ng/uL

- Congelar a $-20^{\circ} \mathrm{C}$.

Una vez que todas las muestras están en una concentración de 5 ng/ uL se realiza el trabajo en campana para preparar las placas o strips.

Las placas o strips se preparan de la siguiente manera:

Se debe preparar una mastermix de telomerasa (TEL) y una mastermix de control endógeno (SCR).

Para la mastermix de TEL se deben añadir las siguientes cantidades proporcionadas por el Kit: 
SYBR: $10 \mathrm{uL}$ por pocillo

Del oligo TEL: $1 \mathrm{uL}$ por pocillo

De esta mezcla se van a utilizar 18 uL por pocillo

De agua: 7 uL por pocillo

Para la mastermix de SCR se deben añadir las siguientes cantidades:

SYBR: $10 \mathrm{uL}$ por pocillo

Del oligo SCR: $1 \mathrm{uL}$ por pocillo

De esta mezcla se van a utilizar 18 uL por pocillo

De agua: $7 \mathrm{uL}$ por pocillo

Los números de la placa del 1 al 6 y de la $\mathrm{A}$ a la $\mathrm{H}$ se van a usar para la TEL, mientras que del 7 al 12 y de la A a la $\mathrm{H}$ se van a usar para el control endógeno (SCR)

\begin{tabular}{|c|c|c|c|c|c|c|c|c|c|c|c|}
\hline $\mathbf{1 A}$ & $\mathbf{2 A}$ & $\mathbf{3 A}$ & $\mathbf{4 A}$ & $\mathbf{5 A}$ & $\mathbf{6 A}$ & $7 \mathrm{~A}$ & $8 \mathrm{~A}$ & $9 \mathrm{~A}$ & $10 \mathrm{~A}$ & $11 \mathrm{~A}$ & $12 \mathrm{~A}$ \\
\hline $\mathbf{1 B}$ & $\mathbf{2 B}$ & $\mathbf{3 B}$ & $\mathbf{4 B}$ & $\mathbf{5 B}$ & $\mathbf{6 B}$ & $7 \mathrm{~B}$ & $8 \mathrm{~B}$ & $9 \mathrm{~B}$ & $10 \mathrm{~B}$ & $11 \mathrm{~B}$ & $12 \mathrm{~B}$ \\
\hline $\mathbf{1 C}$ & $\mathbf{2 C}$ & $\mathbf{3 C}$ & $\mathbf{4 C}$ & $\mathbf{5 C}$ & $\mathbf{6 C}$ & $7 \mathrm{C}$ & $8 \mathrm{C}$ & $9 \mathrm{C}$ & $10 \mathrm{C}$ & $11 \mathrm{C}$ & $12 \mathrm{C}$ \\
\hline $\mathbf{1 D}$ & $\mathbf{2 D}$ & $\mathbf{3 D}$ & $\mathbf{4 D}$ & $\mathbf{5 D}$ & $\mathbf{6 D}$ & $7 \mathrm{D}$ & $8 \mathrm{D}$ & $9 \mathrm{D}$ & $10 \mathrm{D}$ & $11 \mathrm{D}$ & $12 \mathrm{D}$ \\
\hline $\mathbf{1 E}$ & $\mathbf{2 E}$ & $\mathbf{3 E}$ & $\mathbf{4 E}$ & $\mathbf{5 E}$ & $\mathbf{6 E}$ & $7 \mathrm{E}$ & $8 \mathrm{E}$ & $9 \mathrm{E}$ & $10 \mathrm{E}$ & $11 \mathrm{E}$ & $12 \mathrm{E}$ \\
\hline $\mathbf{1 F}$ & $\mathbf{2 F}$ & $\mathbf{3 F}$ & $\mathbf{4 F}$ & $\mathbf{5 F}$ & $\mathbf{6 F}$ & $7 \mathrm{~F}$ & $8 \mathrm{~F}$ & $9 \mathrm{~F}$ & $10 \mathrm{~F}$ & $11 \mathrm{~F}$ & $12 \mathrm{~F}$ \\
\hline $\mathbf{1 G}$ & $\mathbf{2 G}$ & $\mathbf{3 G}$ & $\mathbf{4 G}$ & $\mathbf{5 G}$ & $\mathbf{6 G}$ & $7 \mathrm{G}$ & $8 \mathrm{G}$ & $9 \mathrm{G}$ & $10 \mathrm{G}$ & $11 \mathrm{G}$ & $12 \mathrm{G}$ \\
\hline $\mathbf{1 H}$ & $\mathbf{2 H}$ & $\mathbf{3 H}$ & $\mathbf{4 H}$ & $\mathbf{5 H}$ & $\mathbf{6 H}$ & $7 \mathrm{H}$ & $8 \mathrm{H}$ & $9 \mathrm{H}$ & $10 \mathrm{H}$ & $11 \mathrm{H}$ & $12 \mathrm{H}$ \\
\hline
\end{tabular}

En la imagen anterior se trata de simular una placa o strip. Los cuadrados de color amarillo simulan a los pocillos de TEL de la placa mientras que los cuadrados de color naranja simulan a los pocillos del control endógeno SCR.

De la mastermix de TEL se van a usar $18 \mathrm{uL}$ para cada pocillo. De la mastermix de SCR se van a usar también $18 \mathrm{uL}$ para cada pocillo. Es decir, se deben pipetear $18 \mathrm{uL}$ de la mastermix de TEL en todos los pocillos del 1 al 6, es decir, si simulamos la tabla anterior como una placa se deben pipetar $18 \mathrm{uL}$ de la mastermix de TEL en los cuadrados amarillos, mientras que se deben pipetear $18 \mathrm{uL}$ de la mastermix de SCR en los cuadrados naranjas. Una vez pipeteadas ambas mastermix se deben pipetear $2 \mathrm{uL}$ del DNA que está a una concentración de $5 \mathrm{ng} / \mathrm{uL}$ que anteriormente habíamos preparado 
en el nanodrop, en cada pocillo. Además, en la placa o strip se deben dejar 3 pocillos libres en los cuales, en 2 de ellos se debe pipetear $1 \mathrm{uL}$ de DNA CRTL (DNA control) que nos viene con el kit. Se deja libre un tercer pocillo en el que no se pipetea nada y se deja como control negativo.

Así quedaría la placa:

\begin{tabular}{|l|l|l|l|l|l|l|l|l|l|l|l|}
\hline $\mathbf{1}$ & $\mathbf{1}$ & $\mathbf{1}$ & $\mathbf{2}$ & $\mathbf{2}$ & $\mathbf{2}$ & 1 & 1 & 1 & 2 & 2 & 2 \\
\hline $\mathbf{3}$ & $\mathbf{3}$ & $\mathbf{3}$ & $\mathbf{4}$ & $\mathbf{4}$ & $\mathbf{4}$ & 3 & 3 & 3 & 4 & 4 & 4 \\
\hline $\mathbf{5}$ & $\mathbf{5}$ & $\mathbf{5}$ & $\mathbf{6}$ & $\mathbf{6}$ & $\mathbf{6}$ & 5 & 5 & 5 & 6 & 6 & 6 \\
\hline $\mathbf{7}$ & $\mathbf{7}$ & $\mathbf{7}$ & $\mathbf{8}$ & $\mathbf{8}$ & $\mathbf{8}$ & 7 & 7 & 7 & 8 & 8 & 8 \\
\hline $\mathbf{9}$ & $\mathbf{9}$ & $\mathbf{9}$ & $\mathbf{1 0}$ & $\mathbf{1 0}$ & $\mathbf{1 0}$ & 9 & 9 & 9 & 10 & 10 & 10 \\
\hline 11 & $\mathbf{1 1}$ & $\mathbf{1 1}$ & $\mathbf{1 2}$ & $\mathbf{1 2}$ & $\mathbf{1 2}$ & 11 & 11 & 11 & 12 & 12 & 12 \\
\hline 13 & $\mathbf{1 3}$ & $\mathbf{1 3}$ & $\mathbf{1 4}$ & $\mathbf{1 4}$ & $\mathbf{1 4}$ & 13 & 13 & 13 & 14 & 14 & 14 \\
\hline CRTL & CRTL & $\mathbf{C}-$ & & & & CRTL & CRTL & C- & & & \\
\hline
\end{tabular}

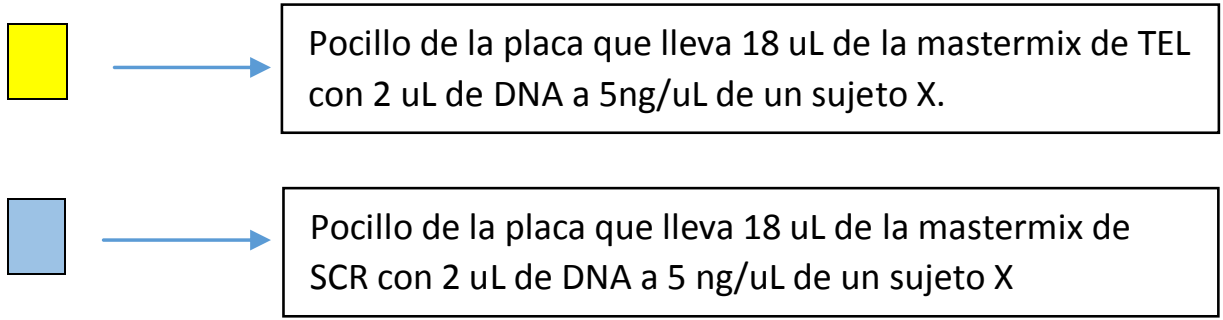

Los números representan el pocillo de cada paciente en la placa. Como se puede observar se pueden hacer como máximo 14 sujetos por placa. Una vez pipeteado todo en la placa correspondiente se deben sellar las placas con un plástico. Una vez selladas las placas se les debe de dar un spin para que quede todo abajo del pocillo y sin burbujas.

Con esto estaría la placa preparada para realizar la qPCR siguiendo las indicaciones del programa. El programa tarda aproximadamente 3 horas en realizar las qPCR. Para la cuantificación en tiempo real de la expresión génica objetivo, se realizó una reacción en cadena de la polimerasa en tiempo real de un paso (RT-PCR) utilizando FastStart Universal SYBR Green Master (ROX) en un sistema de PCR en tiempo real StepOnePlus ${ }^{\text {TM }}$ (Life Technologies-Invitrogen, California, EEUU).Cuando la qPCR ha finalizado, el programa nos da unos valores que debemos convertir mediante fórmulas matemáticas en longitud telomérica cuya unidad de medida es el kilobase (kb). 
Como se refleja en el marco teórico, para determinar cambios en la longitud relativa del telómero en mujeres son necesarios estudios longitudinales de al menos 12 meses de intervención.

Esta situación nos llevó desde un punto metodológico a no realizar una toma basal de la longitud telomérica en los sujetos de ambos grupos al inicio del estudio, teniendo en cuenta que la fluctuación en la longitud telomérica se observa en el periodo de un año y no a los 6 meses. Lo que también parece claro y hay bastante concordancia es que en las mujeres la tasa promedio de pérdida de longitud es menos evidenciada que en el sexo masculino, por lo tanto, para observar diferencias en la longitud telomérica en un grupo de mujeres habría que esperar más tiempo, situación similar que presenta nuestra muestra de estudio.

\subsubsection{Diseño de la investigación}

En esta investigación se ha utilizado un diseño experimental pre-post,de dos grupos: un grupo de intervención y un grupo control sin intervención.

Las variables dependientes definidas son las funciones cognitivas y la longitud teloméricas. Las variables independientes han sido el tipo de grupo experimental, los tiempos que definen el pre y post y en el caso que la función cognitiva se medía en diferentes subescalas, el tipo de subescala.

La intervención se ha administrado únicamente al GE, mientras que realizaba su vida de manera normal y participaba en las actividades que venía participando con regularidad.

\subsubsection{Análisis estadístico}

Para la descripción de los datos de las variables cualitativas se han utilizado medias, desviaciones típicas, medianas y Rangos intercuartílicos. En el caso de variables cualitativas se han calculado porcentajes. El análisis de la normalidad de las observaciones se ha llevado a cabo mediante el test de Kolmogorov-Smirnov con la corrección de lilliefors y la interpretación de los box-plot.

En la comparación de dos grupos se ha utilizado el test t para datos independientes cuando las variables seguían distribuciones normales y el test no paramétrico U de Mann-Whitney en el caso de distribuciones no normales. Para la elección de los grados de libertad del test $t$, se ha utilizado el test de Levene para contrastar la igualdad de varianzas poblacionales. 
En el análisis del cambio en el tiempo entre los grupos experimentales para instrumentos unidimensionales se ha utilizado el ANOVA de dos factores, uno de ellos de medidas independientes (grupo experimental, grupo control) y otro de medidas dependientes (pre, post).En el caso de que el instrumento presentara varías dimensiones se ha utilizado el ANOVA de tres factores, uno de medidas independientes (intervención, control) y dos de medidas dependientes, tiempo (pre-post) y dimensión. Para las comparaciones entre los grupos se han utilizado los test a posteriori del ANOVA con la corrección de Bonferroni.

Para el análisis de la asociación entre la longitud telomérica y las funciones cognitivas se ha utilizadoel coeficiente de correlación de Pearson. Se ha interpretado tanto la magnitud de la asociación ( 0 no hay asociación lineal y 1 existe una dependencia lineal perfecta) como el sentido de la asociación: directa (aumento del valor la longitud telomérica (función cognitiva) produce el aumento del valor de la función cognitiva (longitud telomérica) como inversa (el aumento del valor de la longitud telomérica(función cognitiva) produce el descenso de la función cognitiva(longitud telomérica)

Para la estimación de los parámetros se han calculado los intervalos de confianza al 95\%. La significación estadística se considera cuando los p-valores son menores que el nivel de significación del 0,05.

El análisis de los datos se ha llevado a cabo con el programa IBM-SPSS versión 25. 


\section{RESULTADOS}




\section{Resultados}

\subsection{Estadísticos descriptivos y distribución de los sujetos en ambos grupos}

Se ha realizado un análisis descriptivo de las variables sociodemográficas de los sujetos para analizar la comparabilidad de los grupos de la muestra.

En lo referente a la edad (Tabla 2) el GE presentaba una edad media de 72,70 y el GC de 71,21 años. (Todas las tablas se resultados se encuentran en el APÉNDICE: TABLAS)

La edad presenta una distribución simétrica en ambos grupos, en el grupo control encontramos cierta asimetría hacia la derecha. No se han detectado diferencias significativas entre los grupos experimentales en relación a la edad ( $p$-valor=0,138). (Gráfico 1).

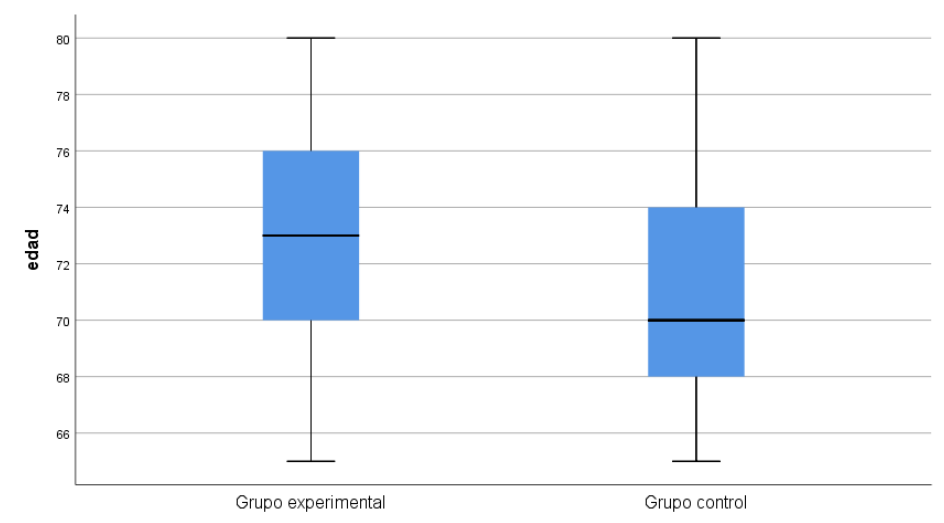

Gráfico 1: Intervalos de confianza de ambos grupos para la variable edad

Los años de escolarización presentan asimetrías opuestas, en el grupo experimental hay más valores altos mientras que en el grupo control nos encontramos valores más bajos, si bien no se han detectado diferencias significativas (p-valor=0,576). (Gráfico 2)

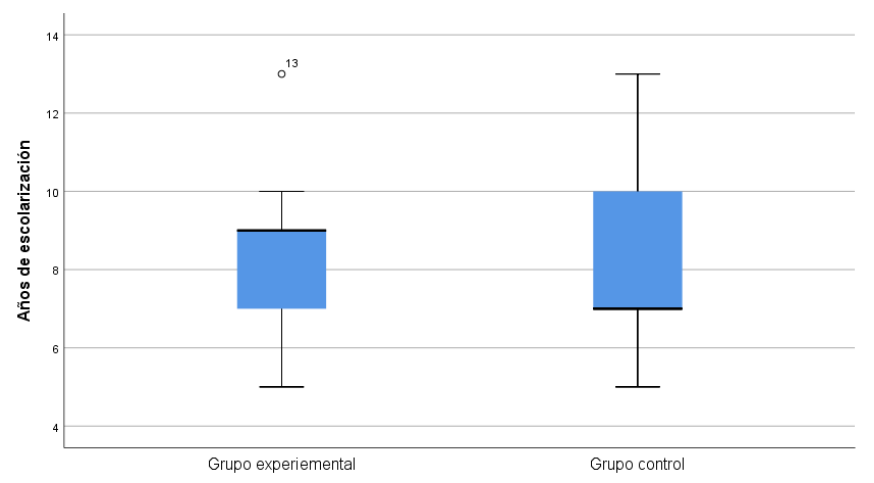

Gráfico 2: Intervalos de confianza de ambos grupos para la variable años de escolaridad 
En relación a las variables cualitativas (tabla 3), no se ha detectado una asociación significativa entre los grupos en el estado civil ( $\mathrm{p}$-valor=0,238), si bien, existe un porcentaje mayor de casados en el GE, en relación al GC. (Gráfico3).

En el gráfico 3 se observa la distribución de los sujetos según el estado civil.

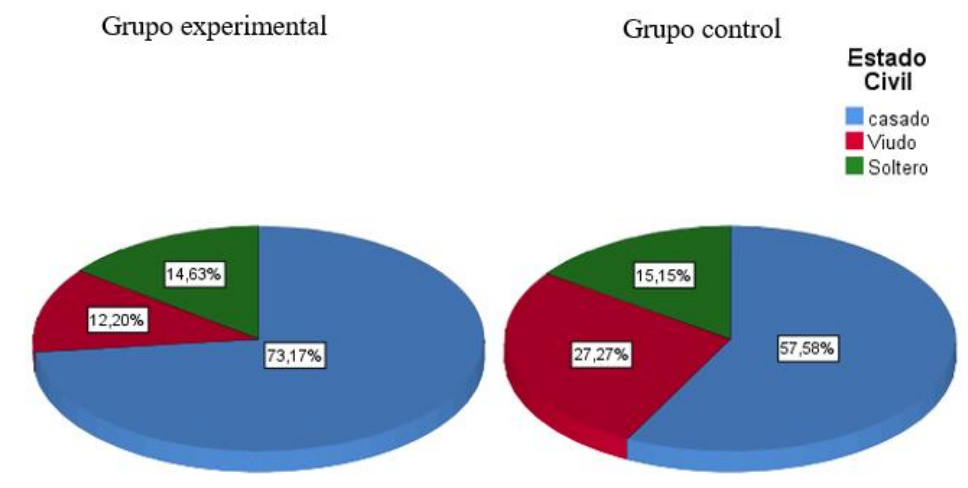

Gráfico 3. Distribución de los sujetos según el estado civil

En el Nivel de Estudios, (tabla 4), si se ha detectado una asociación significativa (pvalor $=0,038)$, si bien, las frecuencias son muy bajas y pueden estar afectando a la significación. Si se realiza la prueba exacta de Fisher, se mantiene la significación (pvalor=0,031).

En el gráfico 4 se observa la distribución de los sujetos según el Nivel de Estudios.

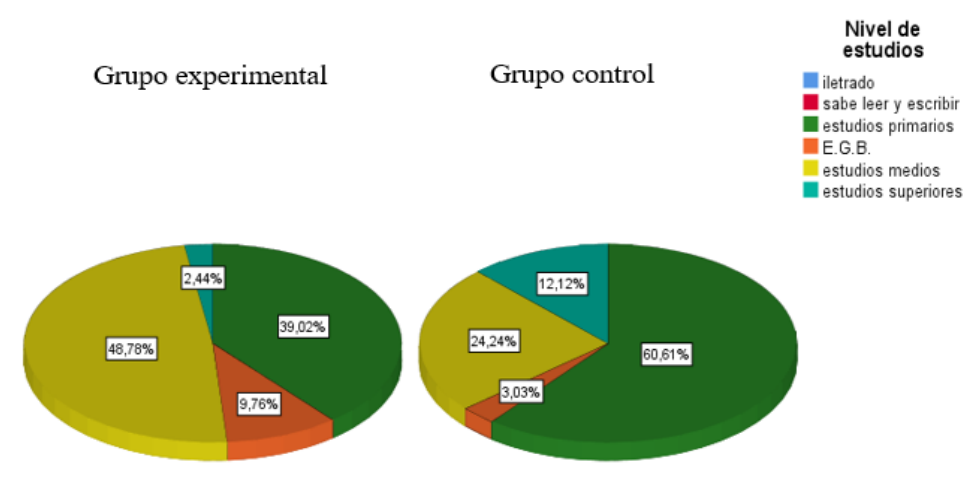

Gráfico 4. Distribución de los sujetos según el Nivel de Estudios. 
En cuanto a la profesión, no se ha encontrado una asociación entre los grupos de la muestra ( $\mathrm{p}$-valor $=0,515$ ) aunque como en el caso anterior las frecuencias son muy bajas. Si aplicamos el test exacto de Fisher se mantiene resultado ( $p$-valor=0,633).

En el gráfico 5 se refleja la distribución de los sujetos de ambos grupos, en relación a la Profesión

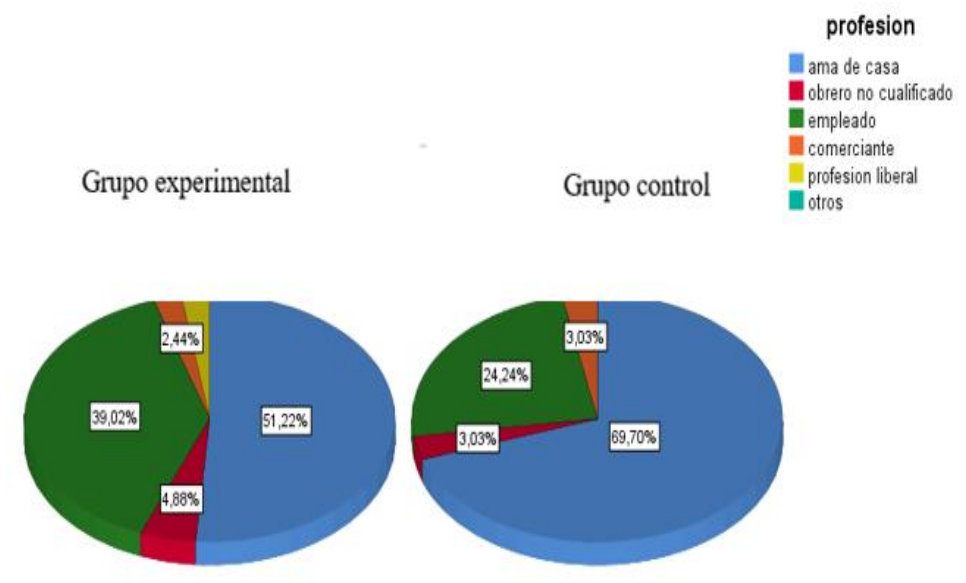

Gráfico 5. Distribución de los sujetos según la Profesión.

En cuanto a las distribuciones relacionadas con las variables antropométricas, se observa como las distribuciones son simétricas con algunas desviaciones como en la talla aunque el test de Normalidad no es significativo, o en el porcentaje de grasa en el segundo tiempo para ambos grupos y para el primer tiempo en el grupo donde el test de normalidad es significativo (CG: p-valor=0,004; GE:p-valor<0,0001). (Tabla 5)

En el caso del porcentaje de grasa se han detectado diferencias estadísticamente significativas tanto en el tiempo 1 como en el tiempo 2 ( $p$-valor $<0,0001$; $p$-valor $=0,001$, respectivamente). En ambos tiempos el porcentaje de grasa mediano es mayor en el grupo de intervención que en los controles. En la altura media de los individuos también se han detectado diferencias significativas con valores medios mayores en el grupo control (p-valor $<0,0001)$. En el peso graso en ambos tiempos se ha detectado diferencias significativas (tiempo1: $\mathrm{p}$-valor=0,035; tiempo 2; $\mathrm{p}$-valor=0,024). En ambos tiempos el peso medio de las muestras es mayor en el GE. 


\subsection{Influencia del Programa de Revitalización sobre las funciones cognitivas evaluadas.}

\subsubsection{Examen Cognoscitivo Mini-Mental}

Para obtener los resultados en el Examen Cognoscitivo Mini-Mental realizaremos un análisis de la varianza de dos factores uno de datos independientes y otro de datos dependientes. Nos interesa conocer si el cambio es diferente en el grupo control al cambio del grupo experimental.

Se ha detectado que la interacción entre la intervención y los tiempos es altamente significativa ( $\mathrm{p}$-valor $<0,0001$ ), es decir el cambio que se produce en el tiempo 2 en el GE es diferente al del GC, como se refleja en el gráfico 6.

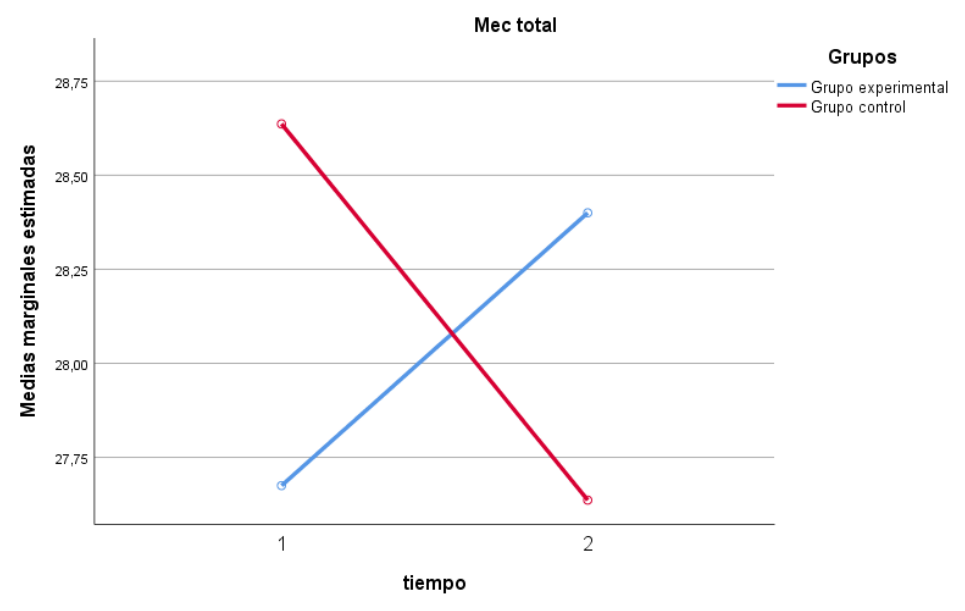

Gráfico 6: Interacción entre ambos grupos en el MEC

En la tabla 6podemos observar que en el GC hay un descenso en las puntuaciones medias del MEC en el tiempo 2, por el contrario,en el GE se refleja un ascenso en dicho tiempo, en relación al tiempo 1.

Estos resultados, en primer lugar, nos están informando que ninguno de los sujetos participantes, presentaba deterioro cognitivo global, considerando que las puntuaciones medias obtenidas se sitúan en el intervalo de la normalidad.

En segundo lugar, y como queda reflejado en los resultados, la existencia de diferencias significativas entre ambas medidas, obteniendo en la segunda valoración mayores puntuaciones los sujetos del grupo experimental, frente a las puntuaciones de los sujetos 
del grupo control, nos ratifica el beneficio de las intervenciones practicadas, mejorando la función cognitiva de los sujetos pertenecientes al programa de Revitalización.

\subsubsection{Aprendizaje audio-verbal de Rey}

La interacción triple ha sido significativa y por lo tanto los cambios (diferencias entre tiempos 1 y 2) que se han producido en cada nivel de audio son diferentes entre los grupos control y experimental. En los siguientes gráficos $(7$ y 8$)$, se observa el comportamiento de las puntuaciones para los niveles de audio-verbal de Rey en cada tiempo. Se observa como en el tiempo 1 los valores medios en las escalas de audio del grupo control están por encima, mientras que en el tiempo 2, tras la intervención la situación se invierte, siendo el GE el que alcanza mayores puntuaciones.

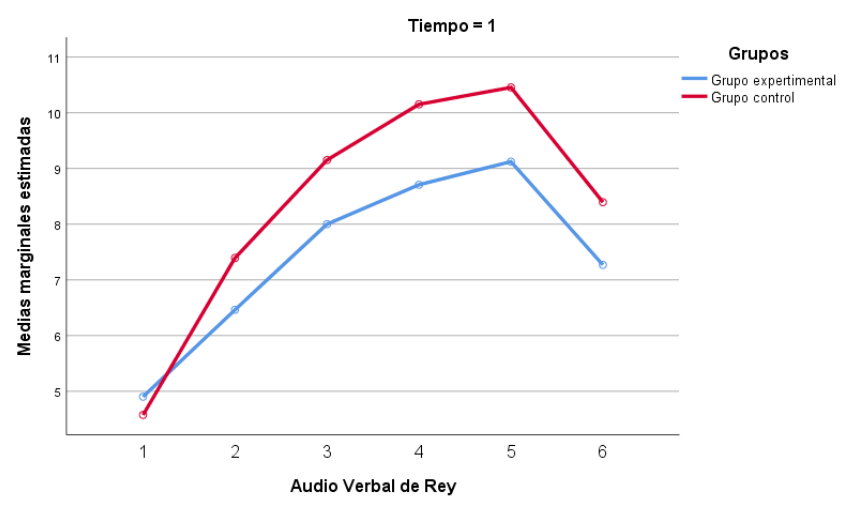

Gráfico 7: Curva de Aprendizaje en el tiempo 1

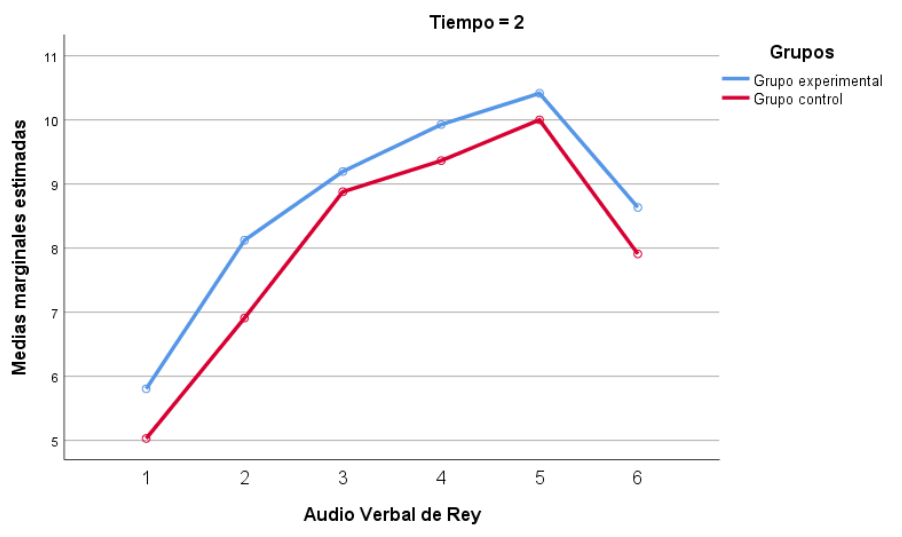

Gráfico 8: Curva de Aprendizaje en el tiempo 2 
Los valores descriptivos para cada dimensión de audio-verbal de Reyen cada tiempo y para cada grupo, aparecen en la tabla 7.

Si se realizan los contrastes para los cambios producidos en cada dimensión se observa cómo sólo en la dimensión 1 las diferencias no son significativas. (Tabla 8)

Si analizamos los cambios producidos para cada grupo en el total de palabras recordadas, observamos un descenso pronunciado en el grupo experimental en el tiempo 1, mientras que en el grupo control se produce un ascenso, aunque no es estadísticamente significativo. Por el contrario, en el tiempo 2 tras la intervención, se observa la misma tendencia que en pruebas anteriores, los sujetos del GE son capaces de recordar un mayor número de palabras que los sujetos pertenecientes al GC.

En el análisis de la escala global, se han detectado diferencias significativas en el cambio como cabría esperar (p-valor $<0,0001$ ). Por lo tanto, los cambios son diferentes en el grupo control que en el grupo intervención. (Gráfico 9).

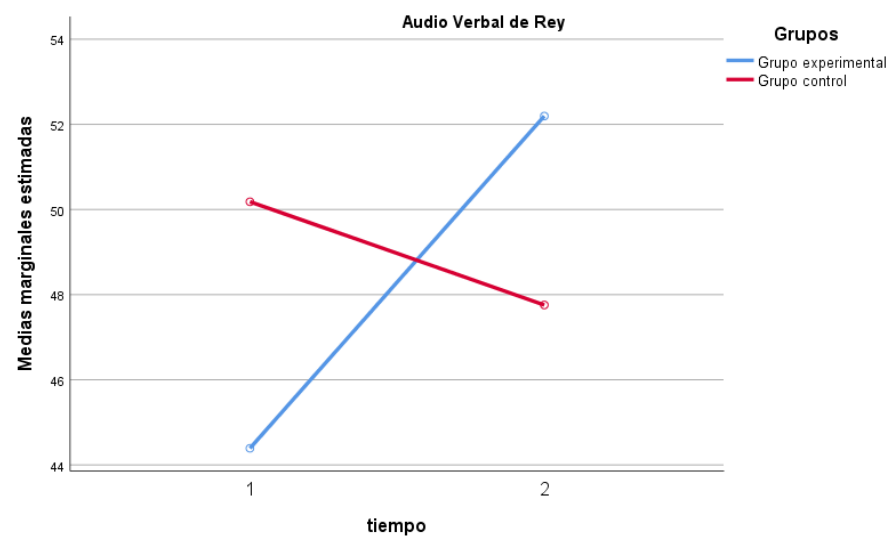

Gráfico 9: Interacción entre ambos grupos y tiempos en la escala global de Audioverbal de Rey

Los valores descriptivos de cada tiempo aparecen en la siguiente tabla 9.

La conclusión relevante, y que se repite en los resultados citados anteriormente, nos informa que los sujetos tras la intervención aumentan la memoria inmediata, proporcionando una curva de aprendizaje, lo que refleja una significativa retención, incluso después una actividad mediadora. Los sujetos del GE obtienen en la segunda valoración mayores puntuaciones, frente a las puntuaciones de los sujetos incluidos en el grupo control, esta situación nos vuelve a ratificar el beneficio de las intervenciones 
practicadas, mejorando la memoria verbal inmediata en aquellos sujetos incluidos en el programa de Revitalización.

\subsubsection{Test de Retención Visual de Benton}

Para analizar los resultados obtenidos en el Test de Retención Visual de Benton (TRVB) y teniendo en cuanta sus diferentes medidas, se realiza un test de ANOVA con dos factores dependientes (aciertos/errores y tiempos 1 y 2 ) y uno independiente (intervención). Los descriptivos del análisis estadístico aparecen en la tabla10.

El análisis de la varianza arroja resultados estadísticamente significativos en la interacción tiple entre tiempo 1 y 2, medidas del TRVB y GE (p-valor<0,001). Es decir que el cambio que se produce en el tiempo 1 y 2, para el GE no es el mismo en las distintas medidas del test. Si observamos el grafico 10, podemos ver como en el tiempo 1 el CG tiene puntuaciones mayores en el número aciertos que el GE, y sin embargo como cabría esperar es al contrario en el número de errores. Si bien la diferencia en errores es mayor que en aciertos. Sin embargo, la situación se invierte en el tiempo 2 (gráfico 11), aunque en esta ocasión las diferencias en errores y aciertos entre los grupos experimentales son parecidas.

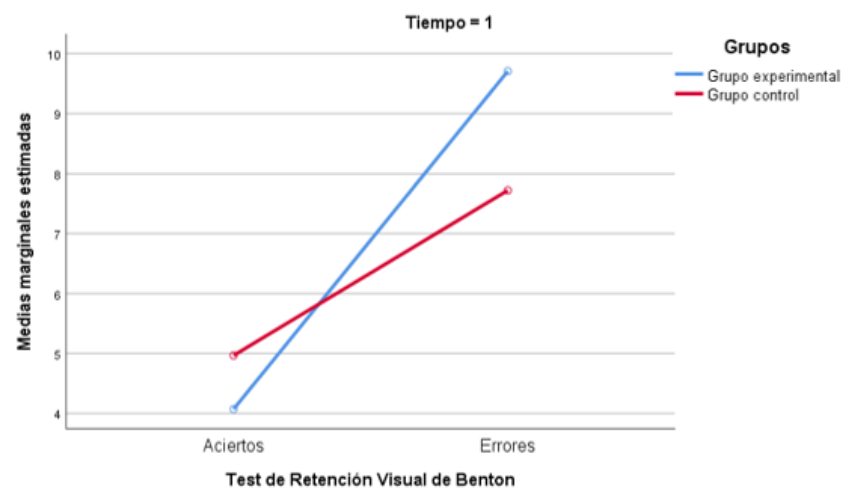

Gráfico 10. Interacción entre ambos grupos en el tiempo1 en el TRVB

Si analizamos los gráficos 12 y 13 de interacción donde se analiza en cambio que se produce en el tiempo para los grupos experimentales en cada dimensión, se observa como en el tiempo 1 los aciertos son mayores en el grupo control, pero después de la intervención la situación se invierte. Lo mismo ocurre con los errores, pero en la modalidad de errores en el tiempo 1 el grupo control presenta menos puntuación que el grupo intervención y esa situación se invierte en el tiempo 2. 


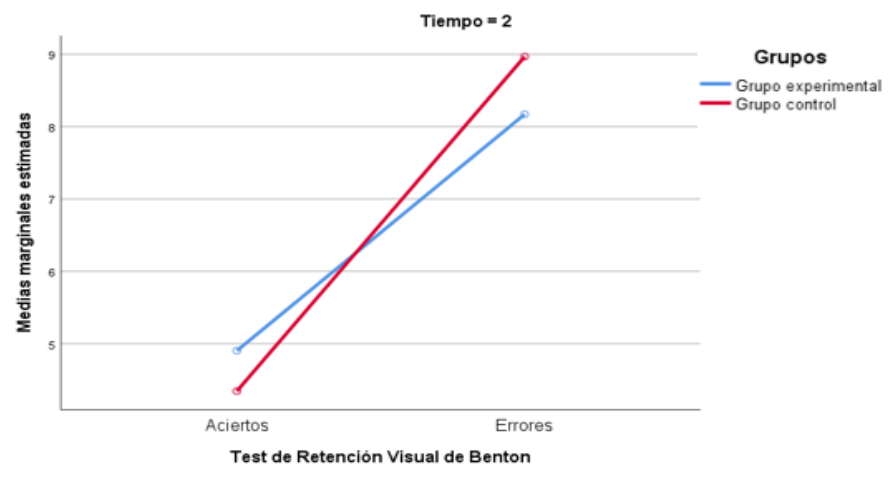

Gráfico 11. Interacción entre ambos grupos en el tiempo2 en el TRVB.

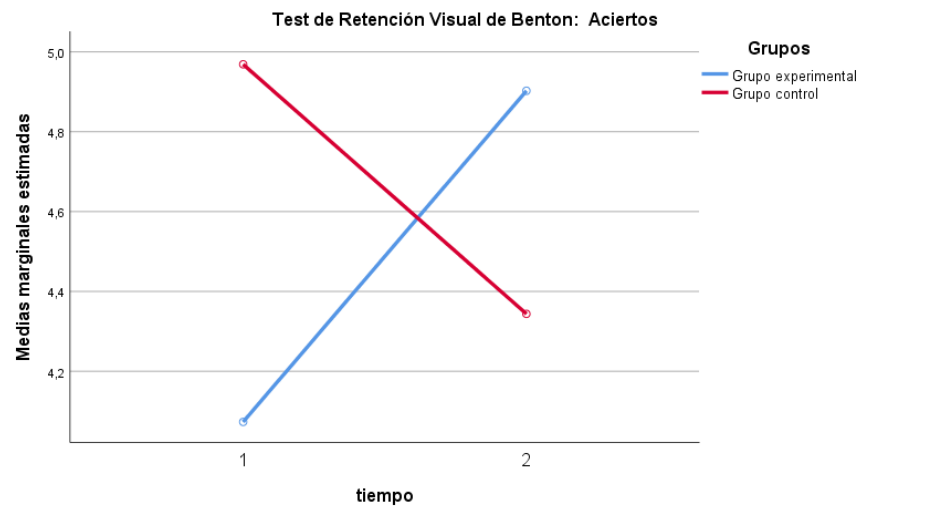

Gráfico 12. Interacción entre ambos grupos y tiempos 1y 2 en el TRVB (Aciertos).

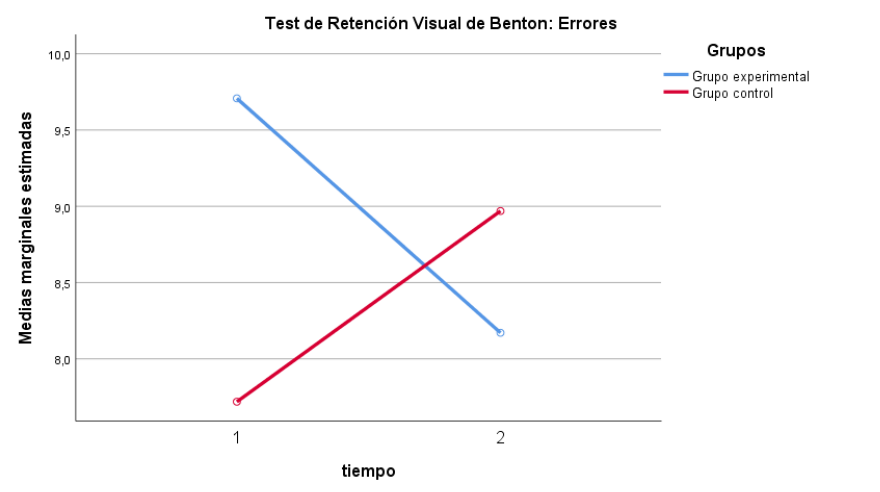

Gráfico 13. Interacción entre ambos grupos y tiempos 1y 2 en el TRVB (Errores).

Si se analiza el cambio medio producido en el tiempo para cada dimensión en cada grupo, observamos como los cambios son positivos en el número de errores en el GE y 
negativos en el GC y ese cambio se invierte, como cabría esperar en el número aciertos con un cambio negativo en el GE (se producen más aciertos en el tiempo 2), mientras que en el GC el cambio es positivo (se produce un menor número de aciertos en el tiempo 2) aunque en este caso es estadísticamente no significativo diferente de cero. Si realizamos los contrastes del cambio producido en el tiempo entre los grupos experimentales se detectan diferencias estadísticamente significativas en ambas comparaciones. (Tabla 11)

\subsubsection{Test de Stroop}

El análisis estadístico es similar al empleado en los resultados anteriores. Se ha detectado diferencias significativas en la interacción tiple ( $\mathrm{p}$-valor=0,009), por lo tanto, los cambios que se producen en ambos grupos son diferentes en función de las variables empleadas en esta prueba.

En la tabla 12 aparecen los descriptivos de las modalidades del Test de Stroop para cada tiempo y en ambos grupos.

No se ha detectado la interacción triple significativas (p-valor=0,499), entre modalidades tiempo y ambos grupos. La única interacción significativa ha sido la que implica al tiempo y el GE (p-valor<0,0001).

Esto significa que el cambio en los tiempos 1 y 2, ha sido diferente y estadísticamente significativo para el GE y que esas diferencias se han mantenido para las diferentes dimensiones del Test de Stroop.

Si se analiza el comportamiento de las puntuaciones de las diferentes escalas del Test de Stroop en el tiempo 1 se observa como presentan valores superiores los sujetos del GC, sin embargo, en el tiempo 2 se invierte el sentido y toman valores mayores medios el GE para todas las dimensiones, aunque las diferencias no son tan grandes (Gráficos 13 y $14)$.

Si analizamos el cambio para cada dimensión del Test de Stroop, se puede observar cómo en tiempo 1 en las dimensiones Palabras y Colores las diferencias son importantes entre GC y GE, presentando valores superiores el GC, pero en el tiempo 2 esas diferencias disminuyen e incluso se invierten presentando valores medios mayores el GE. En el caso P/C, la situación es similar, aunque las diferencias en el tiempo 2 son 
mayores. En el caso de interferencia las diferencias del tiempo 1 son menores que las diferencias en tiempo 2.

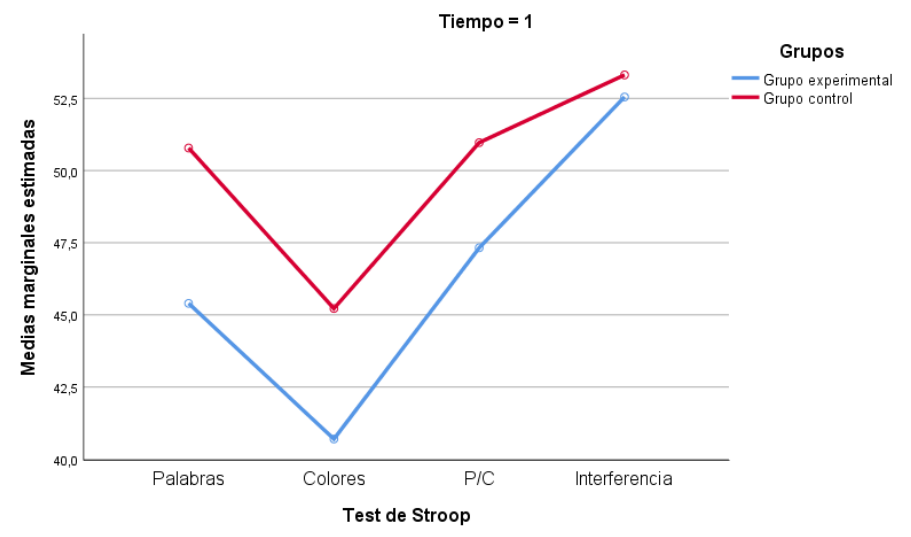

Gráfico 13: Interacción entre ambos grupos en el Tiempo 1

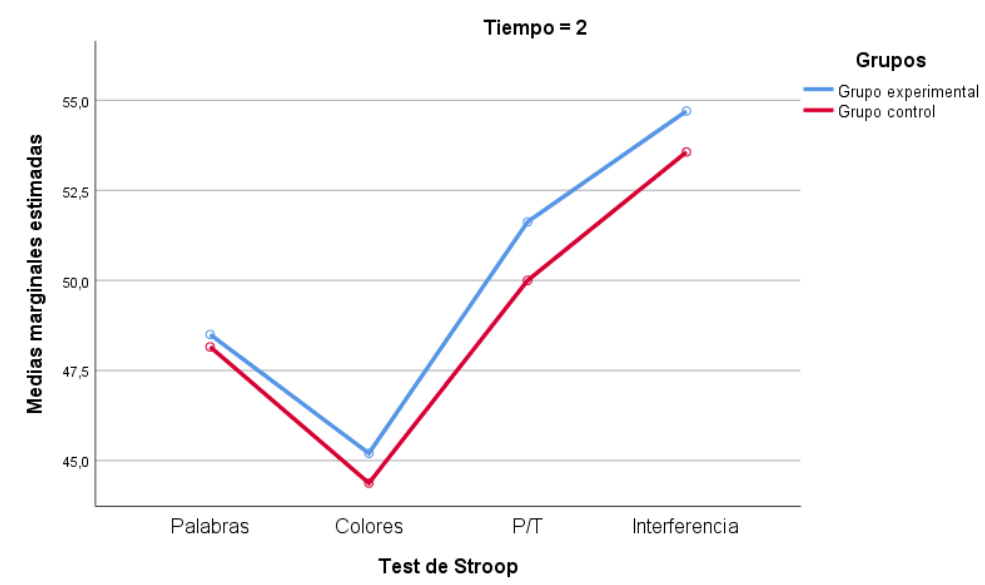

Gráfico 14: Interacción entre ambos grupos en el Tiempo 2

En el gráfico 15 presentamos los intervalos de confianza del cambio en el tiempo para las cuatro dimensiones y se puede observar como en el caso los cambios en el tiempo han sido negativos (valores mayores en el segundo tiempo) para las cuatro dimensiones, siendo el cambio estadísticamente diferente de cero en todas las dimensiones, excepto en el caso de interferencia. Por el contrario, en el GC, los cambios en los tiempos han sido positivos (puntuaciones mayores en el tiempo 2) y todas las dimensiones presentan cambios que estadísticamente no son diferentes de cero excepto Palabras. 


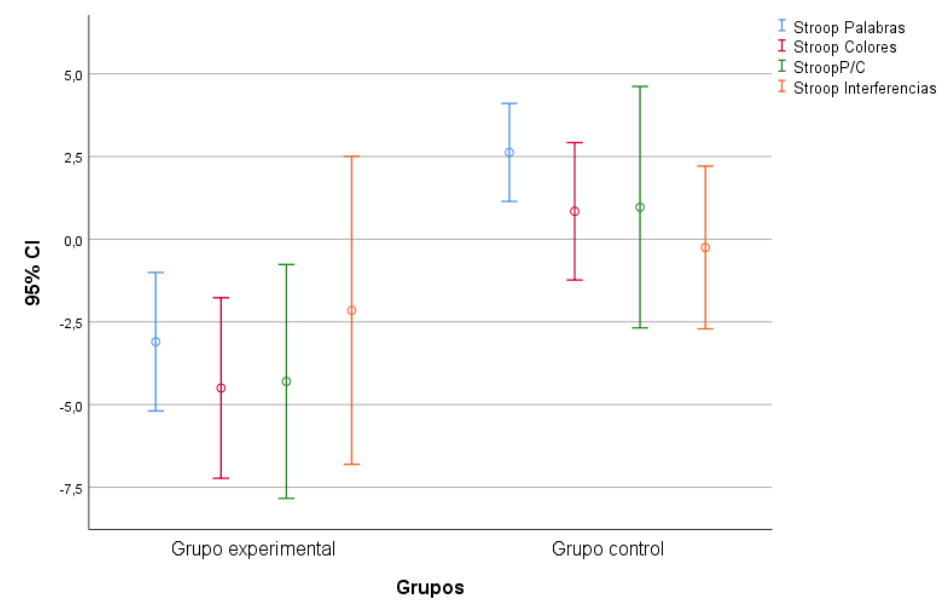

Gráfico 15: Intervalos de confianza en ambos tiempos y ambas modalidades

Si realizamos los contrastes por cada modalidad y así observar si los cambios que se han producido entre el GE y GC.se detectan diferencias en Palabras y Colores, pero no en las otras dos dimensiones. (Tabla 13)

\subsubsection{Test del Trazo}

En la tabla 14 se reflejan los estadísticos descriptivos para el Test del Trazo en ambas modalidades, en los tiempos 1 y 2 , y para ambos grupos de la muestra.

Se ha detectado interacción triple significativa ( $\mathrm{p}$-valor $=0,002)$, entre los tres factores. Si analizamos los gráficos de interacción se puede explorar cómo se comportan las diferencias de ambos grupos en función de la modalidad del Test del Trazo, así como en ambos tiempos.

En el gráfico 16 podemos observar como en el tiempo 1 hay diferencias entre el GE y el GC, si bien son mayores en el trazo B que en el A.

Sin embargo, esas diferencias entre los grupos realizan un viraje en el tiempo 2, además de ser mayor los valores en el grupo control que en el grupo experimental, lo que nos indica que los sujetos del GE tardan menos tiempo en realizar la prueba que los sujetos del GC, en el tiempo 2. 


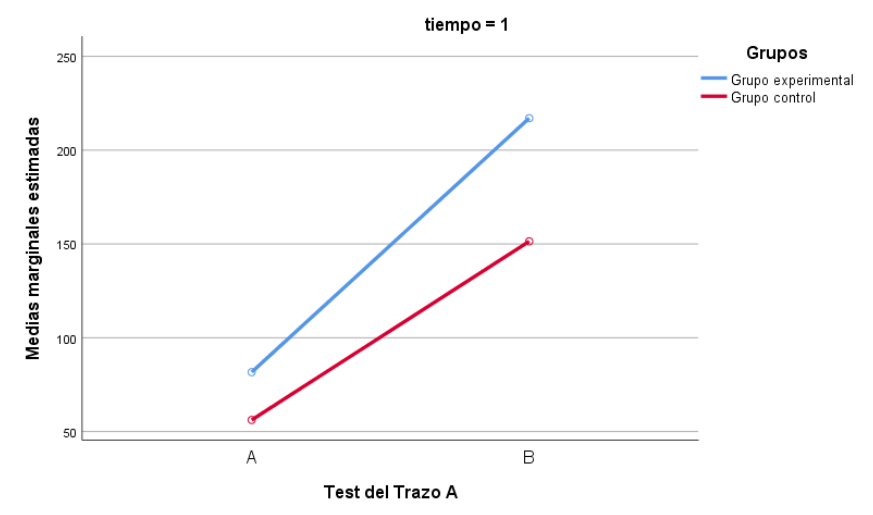

Gráfico 16: Interacción entre ambos grupos en el Test del Trazo A (Tiempo 1)

En el gráfico 17 se observa como la situación cambia en el tiempo 2, siendo los sujetos del GE los que realizan la prueba en menos tiempo que el empleado por los sujetos del GC.

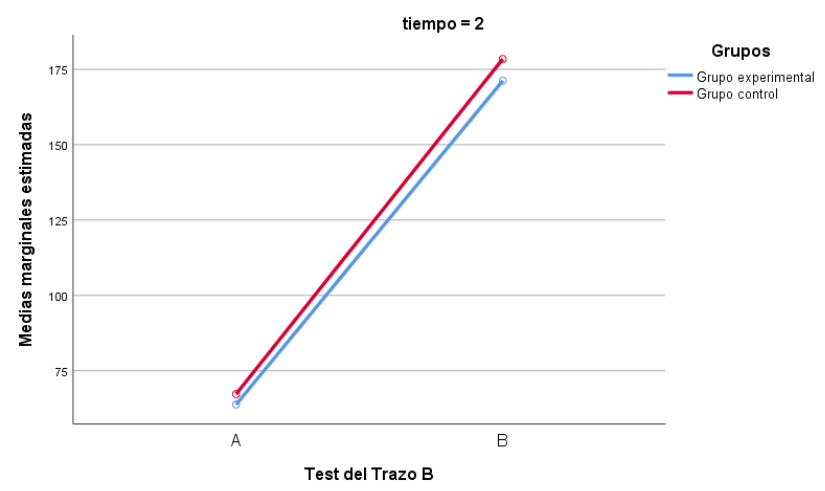

Gráfico 17: Interacción entre ambos grupos en el Test del Trazo A (Tiempo 2)

Si analizamos los gráficos 18 y 19 donde se refleja el cambio en los tiempos 1 y 2 , para cada modalidad del Test del Trazo, se observa como el comportamiento en ambas modalidades es muy similar hay un descenso en el tiempo de realización de la prueba en el GE del tiempo 1 al 2, sin embargo, en el GC la situación cambia, aumentando el tiempo de realización.

Si valoramos los cambios en los tiempos entre ambos grupos, para ambas modalidades, se observa como en la forma A el cambio es positivo para el GE y negativo para el GC, situación que se repite en la forma B. (Gráfico 20) 


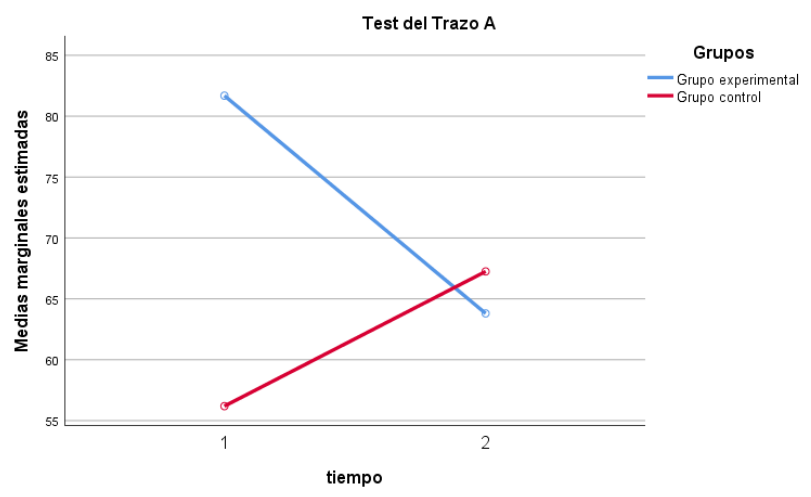

Gráfico 18: Interacción entre ambos grupos en el Test del Trazo A (Tiempos 1 y 2)

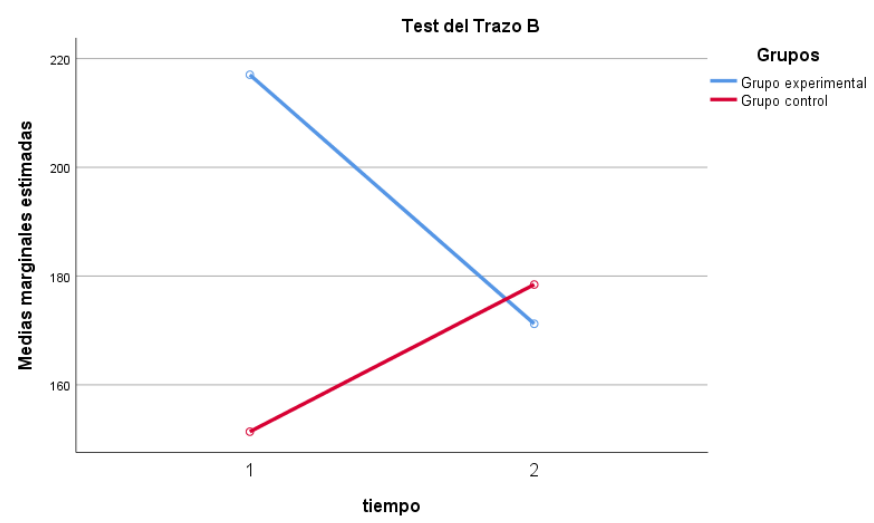

Gráfico 19: Interacción entre ambos grupos en el Test del Trazo B (Tiempos 1 y 2)

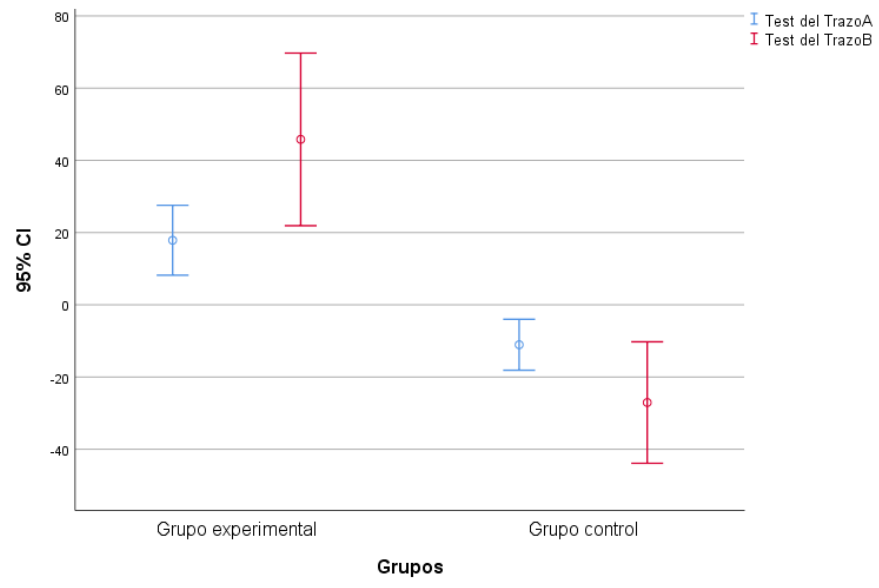

Gráfico 20: Intervalos de confianza en ambos tiempos y ambas modalidades 
En general los sujetos del GE, ejecutan en menor tiempo y en ambas modalidades el Test del Trazo en la segunda valoración, frente a los tiempos empleados por los sujetos que forman el grupo control, esta situación nos vuelve a indicar el beneficio de las intervenciones practicadas, mejorándola velocidad de búsqueda visual y la rapidez perceptivo-motora, en los sujetos incluidos en el programa de Revitalización.

\subsubsection{Escala de Vida WHOQOL-BREF}

Por último y para la valoración de la calidad de vida de los sujetos, y su posible relación con el proyecto de Revitalización Geriátrica, se ha utilizado la Escala de Calidad de Vida WHOQOL-BREF, que produce una visión de calidad de vida y se puede separar en puntajes de cuatro dominios.

Los descriptivos del global de calidad de vida aparece se pueden observar en la tabla 15.

No se ha detectado una interacción entre los tiempos, 1 y 2 y el GE estadísticamente significativa ( $\mathrm{p}$-valor=0,498). Por lo tanto, el cambio en el tiempo de la calidad de vida personal no ha sido diferente entre el GE. Si analizamos el grafico de interacción (gráfico 21), se observa que hay un ligero ascenso en el GE y un descenso en el GC, aunque esas diferencias no son significativas. Si analizamos los intervalos de confianza, aunque el cambio es negativo en el GC y positivo en el GE, la magnitud del cambio es pequeña (próxima a cero) y las diferencias no son significativas.

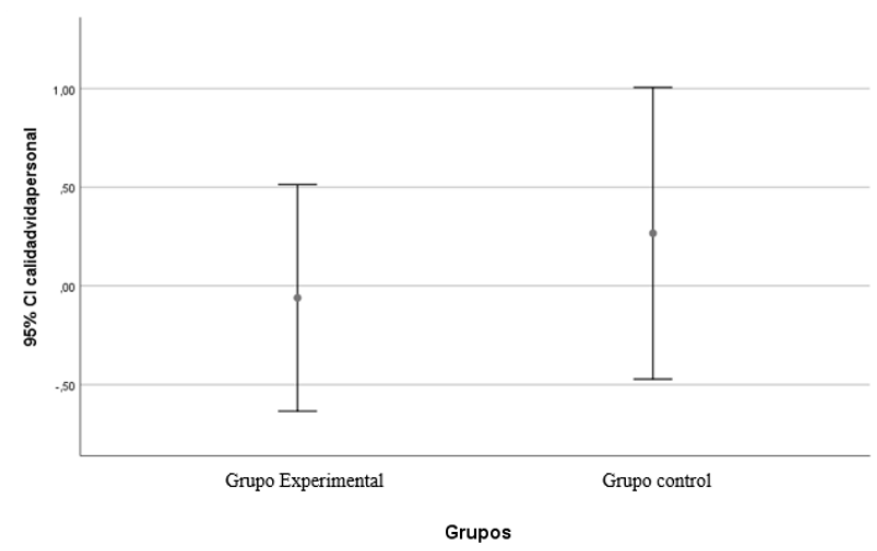

Gráfico 21: Intervalos de confianza en Calidad de Vida Personal

Los análisis descriptivos en ambos tiempos en los diferentes dominios se reflejan en la tabla 16. 
No se ha detectado diferencias estadísticamente significativas en la triple interacción (pvalor=0,966). Sólo se ha detectado diferencias en la interacción doble entre el tiempo 1 y 2 y las dimensiones de calidad ( $p$-valor=0,035), es decir, los cambios que se producen entre el tiempo 1 y 2 son diferentes en los dominios del Test. Sin embargo, la interacción que nos interesa entre el tiempo y en el GE no es significativo (pvalor=0,09). Si analizamos el gráfico de interacción de las diferentes dimensiones se observa cómo tanto en el tiempo 1 como en el 2, el GE presenta mayores puntuaciones en las cuatro escalas con la mayor diferencia en las relaciones interpersonales. Las diferencias se aminoran en el tiempo 2 en todas las escalas excepto en relaciones interpersonales que aumenta.

Si se analizan los intervalos de confianza del cambio entre los tiempos 1 y 2(gráfico 22), se observa como todos los valores medios están cercanos al cero que indica que no se ha producido cambio entre los tiempos.

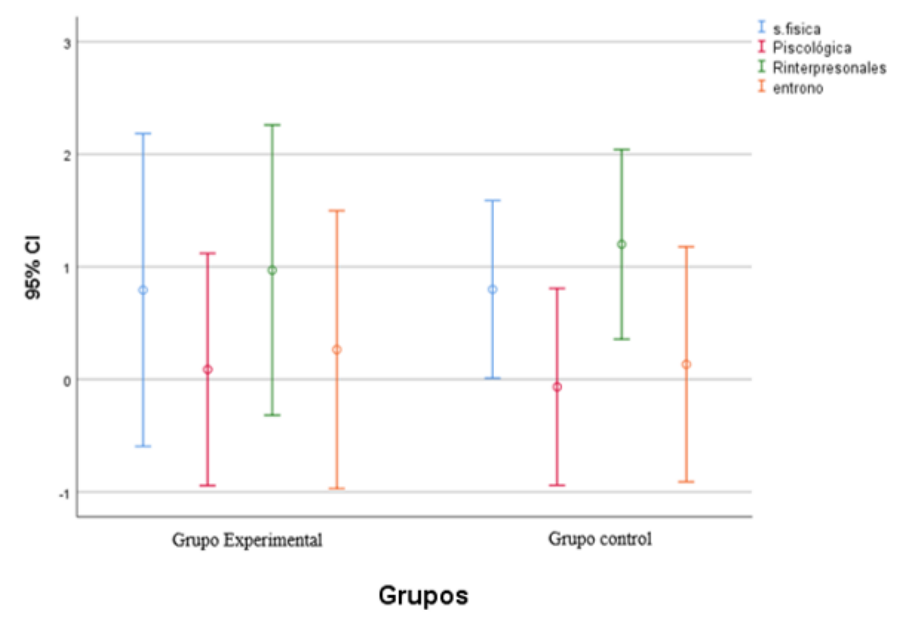

Gráfico 22: Intervalos de confianza entre los tiempos y las dimensiones

Por último, si se realizan los contrastes y como se puede observar en la tabla 17, en ninguna de las dimensiones existe un cambio significativo.

\subsection{Influencia de la intervención en la actividad de la telomerasa.}

En este apartado presentamos los resultados en relación a la posible influencia del Programa de Revitalización sobre la actividad de la telomerasa. 
En relación a la longitud telomérica, en la tabla 18 se reflejan los valores descriptivos de ambos grupos de sujetos.

Se ha detectado una diferencia estadísticamente significativa en la interacción entre ambos grupos y los tiempos 1 y 2. Es decir, que el cambio que se produce en los tiempos, es diferente en el GE en relación al GC (p-valor<0,001). Si se analiza el gráfico23, se observa que en el GE hay un aumento de la longitud telomérica en el tiempo 2, tras la intervención, mientras que en el GC se produce un descenso en dicha longitud. Por otra parte, la diferencia entre ambos grupos en el tiempo 1, es más pequeña que en el tiempo 2 , además de invertirse el signo de la diferencia.

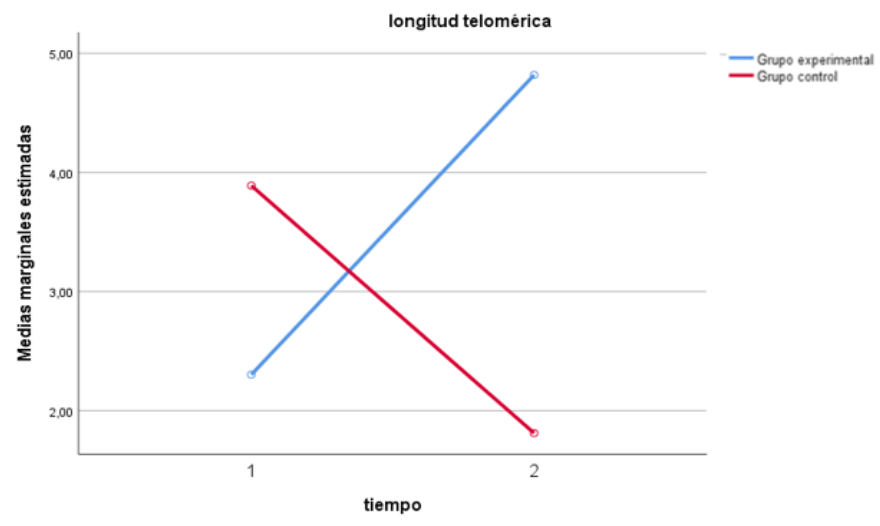

Gráfico 23: Interacción entre ambos grupos en la longitud telomérica

Si se analizan los intervalos de confianza, se puede observar que los cambios son significativos y que el cambio en el GC (un descenso de los valores) no es significativo mientras que en el GE el cambio (un aumento) si es estadísticamente diferente de cero. (Gráfico 24)

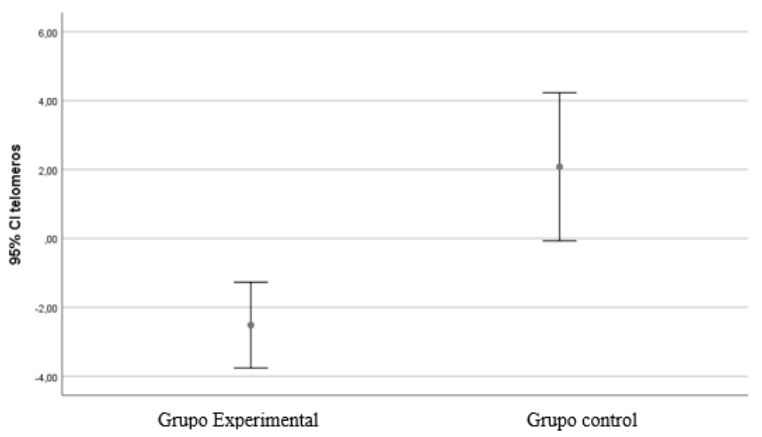

Gráfico 24: Intervalos de confianza de ambos grupos en la longitud telomérica 
Estos resultados presentan la misma tendencia que los datos expuestos anteriormente, donde podemos ratificar que los sujetos del GE, en la segunda valoración presentan una mayor longitud telomérica que los sujetos del GC, y teniendo en cuenta que la variable que diferencia la acción de ambos grupos, consiste en las intervenciones realizadas mediante el Programa de Revitalización, esta variable puede ser la causa directa del aumento de la actividad de la telomerasa.

\subsection{Influencia del crecimiento de la actividad de la telomerasa en el rendimiento de las funciones cognitivas.}

En el siguiente apartado exponemos los resultados en relación al estudio de las asociaciones observacionales entre la longitud telomérica y el rendimiento cognitivo en funciones como, la actividad cognitiva general, la velocidad de procesamiento visoespacial, las habilidades visoconstructivas, la función mnésica y el funcionamiento ejecutivo. Para ello se ha utilizado el coeficiente de correlación de Pearson para medir el grado de relación de dos variables, por una parte, la longitud telomérica de la primera medición y por otra las medidas cognitivas obtenidas en el tiempo 2, tras la finalización del Programa de Revitalización en los sujetos de la muestra.

En la tabla 19 se reflejan los valores de correlación del grupo control y los del grupo experimental, con su p-valores y el tamaño muestral.

Se observan asociaciones positivas para la función cognitiva general, siendo los sujetos del GE con mayor longitud telomérica los que presentan una mejor función cognitiva.

Los resultados nos informan de la presencia de asociación negativa significativa, apoyando la relación entre telómeros más largos y mejor capacidad cognitiva, en el Test de Retención Visual de Benton en el número de aciertos, siendo los sujetos del GC con mayor longitud telomérica los que presentan un peor rendimiento en dicha prueba.

Por el contrario, en el número de errores, observamos una asociación negativa no significativa, en los sujetos del GE con mayor longitud telomérica, que comenten un menor número de errores en dicha prueba.

Esta misma tendencia se constata en el Test del Trazo A y B, donde los sujetos del GE, presentan una asociación negativa no significativa, que nos indica que los sujetos con mayor longitud telomérica, ejecutan las dos modalidades de la prueba en menor tiempo, obteniendo un mejor rendimiento en relación a los sujetos del grupo control. 
En el Stroop, en la dimensión Palabras, los sujetos del GE, presentan una asociación positiva en relación a los sujetos del GC, ya que los sujetos con mayor longitud de los telómeros obtienen un mayor número de palabras.

En la dimensión Stroop Colores, encontramos la misma tendencia en la asociación positiva que muestran los sujetos de GE.

Y por último en la dimensión Stroop Interferencia, los sujetos del GE, presentan una asociación negativa, que nos indica que estos sujetos con mayor longitud telomérica presentan una menor inhibición a la hora de ejecutar la prueba.

En el Test Audio Verbal de Rey, encontramos una asociación negativa no significativa en ambos grupos, donde se observa la no relación entre el crecimiento telomérico y el rendimiento en dicha prueba.

A modo de conclusión, la tendencia de las asociaciones encontradas mediante el coeficiente de correlación de Pearson, avalan la hipótesis planteada, en relación a que los telómeros más largos están asociados con un mejor rendimiento cognitivo en las habilidades de rastreo visual y exploración visoconceptual y visomotora, en los sujetos incluidos en el Programa de Revitalización. 


\section{DISCUSIÓN}




\section{Discusión}

En este momento, el envejecimiento de la población mundial tiene importantes implicaciones sociales y económicas. Hoy más que nunca, es necesario destacar las estrategias para aminorar las manifestaciones clínicas de las enfermedades relacionadas con la edad. Desde esta investigación se pretendía observar que influencia puede tener el Programa de Revitalización Geriátrica en el envejecimiento, concretamente en las funciones cognitivas y en la longitud telomérica. En base a ello, en este trabajo se han obtenido varios hallazgos principales. En primer lugar, hemos encontrado una mejoría en las funciones cognitivas, en segundo lugar, hemos observado cambios significativos en la actividad de la telomerasa, que se traduce en un aumento de la longitud de los mismos y, en tercer lugar, una asociación entre la longitud telomérica y la cognición.

En relación con el primer hallazgo, uno de los objetivos se centraba en comprobar la influencia positiva de la práctica de ejercicio físico de manera regular a través del Programa de Revitalización Geriátrica en funciones cognitivas como procesamiento visoespacial, memoria visual, habilidades visoconstructivas, memoria inmediata, fluidez verbal, eficacia cognitiva y rapidez perceptivo-motora, con respecto a otro grupo de sujetos que no realizan ejercicio físico de manera regular. Los resultados obtenidos nos indican que el ejercicio físico a través del Programa de Revitalización Geriátrica es capaz de producir un mejor rendimiento en las funciones cognitivas anteriormente citadas.

En el apartado de resultados mostramos que las puntuaciones obtenidas por parte de los sujetos (en ambos grupos) en el Examen Cognoscitivo Mini-Mental en la primera medición nos informan de la no existencia de deterioro cognitivo. El hecho de que nuestros sujetos no presenten deterioro cognitivo, es decir, las puntuaciones obtenidas en el MMSE se sitúan en el rango de normalidad (Lobo, Ezquerra \& Bugarda, 1979), lo que nos imdica que los resultados obtenidos, presentan una alta consistencia y fiabilidad.

En relación con el Examen Cognoscitivo Mini-Mental, los resultados muestran una interacción positiva en las puntuaciones obtenidas por ambos grupos en las dos mediciones, es decir, los sujetos del grupo experimental obtuvieron una mejoría significativa en las puntuaciones de dicho test tras el PREGE. Autores como John y colaboradores (2015) obtienen resultados idénticos a los nuestros en una muestra de 199 sujetos tras 12 meses de intervención. Cabe resaltar que nosotros únicamente hemos 
necesitado 6 meses para obtener una mejoría en nuestros sujetos. Lin y colaboradores (2019) con una muestra de 2.074 sujetos divididos en un grupo intervención (1.372) que realizaba ejercicio físico y un grupo control (702) que no realizaban ejercicio, obtuvieron resultados similares a los nuestros, los sujetos del grupo intervención obtuvieron mejor rendimiento cognitivo en el MMSE con respecto a los sujetos del grupo control. Además, los sujetos del grupo experimental mostraron una mejoría en las puntuaciones obtenidas en el test tras la intervención, tal y como ocurre con los sujetos de nuestro estudio.

Por otro lado, el efecto del PREGE sobre el procesamiento visoespacial, memoria visual y habilidades visocontructivas produce una mejoría en dichas variables. Los sujetos del grupo experimental al inicio del programa mostraban un mayor número de fallos y un menor número de aciertos con respecto al grupo control, sin embargo, tras la intervención la tendencia de esas puntuaciones se invierte, es decir, dichos sujetos obtuvieron un mayor número de aciertos y un menor número de fallos. Nuestros resultados están en consonancia a los obtenidos en un reciente metaanálisis de Northey y colaboradores (2017) en el que incluyen 36 ensayos clínicos aleatorizados concluyendo, que el ejercicio físico puede jugar un papel esencial en la cognición, concretamente en las variables estudiadas a través del Test de Retención Visual de Benton (TRVB). Asimismo, en un artículo reciente, Freudenberger y colaboradores (2016) informaron que aquellos adultos mayores que mostraban un mayor nivel de condición física de un total de 877 sujetos, mostraban mejores puntuaciones en memoria visual y en habilidades visoconstructivas. Vidoni y colaboradores (2015) estudiaron la posible relación entre la cantidad de ejercicio aeróbico yel rendimiento cognitivo, concretamente con las funciones visoespaciales, dividiendo la muestra en 4 grupos: grupo control, grupos de 75 minutos de ejercicio físico / semana, 150 minutos / semana y 225 min / semana durante 26 semanas. Concluyeron que el procesamiento visoespacial mejoró en esos 6 meses de intervención en todos los grupos de ejercicio, sin embargo, en los sujetos del grupo control no se observó mejoría, siendo resultados similares a los obtenidos en nuestro estudio.

En cuanto a la memoria inmediata, nuevamente observamos una interacción significativa entre las puntuaciones obtenidas por ambos grupos. Por lo tanto, la práctica de ejercicio físico de manera regular influye positivamente en la memoria inmediata tras la intervención, proporcionando una curva de aprendizaje en la que observamos su 
evolución parabólica, lo que refleja una significativa retención incluso, después de una actividad mediadora. Dichos resultados están en concordancia con las conclusiones emitidas por los autores del anterior metaanálisis citado (Northey, Cherbuin, Pumpa, Smee y Rattray, 2018) que indican que la práctica de ejercicio físico de manera regular mejora significativamente la memoria a corto plazo de los adultos mayores sanos. Autores como Kramer y colaboradores (2001) obtuvieron resultados similares en la mejoría de la memoria inmediata en un grupo de sujetos entrenados aeróbicamente durante 6 meses. Asimismo, Williamson (2009) y van Uffelen (2008) en sus estudios, se sitúan en la línea de los nuestros, afirmando que el ejercicio físico produce una mejoría en la memoria inmediata. Antunes y colaboradores (2015) utilizando un programa de ejercicio físico aeróbico de 6 meses en un grupo de 51 mujeres, entre los 60 y 70 años,obtenían mejorías significativas en la memoria inmediata.

En relación con las funciones ejecutivas, concretamente en los procesos atencionales y velocidad de procesamiento, los resultados siguen la misma tendencia que hemos expuesto hasta ahora, los sujetos del grupo experimental muestran una mejoría en dichas variables tras la práctica de ejercicio físico. En el metaanálsis publicado por (Smith, Blumenthal, Hoffman, Cooper, Strauman, et al. 2010) en el que se incluyen 29 ensayos clínicos aleatorizados, se concluye que el ejercicio físico produce una mejoría en las funciones ejecutivas, como la velocidad de procesamiento y la atención, estando en consonancia con nuestros resultados. En estudios transversales también se demuestra el impacto positivo del ejercicio físico en las funciones ejecutivas, Bixby y colaboradores (2007) concluyeron que el ejercicio físico se asocia con un mejor rendimiento de las funciones ejecutivas en una muestra de 122 sujetos entre los 68 y 92 años. Como hemos comentado anteriormente, el GE de nuestro estudio obtuvo mejor puntuación en la velocidad de procesamiento, observándose una mejoría significativa tras la intervención, dichos resultados están en consonancia con autores como, Marmeleria y colaboradores (2012) que concluyeron que las personas entre los 61 y 81 años físicamente activas mostraban una mayor velocidad de procesamiento y un mejor desempeño en la realización de doble tarea con respecto a otro grupo de personas de su misma edad pero que no realizaban ejercicio físico. Spartano y colaboradores (2019), utilizando una cohorte de 909 adultos mayores, concluyeron, que los sujetos con mayor nivel de actividad física presentaban un mejor rendimiento en las funciones ejecutivas. Baker y colaboradores (2010) demostraron que en 6 meses de ejercicio físico en una 
muestra únicamente formada por mujeres (similar a la utilizada en nuestro estudio) obtuvieron una mejoría significativa en las puntuaciones de las funciones ejecutivas evaluadas. Albinet y colaboradores (2016) observaron en un programa de ejercicio físico de 5 meses de duración una mejoría de las funciones ejecutivas en las mujeres del grupo intervención con respecto a los controles.

Otros autores como Antunes (2015), Ferreira (2015), Maillot (2012) encontraron idénticos resultados a los expuestos anteriormente. En relación con la flexibilidad cognitiva, Goncalves y colaboradores (2019) a través de un programa de ejercicio físico moderado de 26 semanas ( 2 sesiones/semana) en una muestra de 436 adultos mayores (89\% mujeres) obtuvieron resultados similares a los nuestros, concluyendo que el programa de ejercicio físico moderado producía mejoras en la flexibilidad cognitiva de los adultos mayores.

Para finalizar la discusión sobre las variables cognitivas, los sujetos del GE realizan la tarea del Test del Trazo, en menor tiempotras la intervención, que los sujetos del GC. Esto nos indica una mejoría significativa en la variable de rapidez perceptivo-motora. Dichos resultados son similares a los obtenidos por Langlois y colaboradores (2012) que aplicaron un programa de ejercicio físico a 83 sujetos entre los 61 y 89 años durante 3 meses y observaron una mejoría en la rapidez perceptivo-motora de dichos sujetos y además puntuaciones más altas con respecto a un grupo control. Mekari y colaboradores (2019) observaron que existía una asociación entre el nivel de aptitud cardiorrespiratoria y el rendimiento cognitivo, concretamente en la tarea B del Test del Trazo (rapidez perceptivo-motora), es decir de los 66 sujetos del estudio, de los cuales 44 eran mujeres, aquellos que mostraban una mayor aptitud cardiorrespiratoria, mostraban a su vez mejor desempeño en la evaluación de la tarea. La explicación que dieron a estos resultados radicaba en que la relación positiva entre la aptitud cardiorrespiratoria y la rapidez perceptivo-motora, estaba mediada por una mejor oxigenación cerebral, es decir, los adultos mayores con mayor disponibilidad de oxigenación cerebral pueden responder a un aumento en la demanda de tareas. Estudios transversales se sitúan en consonancia con nuestros resultados. Bouchard y colaboradores (2012), Dupuy y colaboradores (2013) han demostrado que los adultos mayores con un aumento en su aptitud cardiorrespiratoria muestran beneficios en la tarea de rapidez perceptivo-motora.

Otro de los objetivos planteados en este trabajo, consistía en determinar si los sujetos del PREGE percibían una mejora en su calidad de vida. No hemos detectado interacción 
estadísticamente significativa en esta variable. Sin embargo, en la literatura actual está evidenciado que la práctica de ejercicio físico de manera regular produce mejorías en el estado de salud general, disminuyendo el riesgo de enfermedades crónicas, (Warburton, Nicol \&Bredin; 2006) y produciendo a su vez una mejora en la calidad de vida (Arslan, Alemdaroglu, Karamduma \&Yilmaz; 2019). Una posible explicación a nuestros resultados, puede deberse a que la escala utilizada para la evaluación de la calidad de vida de nuestros sujetos es una escala autoaplicada y por ello puede presentar cierto sesgo en las respuestas.

En relación a la influencia del ejercicio físico en la actividad de la enzima telomerasa, nuestros resultados indican que la longitud telomérica aumenta en aquellos sujetos que han participado en el Programa de Revitalización Geriátrica a los seis meses de haberlo finalizado. Podemos observar una interacción entre ambos grupos, en relación a los tiempos transcurridos, el grupo experimental presenta un aumento de la longitud telomérica, incluso obteniendo valores superiores a los del grupo control en la primera medición tras la intervención, mientras que en el grupo control se produce un descenso en dicha longitud.

En un estudio realizado por Werner y colaboradores (2019) se observó que únicamente el entrenamiento a intervalos producía un aumento en la actividad de la telomerasa tras seis meses de dicha actividad, en relación con un grupo de entrenamiento con ejercicio físico de resistencia, otros autores concluyen, que el entrenamiento excesivo podría ser perjudicial para la actividad de la telomerasa, disminuyendo así la longitud telomérica y obteniéndose valores similares a los que presentan las personas con vida sedentaria. (Mathur, Ardestani, Parker, Cappizzi, Polk\& et al, 2013; Denham, Nelson, O’Brien, Nankervis, Dennif\& et al; 2016).

En la actualidad, se observa cierta controversia en cuanto al papel del ejercicio físico en la actividad de la enzima telomerasa. Existen numerosos tipos específicos de ejercicio físico: ejercicio aeróbico, ejercicio de resistencia, ejercicio a intervalos, ejercicio multicompetente (aeróbico+resistencia), no estando muy bien definido el papel de cada uno de ellos en la actividad de la enzima, siendo el ejercicio aeróbico el que más se asocia positivamente con la longitud de los telómeros (Denham\& et al; 2013; Osthus, Sgura, Berardinelli, Alsnes\& et al, 2012; LaRocca, Seal s\& Pierce, 2012) debido a que aumenta la captación de oxígeno (Sfeir\& de Lange, 2012) 
Es importante destacar que el ejercicio físico de manera regular reduce los niveles de ROS y, por ende, influye positivamente en la actividad de la telomerasa ( $\mathrm{He}, \mathrm{Li}, \mathrm{Liu}$, Chuang, Yang \& et al, 2016), razón suficiente que justificaría que nuestros sujetos mostraran una mayor longitud telomérica a los seis meses de haber finalizado el PREGE. Shadyab y colaboradores (2017) observaron en una muestra de 1.481 mujeres de edad avanzada, que aquellas que practicaban ejercicio físico moderado presentaban una longitud telomérica mayor, siendo resultados idénticos a los obtenidos en este trabajo.

Numerosos estudios concluyen que únicamente el ejercicio físico a intensidad moderada es capaz de provocar cambios en la longitud telomérica, mientras que el ejercicio físico a intensidades leves no es capaz de provocar cambios en la longitud (Savela, Saijonmaa, Strandberg, Koistinen, Stransberg\& et al 2013; Ludlow\& Roth, 2011).

En esta línea de resultados, autores como Rae y colaboradores (2010), midieron la longitud de los telómeros en el músculo esquelético de 18 corredores de resistencia de mediana edad vs 19 sujetos sedentarios, no encontrando diferencias entre los grupos, no obstante, la longitud de los telómeros en el músculo de los atletas de resistencia, estaba inversamente relacionada con el número de años practicando esta modalidad de deporte y las horas de entrenamiento, lo que podría indicar que un alto nivel de resistencia podría acelerar el desgaste de los telómeros, y por tanto, potenciar el envejecimiento biológico

Los resultados sugieren que altas cantidades de ejercicio podrían no ser beneficiosas para la actividad de la enzima telomerasa, sin embargo, se necesitan mayor número de ensayos clínicos aleatorizados para poder llegar a una conclusión clara. Es por ello por lo que quizás nuestros sujetos del Programa de Revitalización Geriátrica muestren una menor actividad de la telomerasa justo en el momento de finalizar el programa con respecto al grupo control.

Autores como Woo y colaboradores (2008) no observaron correlación entre los diferentes niveles de ejercicio físico y la longitud telomérica en una muestra de casi 4000 sujetos mayores de 65 años, determinando según estos resultados, que no existe una correlación positiva entre la práctica de ejercicio físico y la longitud telomérica 
En un reciente metaanálisis realizado por Lin y colaboradores (2019), se concluye que los individuos físicamente activos, en comparación con los inactivos muestran una mayor longitud de sus telómeros independientemente de la intensidad del ejercicio.

Por el contrario, el metaanálisis de Mundstock y colaboradores (2015) concluye que no hay suficiente evidencia para establecer que existe una asociación positiva entre la práctica de ejercicio físico y la longitud telomérica.

Otro de los aspectos importantes encontrados en nuestro estudio ha consistido en observar la fluctuación que existe en la longitud telomérica en los adultos mayores con o sin intervención durante un periodo de tiempo relativamente corto. Hemos determinado que la fluctuación telomérica no sigue un proceso lineal, sino que se trata de un proceso dinámico. Svenson y colaboradores (2011) con una muestra de 50 sujetos, durante seis meses de seguimiento, siendo la mayoría mujeres, mostraron que el tamaño telomérico podría experimentar un acortamiento y alargamiento durante ese periodo, por lo tanto, se podría considerar que la longitud telomérica es una característica dinámica influenciada por el ejercicio físico. Itzkovitz y colaboradores (2008), concluyen que las fluctuaciones de la longitud, siguen una dinámica no lineal.

Como se ha demostrado en la literatura científica, las especies reactivas de oxígeno (ROS) contribuyen a aumentar el daño del DNA, la apoptosis y la senescencia celular (Kawanishi \& Oikawa, 2004), concretamente, en el segmento central de guanina 5'GGG-3', siendo éste un segmento muy abundante en el DNA telomérico (Arsenis, You, Ogawa, Tinsley \& Zuo, 2017).

De la bibliografía consultada en la literatura científica, que evalúan el impacto del ejercicio físico en todas sus modalidades e intensidades, ninguno de ellos estudia qué ocurre una vez que han finalizado los programas de intervención, es por lo cual, que en este trabajo de investigación, nos planteamos estudiar la influencia que podría tener el PREGE en el tamaño telomérico de nuestros sujetos a los 6 meses de haber finalizado la intervención. Con nuestros resultados podemos concluir que el efecto del PREGE en el proceso de envejecimiento medido a través de la longitud telomérica, es un impacto a largo plazo. Las distintas metodologías empleadas en distintos trabajos, las diferentes modalidades de ejercicio físico utilizadas en los numerosos estudios consultados, podrían ser las principales causas por las cuales existe tanta controversia entre el impacto del ejercicio físico y la longitud telomérica. 
Por último, otro de los objetivos establecidos en este trabajo de investigación, consistía en determinar si existía algún tipo de asociación causal entre la longitud telomérica y el rendimiento cognitivo. Nuestros resultados no han demostrado una relación estadísticamente significativa, sin embargo, sí observamos cierta tendencia positiva en la asociación entre la longitud telomérica,y las variables cognitivas, es decir, aquellos sujetos con mayor longitud telomérica, han obtenido un mayor rendimiento cognitivo.

Nuestros resultadosse sitúan en la línea de los publicados por autores como Kaja y colaboradores (2019) donde examinaron la relación de la LT y el rendimiento cognitivo, en una muestra de más de 2000 sujetos. La capacidad cognitiva fue evaluada a través del MoCA Test, concluyeron que no existía una relación estadísticamente significativa entre la longitud telomérica y las puntuaciones obtenidas en el Test.

Autores como Hagg y colaboradores (2017) obtuvieron resultados similares, analizando las asociaciones observacionales y causales entre longitud telomérica y cinco variables cognitivas: función cognitiva general, velocidad de procesamiento, funcionamiento visoespacial, memoria y funcionamiento ejecutivo, en 12 cohortes poblacionales, observando asociación entre la LT y las puntuaciones obtenidas en rendimiento cognitivo, aunque no alcanzaron niveles de significación estadística.

En el estudio de Brown y colaboradores (2018) tampoco se encuentra asociación estadísticamente significativa en una muestra de 4.074 sujetos, entre la LT y la capacidad cognitiva medida a través de una prueba de memoria inmediata.

En la revisión realizada, únicamente se ha encontrado un trabajoque ha estudiado la posible asociación causal, entre la longitud telomérica y el funcionamiento ejecutivo, valorado mediante el test de Stroop los autores tampoco encuentran niveles de significación estadística (Cohen, Doniger, Sinreich, Simon \& et al; 2016). Por el contrario, otros estudios sí han encontrado asociación estadísticamente significativa entre LT y rendimiento cognitivo.

Yaffe y colaboradores (2011) con una muestra de 2,734 adultos sanos con una edad media de 74 años, mostraron que los sujetos con una mayor LTal inicio del estudio, obtuvieron una menor disminución de la puntuación del MMSE con el paso de los años, concluyendo que la longitud de los telómeros, podría servir como un biomarcador/testigo, para el envejecimiento cognitivo. 
Queda de manifiesto, que existe demasiada incertidumbre entre la asociación de la longitud telomérica y el rendimiento cognitivo. Dicha incertidumbre puede deberse a varias variables, como al tamaño de la muestra de los diferentes estudios, a la heterogeneidad de las muestras utilizadas, al método de cuantificación de la enzima telomerasa y a los instrumentos neuropsicológicos empleados por los autores para la evaluación de las funciones cognitivas. Por lo tanto, para llegar a resultados más consistentes, se necesita un mejor control y homogeneidad, de las variables expuestas anteriormente. 


\section{CONCLUSIONES}




\section{Conclusiones}

Se pueden extraer diversas conclusiones del presente estudio, tomando como referencia las hipótesis planteadas al inicio de la investigación.

En referencia a la primera hipótesis:

1. Los sujetos participantes del Programa de Revitalización Geriátrica obtuvieron una mejoría tras la intervención en la función cognitiva, con respecto al grupo control

2. Los sujetos participantes del Programa de Revitalización Geriátrica obtuvieron una mejoría tras la intervención en las variables de procesamiento visoespacial, memoria visual y habilidades visoconstructivas.

3. Los sujetos participantes del Programa de Revitalización Geriátrica obtuvieron una mejoría tras la intervención en la variable de memoria inmediata con respecto al grupo control, obteniendo una ganancia significativa en su capacidad de retención.

4. Los sujetos participantes del Programa de Revitalización Geriátrica obtuvieron una mejoría tras la intervención en las variables de fluidez verbal y sobre todo eficacia cognitiva aumentando su flexibilidad cognitiva con respecto al grupo control

5. Los sujetos participantes del Programa de Revitalización Geriátrica obtuvieron una mejoría tras la intervención en las variables derastreo visual, exploración visoconceptual, atención y rapidez perceptivo-motoracon respecto al grupo control.

En referencia a la segunda hipótesis:

6. A los seis meses de haber finalizado el programa de Revitalización Geriátrica, aquellos sujetos participantes en dicho programa, presentaron una longitud telomérica mayor con respecto a la puntuación obtenida nada más finalizarel mismo.

Esta conclusión nos informa que el efecto del PREGE sobre la longitud telomérica, y, por ende, sobre el envejecimiento, no es un efecto inmediato, sino que se trata de un efecto a largo plazo. 
En referencia a la tercera hipótesis:

7. Aunque no hayamos encontrado diferencias estadísticamente significativas en las asociaciones entre la longitud telomérica y la cognición, sí hemos observado tendencias entre ambas variables, a telómeros más largos mejor rendimiento cognitivo, especialmente en rastreo visual, exploración visoconceptual, atención y rapidez perceptivo-motora.

A modo de conclusión general cabe destacar que los sujetos del Programa de Revitalización Geriátrica toleraron muy bien el programa de ejercicio físico diseñado por Fisioterapeutas, ya que, la tasa de abandono fue muy baja. Esto podría deberse a que las sesiones de ejercicio físico fueron individualizadas al máximo posible y supervisadas por Fisioterapeutas cualificados.

Todas estas conclusiones nos indican que el Programa de Revitalización Geriátrica (PREGE) puede ser una herramienta útil en aminorar la pérdida de aquellas funciones cognitivas relacionadas con la edad y, por lo tanto, podría tratarse de una buena herramienta para retrasar el envejecimiento en general. 


\section{LIMITACIONES}




\section{Limitaciones.}

Una de las principales limitaciones es la muestra utilizada ya que el número de participantes en el estudio es bajo con respecto a estudios similares encontrados en la literatura científica. Es probable que replicando este estudio con un mayor número de sujetos y estratificándolos en subgrupos de ejercicio físico (resistencia, aeróbico, mixto) podríamos obtener nuevos resultados que nos aporten más información a la obtenida en este estudio.

Con respecto a la última hipótesis de nuestro trabajo, una de las mayores limitaciones que hemos encontrado, ha sido la falta de resultados concluyentes en los estudios de otros autores. Esto podría deberse a la falta de homogeneidad de las muestras y las diferentes metodologías empleadas, por lo tanto, se necesitan un mayor número de estudios longitudinales, con muestras más homogéneas y con metodologías similares, para obtener resultados más consistentes que nos permitan afirmar que existe una asociación entre la longitud telomérica y la cognición. 
APÉNDICE: TABLAS 


\section{Apéndice: Tablas de Resultados}

Tabla 2: Estadísticos descriptivos para la edad y años de escolaridad

\begin{tabular}{|c|c|c|c|c|c|}
\hline & & Media & Mediana & Desviación T. & Rango intercuartil \\
\hline \multirow[t]{2}{*}{ Edad } & GE & 72,70 & 73,00 & 4,127 & 6 \\
\hline & GC & 71,21 & 70,00 & 4,321 & 7 \\
\hline \multirow[t]{2}{*}{ Años de escolarización } & GE & 8,18 & 9,00 & 1,551 & 2 \\
\hline & GC & 8,42 & 7,00 & 2,562 & 4 \\
\hline
\end{tabular}

Tabla 3: Estadísticos descriptivos para el Estado Civil

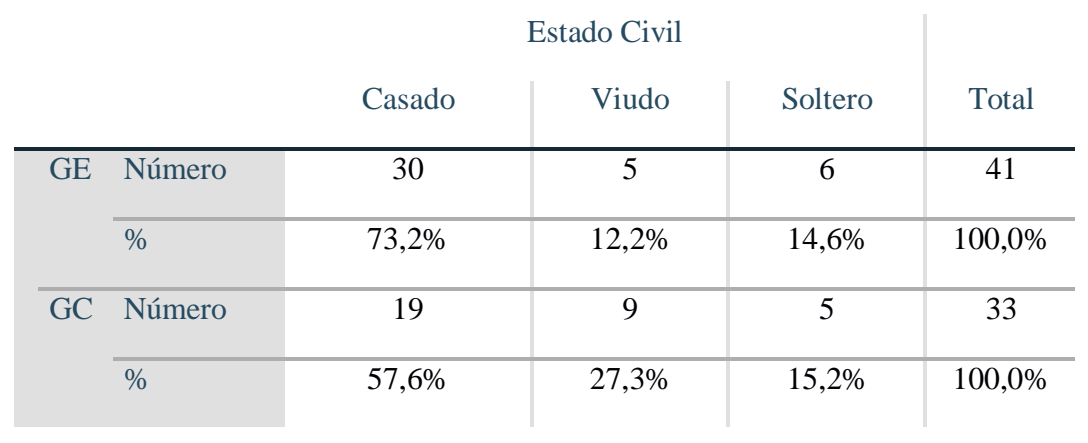

Tabla 4: Estadísticos descriptivos para el Nivel de Estudios

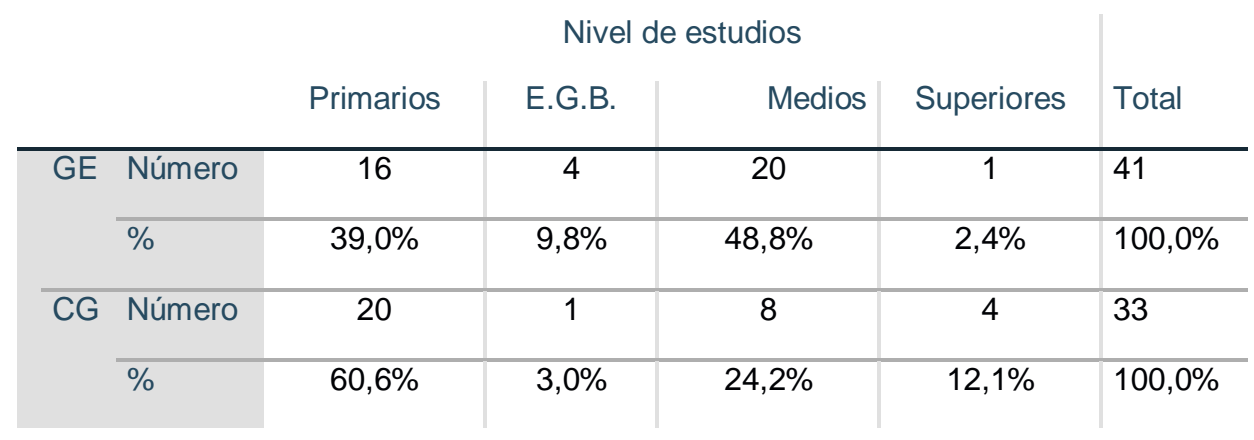


Tabla 5: Estadísticos descriptivos para el Peso, Talla. Peso Grasa y \% de Grasa

\begin{tabular}{|c|c|c|c|c|c|}
\hline & Grupos & Media & Mediana & Desviación T, & Rango intercuartil \\
\hline \multirow[t]{2}{*}{ PesoTiempo 1} & GE & 64,9805 & 64,6000 & 8,41401 & 9,85 \\
\hline & GC & 62,7273 & 61,9000 & 8,48923 & 13,00 \\
\hline \multirow[t]{2}{*}{ Peso Tiempo 2} & GE & 64,7049 & 64,0000 & 8,84799 & 13,45 \\
\hline & GC & 63,1273 & 62,0000 & 8,40247 & 12,75 \\
\hline \multirow[t]{2}{*}{ Talla Tiempo 1} & GE & 153,2707 & 152,0000 & 5,26395 & 7,10 \\
\hline & GC & 158,1606 & 158,0000 & 5,74581 & 9,25 \\
\hline \multirow[t]{2}{*}{ Peso graso Tiempo 1} & GE & 28,3000 & 28,4000 & 4,81902 & 6,10 \\
\hline & GC & 25,6545 & 26,3000 & 5,76975 & 6,90 \\
\hline \multirow[t]{2}{*}{ Peso graso Tiempo 2} & GE & 28,8610 & 29,1000 & 5,51892 & 7,80 \\
\hline & GC & 25,8212 & 25,9000 & 5,80333 & 6,25 \\
\hline \multirow[t]{2}{*}{$\%$ grasa Tiempo 1} & GE & 43,0756 & 43,8000 & 3,59568 & 4,65 \\
\hline & GC & 38,7333 & 40,0000 & 5,52193 & 6,70 \\
\hline \multirow[t]{2}{*}{$\%$ grasaTiempo 2} & GE & 42,8122 & 44,0000 & 4,93311 & 4,00 \\
\hline & GC & 39,3727 & 41,0000 & 5,44984 & 6,65 \\
\hline
\end{tabular}

Tabla 6: Estadísticos descriptivos en el MEC

\begin{tabular}{ccc|c|c}
\multicolumn{1}{c}{} & \multicolumn{2}{c}{ Grupos } & Media & \multicolumn{2}{c}{ Desviación T } & N \\
MEC 1 & GE & 27,67 & 1,716 & 40 \\
\cline { 2 - 5 } & GC & 28,64 & 1,496 & 33 \\
\cline { 2 - 5 } & Total & 28,11 & 1,680 & 73 \\
\hline MEC 2 & GE & 28,40 & 1,499 & 40 \\
\cline { 2 - 5 } & CG & 27,64 & 1,747 & 33 \\
\hline & Total & 28,05 & 1,649 & 73 \\
\hline
\end{tabular}


Tabla 7: Estadísticos descriptivos de audio-verbal de Rey

\begin{tabular}{|c|c|c|c|c|c|}
\hline & & Grupo & Media & Desviación $\mathrm{T}$. & N \\
\hline \multirow{18}{*}{ TIEMPO 1} & Audio verbal de Rey 1 & GE & 4,90 & 1,594 & 41 \\
\hline & & GC & 4,58 & 1,696 & 33 \\
\hline & & Total & 4,76 & 1,637 & 74 \\
\hline & Audio verbal de Rey 2 & GE & 6,46 & 1,598 & 41 \\
\hline & & GC & 7,39 & 1,657 & 33 \\
\hline & & Total & 6,88 & 1,679 & 74 \\
\hline & Audio verbal de Rey 3. & GE & 8,00 & 2,168 & 41 \\
\hline & & GC & 9,15 & 1,922 & 33 \\
\hline & & Total & 8,51 & 2,128 & 74 \\
\hline & Audio verbal de Rey 4 & GE & 8,71 & 1,940 & 41 \\
\hline & & GC & 10,15 & 1,955 & 33 \\
\hline & & Total & 9,35 & 2,064 & 74 \\
\hline & Audio verbal de Rey 5 & GE & 9,12 & 2,216 & 41 \\
\hline & & GC & 10,45 & 1,787 & 33 \\
\hline & & Total & 9,72 & 2,130 & 74 \\
\hline & Audio verbal de Rey 6 & GE & 7,27 & 2,530 & 41 \\
\hline & & GC & 8,39 & 2,358 & 33 \\
\hline & & Total & 7,77 & 2,502 & 74 \\
\hline \multirow{12}{*}{ TIEMPO 2} & Audio verbal de Rey 1 & GE & 5,80 & 1,600 & 41 \\
\hline & & GC & 5,03 & 2,023 & 33 \\
\hline & & Total & 5,46 & 1,830 & 74 \\
\hline & Audio verbal de Rey 2 & GE & 8,12 & 1,792 & 41 \\
\hline & & GC & 6,91 & 2,376 & 33 \\
\hline & & Total & 7,58 & 2,145 & 74 \\
\hline & Audio verbal de Rey 3 & GE & 9,20 & 2,015 & 41 \\
\hline & & GC & 8,88 & 1,949 & 33 \\
\hline & & Total & 9,05 & 1,979 & 74 \\
\hline & Audio verbal de Rey 4 & GE & 9,93 & 1,942 & 41 \\
\hline & & GC & 9,36 & 1,817 & 33 \\
\hline & & Total & 9,68 & 1,895 & 74 \\
\hline
\end{tabular}




\begin{tabular}{lll|c|c|c}
\hline Audio verbal de Rey 5 & GE & 10,41 & 1,936 & 41 \\
\cline { 2 - 5 } & GC & 10,00 & 1,969 & 33 \\
\cline { 2 - 5 } & Total & 10,23 & 1,948 & 74 \\
\hline Audio verbal de Rey6 & GE & 8,63 & 2,782 & 41 \\
\cline { 2 - 5 } & GC & 7,91 & 2,156 & 33 \\
\hline & Total & 8,31 & 2,532 & 74 \\
\hline
\end{tabular}

Tabla 8: Contrastes para los cambios producidos en cada dimensión

\begin{tabular}{lrrrrr} 
& & \multicolumn{5}{c}{$\begin{array}{c}\text { 95\% de intervalo de } \\
\text { confianza de la } \\
\text { diferencia }\end{array}$} \\
& Diferencia de medias & $\begin{array}{c}\text { Diferencia de error } \\
\text { estándar }\end{array}$ & Inferior & Superior & p-valor ${ }^{*}$ \\
Audio1 &,- 44789 &, 44764 & $-1,34025$ &, 44447 & 1 \\
Audio2 & $-2,14339$ &, 44906 & $-3,03856$ & $-1,24821$ & $<0,0001$ \\
Audio3 & $-1,46785$ &, 38879 & $-2,24288$ &,- 69282 &, 002 \\
Audio4 & $-2,00739$ &, 43451 & $-2,87357$ & $-1,14121$ &, 000 \\
Audio5 & $-1,74723$ &, 42579 & $-2,59603$ &,,- 89842 &, 000 \\
Audio6 & $-1,85070$ &, 48975 & $-2,82700$ &,,- 87440 &, 002
\end{tabular}

*corrección de Bonferroni.

Tabla 9: Valores descriptivos para los tiempos 1 y 2.

$\begin{array}{lllrr} & \text { Grupos } & \text { Media } & \text { Desviación T. } & \text { N } \\ \text { Audio verbal de Rey Total } & \text { GE } & 44,39 & 9,757 & 41 \\ \text { Tiempo 1 } & \text { GC } & 50,18 & 9,085 & 33 \\ & \text { Total } & 46,97 & 9,836 & 74 \\ \text { Audio verbal de Rey Total } & \text { GE } & 52,20 & 10,252 & 41 \\ \text { Tiempo 2 } & \text { GC } & 47,76 & 9,038 & 33 \\ & \text { Total } & 50,22 & 9,916 & 74\end{array}$


Tabla 10. Descriptivos para el Test de Retención Visual de Benton

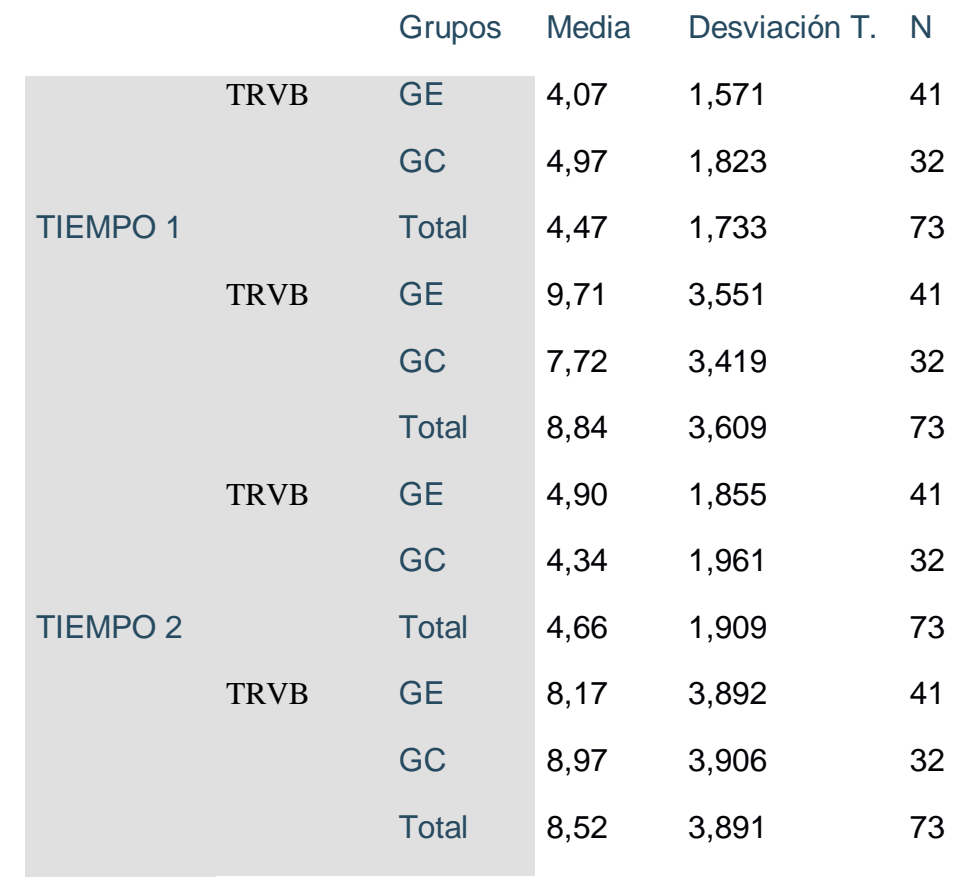

Tabla 11. Contrastes para los cambios producidos en cada dimensión (TRVB)

\begin{tabular}{|c|c|c|c|c|c|}
\hline & \multirow{2}{*}{$\begin{array}{c}\text { Diferencia de } \\
\text { medias }\end{array}$} & \multirow{2}{*}{$\begin{array}{l}\text { Diferencia } \\
\text { de error } \\
\text { estándar }\end{array}$} & \multicolumn{2}{|c|}{$\begin{array}{l}95 \% \text { de intervalo de } \\
\text { confianza de la } \\
\text { diferencia }\end{array}$} & \multirow[b]{2}{*}{ p-valor } \\
\hline & & & Inferior & Superior & \\
\hline TRVB Aciertos & $-1,45427$ & ,40111 & $-2,25406$ &,- 65447 & 0,001 \\
\hline TRVB Errores & 2,78659 & ,71382 & 1,36327 & 4,20990 & $<0,001$ \\
\hline
\end{tabular}

*corrección de Bonferroni. 
Tabla 12. Descriptivos para el Test de Stroop

\begin{tabular}{|c|c|c|c|c|c|}
\hline & & Grupos & Media & Desviación. T & $\mathrm{N}$ \\
\hline \multirow{12}{*}{ TIEMPO 1} & \multirow[t]{3}{*}{ Test de Stroop Palabras } & GE & 45,40 & 10,015 & 40 \\
\hline & & GC & 50,78 & 6,210 & 32 \\
\hline & & Total & 47,79 & 8,898 & 72 \\
\hline & \multirow[t]{3}{*}{ Test de Stroop Colores } & GE & 40,70 & 9,783 & 40 \\
\hline & & $\mathrm{GC}$ & 45,22 & 6,861 & 32 \\
\hline & & Total & 42,71 & 8,845 & 72 \\
\hline & \multirow[t]{3}{*}{ Test de Stroop P/C } & GE & 47,32 & 10,627 & 40 \\
\hline & & $\mathrm{GC}$ & 50,97 & 9,251 & 32 \\
\hline & & Total & 48,94 & 10,136 & 72 \\
\hline & \multirow[t]{3}{*}{ Test de Stroop Inteferencia } & GE & 52,55 & 11,968 & 40 \\
\hline & & GC & 53,31 & 6,606 & 32 \\
\hline & & Total & 52,89 & 9,893 & 72 \\
\hline & \multirow[t]{3}{*}{ Test de Stroop Palabras } & GE & 48,50 & 7,338 & 40 \\
\hline & & GC & 48,16 & 7,717 & 32 \\
\hline & & Total & 48,35 & 7,457 & 72 \\
\hline & \multirow[t]{3}{*}{ Test de Stroop Colores } & GE & 45,20 & 8,007 & 40 \\
\hline & & GC & 44,38 & 7,906 & 32 \\
\hline & & Total & 44,83 & 7,917 & 72 \\
\hline \multirow[t]{6}{*}{ TIEMPO 2} & \multirow[t]{3}{*}{ Test de Stroop P/C } & GE & 51,63 & 8,958 & 40 \\
\hline & & $\mathrm{GC}$ & 50,00 & 11,336 & 32 \\
\hline & & Total & 50,90 & 10,042 & 72 \\
\hline & \multirow[t]{3}{*}{ Test de Stroop Inteferencia } & GE & 54,70 & 8,792 & 40 \\
\hline & & GC & 53,56 & 8,000 & 32 \\
\hline & & Total & 54,19 & 8,410 & 72 \\
\hline
\end{tabular}


Tabla 13. Contrastes para los cambios producidos en cada dimensión (TRVB)

\begin{tabular}{|c|c|c|c|c|c|}
\hline & \multirow{2}{*}{$\begin{array}{l}\text { Diferencia } \\
\text { de medias }\end{array}$} & \multirow{2}{*}{$\begin{array}{l}\text { Diferencia de } \\
\text { error estándar }\end{array}$} & \multicolumn{2}{|c|}{$\begin{array}{c}95 \% \text { de intervalo de } \\
\text { confianza de la } \\
\text { diferencia }\end{array}$} & \multirow[b]{2}{*}{$p$-valor } \\
\hline & & & Inferior & Superior & \\
\hline StroopP & $-6,18598$ & 1,41130 & $-9,00002$ & $-3,37193$ & $<0,0001$ \\
\hline StroopC & $-5,23399$ & 1,74553 & $-8,71448$ & $-1,75351$ & 0,015 \\
\hline StroopP/C & $-5,01753$ & 2,51119 & $-10,02469$ &,- 01037 & 0,200 \\
\hline $\begin{array}{l}\text { StroopPT } \\
\text { Interferencia }\end{array}$ & $-1,90000$ & 2,79233 & $-7,46914$ & 3,66914 & 1 \\
\hline
\end{tabular}

Tabla 14: Estadísticos descriptivos para el Test del Trazo

\begin{tabular}{|c|c|c|c|c|c|}
\hline & & Grupos & Media & Desviación $\mathrm{T}$. & $\mathrm{N}$ \\
\hline & Test del Trazo A & GE & 81,68 & 35,737 & 41 \\
\hline & & $\mathrm{GC}$ & 56,19 & 25,632 & 32 \\
\hline & & Total & 70,51 & 33,980 & 73 \\
\hline \multirow[t]{5}{*}{ TIEMPO 1} & Test del Trazo B & GE & 217,02 & 108,519 & 41 \\
\hline & & $\mathrm{GC}$ & 151,38 & 85,230 & 32 \\
\hline & & Total & 188,25 & 103,662 & 73 \\
\hline & Test del Trazo A & GE & 63,80 & 22,457 & 41 \\
\hline & & $\mathrm{GC}$ & 67,25 & 28,952 & 32 \\
\hline \multirow[t]{4}{*}{ TIEMPO 2} & & Total & 65,32 & 25,378 & 73 \\
\hline & Test del Trazo B & $\mathrm{GE}$ & 171,22 & 79,019 & 41 \\
\hline & & $\mathrm{GC}$ & 178,44 & 106,752 & 32 \\
\hline & & Total & 174,38 & 91,589 & 73 \\
\hline
\end{tabular}


Tabla 15: Análisis descriptivos del global de Calidad de Vida

$\begin{array}{llrrr} & \text { Grupos } & \text { Media } & \text {. Desviación T } & \text { N } \\ \text { Calidad de Vida personal } & \text { GE } & 7,06 & 1,870 & 33 \\ \text { Tiempo 1 } & \text { GC } & 6,53 & 1,506 & 15 \\ & \text { Total } & 6,90 & 1,765 & 48 \\ \text { Calidad de Vida Personal } & \text { GE } & 7,12 & 1,616 & 33 \\ \text { Tiempo 2 } & \text { GC } & 6,27 & 1,668 & 15 \\ & \text { Total } & 6,85 & 1,663 & 48\end{array}$

Tabla 16: Análisis descriptivos de la Escala de Vida WHOQOL-BREF

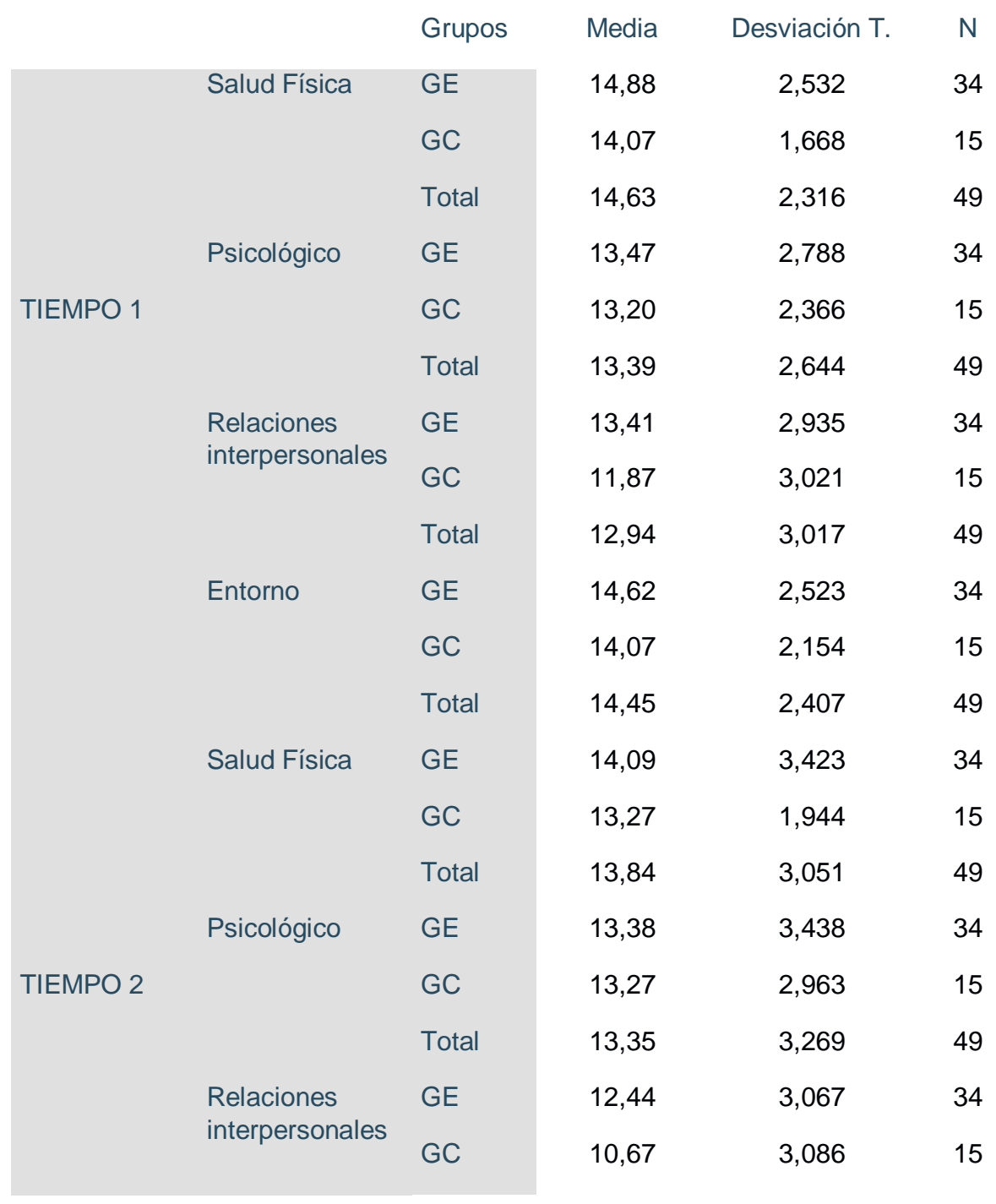




$\begin{array}{lllll} & \text { Total } & 11,90 & 3,151 & 49 \\ \text { Entorno } & \text { GE } & 14,35 & 3,410 & 34 \\ & \text { GC } & 13,93 & 2,086 & 15 \\ & \text { Total } & 14,22 & 3,050 & 49\end{array}$

Tabla 17. Contrastes para los cambios producidos en todos los dominios

\begin{tabular}{lrccrr} 
& & \multicolumn{5}{c}{$\begin{array}{c}\text { 95\% de intervalo de } \\
\text { confianza de la } \\
\text { diferencia }\end{array}$} \\
& $\begin{array}{l}\text { Diferencia } \\
\text { de medias }\end{array}$ & $\begin{array}{l}\text { Diferencia de } \\
\text { error estándar }\end{array}$ & $\begin{array}{c}\text { Inferior } \\
\text { Superior }\end{array}$ & p-valor* \\
Salud Física &,- 00588 & 1,06223 & $-2,14281$ & 2,13104 & 1 \\
Psicológico &, 15490 &, 81342 & $-1,48149$ & 1,79129 & 1 \\
$\begin{array}{l}\text { Relaciones } \\
\text { interpersonales }\end{array}$ &,- 22941 &, 99404 & $-2,22916$ & 1,77034 & 1 \\
Entrono &, 13137 &, 97219 & $-1,82442$ & 2,08716 & 1
\end{tabular}

*corrección de Bonferroni.

Tabla 18: Estadísticos descriptivos de la longitud telomérica

$\begin{array}{llrrr} & \text { Grupos } & \text { Media } & \text { Desviación T. } & \text { N } \\ \text { Longitud telomérica tiempo 1 } & \text { GE } & 2,3022 & 2,41309 & 41 \\ & \text { GC } & 3,8894 & 6,03037 & 33 \\ & \text { Total } & 3,0100 & 4,44552 & 74 \\ \text { Longitud telomerica tiempo 2 } & \text { GE } & 4,8185 & 3,15896 & 41 \\ & \text { GC } & 1,8112 & 2,34162 & 33 \\ & \text { Total } & 3,4774 & 3,18383 & 74 \\ & & & & \end{array}$


Tabla 19: Valores de correlación de Grupo Experimental y Grupo Control

\begin{tabular}{|c|c|c|c|}
\hline \multirow{3}{*}{ MEC } & & Correlación GC & Correlación GE \\
\hline & C. de Pearson & 0,012 & 0,058 \\
\hline & Sig. (bilateral) & 0,946 & ,717 \\
\hline \multirow[t]{2}{*}{ TRVB Aciertos } & C. de Pearson &,$- 371^{*}$ & $-0,006$ \\
\hline & Sig. (bilateral) & 0,040 & 0,973 \\
\hline \multirow[t]{2}{*}{ TRVB Errores } & C. de Pearson & 0,197 & $-0,085$ \\
\hline & Sig. (bilateral) & 0,288 & 0,598 \\
\hline \multirow[t]{2}{*}{ Test de Stroop Palabras } & C. de Pearson & $-0,183$ & 0,117 \\
\hline & Sig. (bilateral) & 0,325 & 0,465 \\
\hline \multirow[t]{2}{*}{ Test de Stroop Colores } & $\mathrm{C}$ de Pearson & 0,023 & 0,168 \\
\hline & Sig. (bilateral) & 0,904 & 0,294 \\
\hline \multirow[t]{2}{*}{ Test de Stroop P/C } & C. de Pearson & $-0,165$ & $-0,008$ \\
\hline & Sig. (bilateral) & 0,375 & 0,961 \\
\hline \multirow[t]{2}{*}{ Test de Stroop Interferencia } & C. de Pearson & 0,016 & $-0,072$ \\
\hline & Sig. (bilateral) & 0,932 & 0,658 \\
\hline \multirow[t]{2}{*}{ Test del Trazo A } & C. de Pearson & 0,005 & $-0,238$ \\
\hline & Sig. (bilateral) & 0,977 & 0,134 \\
\hline \multirow[t]{2}{*}{ Test del Trazo B } & C. de Pearson & 0,160 & $-0,262$ \\
\hline & Sig. (bilateral) & 0,389 & 0,097 \\
\hline \multirow[t]{2}{*}{ Audio Verbal de Rey } & C. de Pearson & $-0,131$ & $-0,047$ \\
\hline & Sig. (bilateral) & 0,475 & 0,769 \\
\hline
\end{tabular}




\section{BIBLIOGRAFIA}




\section{Bibliografía}

Achini, I., Iavarone, A., Senese, V. P., Ruotolo, F., \& Ruggiero, G. (2009). Visuospatial memory in healthy elderly, AD and MCI: a review. Current Aging Science, 2(1), 43-59.

Alberca, R., Lopez-Pousa, S. (2002). Enfermedad de Alzheimer y otras Demencias. $2^{\circ}$ ed. Tomo I. Madrid: Editorial Médica Panamericana: Página 25.

Alberca, R., Lopez-Pousa, S. (2006). Enfermedad de Alzheimer y otras Demencias. $3^{\circ}$ ed. Tomo I. Madrid: Editorial Médica Panamericana.

Albinet, C.T., AbouDest, A., Andre, N., Audiffren, M. (2016). Executive functions improvement following a 5-month aquaerobics program in older adults: role of cardiac vagal control in inhibition performance. Biol. Psychol. 115, 69-77.

American Physical Therapy Association: Guide to Physical Therapist Practice, ed. 2. Phys Ther 81:9-744, 2001.

Anstey, K. J., Dain, S., Andrews, S., \& Drobny, J. (2002). Visual Abilities in Older Adults Explain Age-Differences in Stroop and Fluid Intelligence but Not Face Recognition: Implications for the Vision-Cognition Connection. Aging, Neuropsychology, and Cognition (Neuropsychology, Development and Cognition, 9(4), 253-265.

Antunes, HK., Santos-Galduroz, RF., De Aquino, V., Bueno, O.F., Rzezak, P., de Santana, MG., De Mello, MT. (2015). The influence of physical exercise and leisure activity on neuropsychological functioning in older adults, Age 37, 9815.

Aragonés, MT., Fernández, P., Ley, V. (2016) Actividad física y prevalencia de patologías en la población española. Madrid Ministerio de Educación, Cultura y Deporte. Disponible en: https://sede.educacion.gob.es/ publiventa/actividad-fisicay-prevalencia-de-patologias-en-la-poblacion-espanola/deportes-saludpublica/21268.

Ardila, A., Ostrosky-Solis, F., Rosselli, M., \& C. (2000). Age Related Cognitive Decline During Normal Aging: The Complex Effect of Education. Archives of Clinical Neuropsychology, 15(6), 495-513 
Armanios, M., Blackburn, E.H. (2012). The telomere syndromes. Nat. Rev. Genet. $13,693-704$.

Arsenis N. C., You T., Ogawa E. F., Tinsley G. M., Zuo L. (2017). Physical activity and telomere length: impact of aging and potential mechanisms of action. Oncotarget 8 45008-45019.

Arslan, SS., Alemdaroğlu, İ., Karaduman, AA., Yilmaz, ÖT. (2019). The effects of physical activity on sleep quality, job satisfaction, and quality of life in office workers. Work, 63(1):3-7

Aubert, G., Lansdorp, P.M. (2008). Telomeres and aging. Physiol. Rev. 88, 557-579

Baker, LD., Frank, LL., Foster-Schubert, K., Green, PS., Wilkinson, CW., McTiernan, A., Craft, S. (2010). Aerobic exercise improves cognition for older adults with glucose intolerance, a risk factor for Alzheimer's disease. Journal of Alzheimer's disease : JAD, 22(2), 569-79.

Battaglia, G., Bellafiore, M., Alesi, M., Paoli, A., Bianco, A., Palma, A. (2016). Effects of an adapted physical activity program on psychophysical health in elderly women. Clinical Interventions in Aging, 11, 1009-1015.

Blackburn EH. (1991). Structure and function of telomeres. Nature, 350: 569-73

Blackburn EH. (2001). Switching and signaling at the telomere. Cell, 106(6):661-673

Blackford, R. C., \& La Rue, A. (1989). Criteria for diagnosing age- associated memory impairment: Proposed improvements from the field. Developmental Neuropsychology, 5(4), 295-306.

Bäckman, L., Wahlin, Å., Small, B. J., Herlitz, A., Winblad, B., \& Fratiglioni, L. (2004). Cognitive functioning in aging and Dementia: The Kungsholmen project. Aging, Neuropsychology, and Cognition, 11(2-3), 212-244.

Benton, AL., Hamsher, K.S. (1983). Contributions to neuropsychologic assement. Nueva York: Oxford University Press.

Bixby, WR., Spalding, TW., Haufler, AJ., et al. (2007). The unique relation of physical activity to executive function in older men and women. Med Sci Sports Exerc, 39(8):1408-141 
Borghini, A., Giardini, G., Tonacci, A., Mastorci, F., Mercuri, A., Mrakic-Sposta, S. (2015). Chronic and acute effects of endurance training on telomere length. Mutagenesis, 30:711-6.

Boucard, GK., Albinet, CT., Bugaiska, A., Bouquet, CA., Clarys, D., Audiffren, M. (2012) Impact of physical activity on executive functions in aging: a selective effect on inhibition among old adults. J Sport Exerc Psychol 34(6):808-827.

Brown, A.D., McMorris, CA., Longman, R.S., Leigh, R., Hill, MD., Friedenreich, CM. (2010). Effects of cardiorespiratory fitness and cerebral blood flow on cognitive outcomes in older women. Neurobiology of Aging, 31(12): 2047-2057.

Brown, LL., Zhang, YS., Mitchell, C., Ailshire, J. (2018). Does Telomere Length Indicate Biological, Physical, and Cognitive Health Among Older Adults? Evidence from the Health and Retirement Study. The journals of gerontology. Series A, Biological Sciences and medical sciences, 73(12), 1626-1632

Calvo, JI., Sánchez, C. (2013). Revitalización Geriátrica. Documentos de docencia en Grado Fisioterapia USAL.

Canela, A., Vera, E., Klatt, P., Blasco, M.A. (2007) High-throughput telomere length quantification by FISH and its application to human population studies Proc. Natl. Acad. Sci., 104: 5300-5305

Cascales-Angosto M., Álvarez, J.A. (2010). Telómeros y telomerasa, sus implicaciones en el envejecimiento y el cáncer. Anales de la Real Academia de Doctores de España, 14: 49-70.

Caspersen, C.J., Powell, KE., Christenson, G.M. (1985). Physical activity, exercise, and physical fitness: Definitions and distinctions for health-related research. Public Health Reports, 100(2):126-31.

Cerrillo-Urbina A.J., García-Hermoso A., Sánchez-López M., Pardo-Guijarro M.J., Santos Gómez J.L., Martínez-Vizcaíno V. (2015). The effects of physical exercise in children with attention deficit hyperactivity disorder: a systematic review and meta-analysis of randomized control trials. Child Care Health Dev, 41: 779-788 
Cherkas, L. F., Hunkin, J. L., Kato, B. S. (2008) The association between physical activity in leisure time and leukocyte telomere length. Arch. Intern. Med, 168, $154-158$.

Clemente, Y., García-Sevilla, J., Méndez, I. (2015). Memoria, funciones ejecutivas y deterioro cognitivo en población anciana. European Journal of Investigation in Health, Psychology and Education. 5 (2) 153-63

Cohen, I., Doniger, GM., Sinnreich, R., Simon, ES., Pinchas, R., Aviv, A. (2016). Increased attrition of leukocyte telomere length in young adults is associated with poorer cognitive function in midlife. Eur J Epidemiol, 31: 147-57.

Colcombe, S.J., Erickson, K.I., Raz, N., Webb, A.G., Cohen, N.J., McAuley, E. (2003). Aerobic fitness reduces brain tissue loss in aging humans. Journals of Gerontology Series A Biological Sciences and Medical Sciences, 58(2): 176-180

Colcombe, S.J., Erickson, K.I., Scalf, P.E., Kim, J.S., Prakash, R., McAuley, E. (2006). Aerobic exercise training increases brain volume in aging humans. J Gerontol A Biol Sci Med Sci, 61: 1166-1170.

Colcombe, S., Kramer, AF. (2003). Fitness effects on the cognitive function of older adults: a meta-analytic study. Psychol. Sci. 14, 125-130.

Collins, K., Mitchell, J.R. (2002). Telomerase in the human organism. Oncogene, 21(4):564-579

Córdoba, R., Camarelles, F., Muñoz, E., Gómez, J.M., San José, J., Ramírez, J.I., Martín, C., del Campo, M., Revenga, J. (2018). Recomendaciones sobre el estilo de vida. Actualización del PAPPS 2018. Aten Primaria, 50 (1):29-40

Correia, R., Nieto, MA., Barroso, J. (2010). Cambios cognitivos en el envejecimiento normal: influencias de la edad y su relación con el nivel cultural y el sexo. Universidad de la Laguna, Tenerife, España.

Counter, C.M., Avilion, A.A., Le Feuvre, C.L., Stewart, N.G., Greider, C.W., Harley, C.B. (1992). Telomere shortening associated with chromosome instability is arrested in immortal cells which express telomerase activity. EMBO J, 11: 19219 
Crook, T., Bartus, R., Ferris, S.P. Age associated memory impairment: Proposed diagnostic criteria and measures of clinical change report of a National Institute of Mental Health Work Group. (1986). Developmental Neuropsychology, 2, 261 276.

Denham, J., Nelson, C.P., O’Brien, B. J. (2013). Longer leukocyte telomeres are associated with ultra-endurance exercise independent of cardiovascular risk factors. PLoS One, 8, e69377.

Du, M., Prescott, J., Kraft, P., Han, J., Giovannucci, E., Hankinson, S. E., De Vivo, I. (2012) Physical activity, sedentary behavior, and leukocyte telomere length in women. Am. J. Epidemiol, 175, 414-422.

Dupuy, O., Gauthier, CJ., Fraser, SA., Desjardins-Crepeau, L., Desjardins, M., Mekary, S., Lesage, F., Hoge, RD., Pouliot, P., Bherer, L. (2015). Higher levels of cardiovascular fitness are associated with better executive function and prefrontal oxygenation in younger and older women. Front Hum Neurosci 9:66.

Edifizi, D., Schumacher, B. (2017). Omics approaches for identifying physiological adaptations to genome insbility in aging. Int J Mol Sci, 18(11): E2329

Erickson, KI., Prakash, R.S., Voss, M.W., Chaddock, L., Hu, L., Morris, K.S., Kramer, AF. (2009). Aerobic fitness is associated with hippocampal volume in elderly humans. Hippocampus, 19(10): 1030-1039.

Erickson, K.I., Voss, M.W., Prakash, R.S., Basak, C., Szabo, A., Chaddock, L., Kramer, A.F. (2011). Exercise training increases size of hippocampus and improves memory. Proceedings of the National Academy of Sciences, 108(7): 3017-3022.

Ferreira, L., Tanaka, K., Santos Galduroz, RF., Galduroz, J.C. (2015). Respiratory training as strategy to prevent cognitive decline in aging: a randomized controlled trial. Clin. Interv. Aging 10, 593-603.

Flores, I., Benetti, R., Blasco, M.A. (2006). Telomerase regulation and stem cell behavior. Curr Opin Cell Biol, 18(3):254-260.

Flöel, A., Ruscheweyh, R., Krüger, K., Willemer, C., Winter, B., Völker, K., Knecht, S. (2010). Physical activity and memory functions: Are neurotrophins and cerebral gray matter volume the missing link? NeuroImage, 49(3): 2756-2763. 
Forsyth, N.R., Wright, W.E., Shay, J.W. (2002). Telomerase and differentiation in multicellular organisms: turn it off, turn it on, and turn it off again. Differentiation, 69(4-5):188-197.

Freudenberger, P., Petrovic, K., Sen, A., Toglhofer, A. M., Fixa, A., Hofer, E., Schmidt, H. (2016). Fitness and cognition in the elderly: The Austrian Stroke Prevention Study. Neurology, 86(5), 418-424

Fyhrquist, F., Saijonmaa, O. (2012). Telomere length and cardiovascular aging. Ann.Med, 44 (1): S138-S142

Gallardo, M. (2012). Implicaciones de la longitud de los telómeros en la biología reproductiva. Rev Asoc Est Biol Rep, 17 (2): 39-44.

Gow, A.J., Corley, J., Starr, J.M., Deary, I.J. (2012). Reverse causation in activity cognitive ability assocaitions: the lothian birth cohort 1936. Phychol Aging, 27: 250-255.

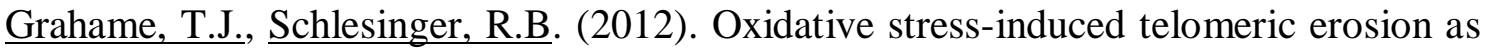
a mechanism underlying airborne particulate matter-related cardiovascular disease $_{2}$ 19;9:21.

Haaland, K. Y., Price, L., \& Larue, A. (2003). What does the WMS-III tell us about memory changes with normal aging? Journal of the International Neuropsychological Society: JINS, 9(1), 89-96.

Haber, D.A. (1995). Clinical implications of basic research: telomeres, cancer, and immortality. N Eng J Med, 332: 955-6,

Hägg, S., Zhan, Y., Karlsson, R., Gerritsen, L., Ploner, A., van der Lee, SJ., Broer, L., Deelen, J., Marioni, RE., Wong, A. (2017). Short telomere length is associated with impaired cognitive performance in European ancestry cohorts. TranslPsychiatry, 7(4): e1100

Hastie, N.D., Dempster, M., Dunlop, M.G., Thompson, A.M., Green, D.K., Allshire, R.C. (1990) Telomere reduction in human colorectal carcinoma and with ageing Nature, 346: 866-868 
Haycock, P.C., Heydon, E.E., Kaptoge, S., Butterworth, A.S., Thompson, A., Willeit, P. (2014). Leucocyte telomere length and risk of cardiovascular disease: systematic review and meta-analysis. The BMJ, 349: 4227.

Hayflick, L. (1965). The limited in vitro lifetime of human diploid cell strains. Exp Cell Res, 37: 614-36

He, F., Li, J., Liu, Z., Chuang, CC., Yang, W., Zuo, L. (2016). Redox mechanism of reactive oxygen species in exercise. Front. Physiol.7: 486

Hernández-González, C., González-Martínez, J. (2013). Teorías del envejecimiento. In: L. Rocha Durán, La vejez en movimiento. Un enfoque integral, 1 ed. Capítulo 3. Buenos Aires: Dunken, 43-50.

Hertzog, C., Kramer, A., Wilson, R., Linderberg, U. (2009). Fit body, fit mind. Sci Am Mind, 20: 24-31

Holt, S.E., Wright, W.E., Shay, J.W. (1996). Regulation of telomerase activity in immortal cells lines. EMBO J, 16: 2932-9

Hötting, K., Röder, B. (2013). Beneficial effects of physical exercise on neuroplasticity and cognition. Neurosci Biobehav Rev, 37: 2243-2257

Huzen, J., Wong, L.S., van Veldhuisen, D.J., Samani, N.J., Zwinderman, A.H., Codd, V., Cawthon, R.M., Benus, G.F., van der Horst, I.C., Navis, G., Bakker, S.J., Gansevoort,R.T., de Jong, P.E., Hillege, H.L., van Gilst, W.H., de Boer, R.A., van der Harst, P. (2013). Telomere length loss due to smoking and metabolic traits. J. Intern. Med, 275(2):155-63.

Instituto Nacional de Estadísticas. (2018). España en Cifras 2018. Publicaciones INE.

Itzkovitz, S., Shlush, LI., Glyck, D., Skorecki, K. (2008). Population mixture model for nonlinear telomere dynamics. Phys Rev, E78 060902-1-060902-4.

Iwama, H., Ohyashiki, K., Ohyashiki, J.H., Hayashi, S., Yahata, N., Ando, K., Toyama,

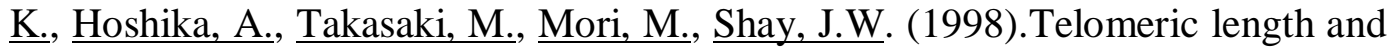
telomerase activity vary with age in peripheral blood cells obtained from normal individuals. Hum Genet., 102(4):397-402. 
John, RB., Jennifer, CD., Teresa, LA. (2015). Longitudinal Analysis of Physical Performance, Functional Status, Physical Activity, and Mood in Relation to Executive Function Among Older Fallers. J Am Geriatr Soc., 63(6): 1112-1120.

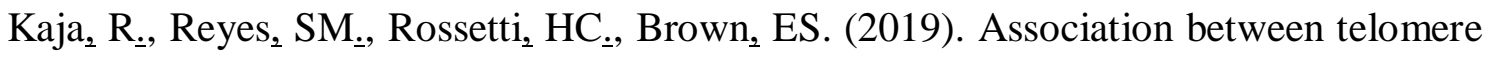
length and cognitive ability in a community-based sample. Neurobiol Aging, 75:51-53

Karr, JE., Areshenkoff, CN., Rast, P., Garcia-Barrera, MA. (2014). An empirical comparison of the therapeutic benefits of physical exercise and cognitive training on the executive functions of older adults: a meta-analysis of controlled trials. Neuropsychology, 28: 829-845

Khan, S.S., Singer, B.D., Vaughan, D.E. (2017). Molecular and physiological manifestations and measurement of aging in humans. Aging Cell, 16(4): 624-33

Kawanishi, S., Oikawa, S. (2004). Mechanism of telomere shortening by oxidative stress. Ann. New York Acad. Sci. 1019 278-284

Kisner, C, Colby, L. (2010). Ejercicio Terapéutico. Fundamentos y técnicas, ed. 5. Ed Pan 1: 2-36

Kojda, G., Hambrecht, R. (2005). Molecular mechanisms of vascular adaptations to exercise: physical activity as an effective antioxidant therapy? Cardiovasc Res, $67: 187-9$

Kramer, AF., Hahn, S., McAuley, E., Cohen, NJ., Banich, MT., Harrison, C., et al. (2001). Exercise, aging and cognition: Healthy body, healthy mind. En: A. D. Fisk $\&$ W. Rogers. Human factors interventions for the health care of older adults 91120

Kramer, A., Madden, D. (2008). Attention. In F. Craik \& T. Salthouse, The handbook of aging and cognition 3rd Edition. New York: Psychology Press,189-249.

Kramer, A.F., Colcombe, S. (2018). Fitness effects on the cognitive function of older adults: a meta-analytic study-revisited. Perspect Psychol Sci, 13: 213-217

Ku, P., Stevinson, C., Chen, L. (2012). Prospective associations between leisure-time physical activity and cognitive performance among older adults across an 11 years period. J Epidemiol, 22: 230-237 
Lanfranco, R., Manriquez-Navarro, P., Avello, L., Canales-Johnson, A. (2012). Evaluación de la enfermedad de Alzheimer en etapa temprana: biomarcadores y pruebas neuropsicológicas. Revista médica de Chile, 140(9): 1191-1200

Langlois, F., Vu, TM., Chasse, K., Dupuis, G., Kergoat, MJ., Bherer, L. (2012). Benefits of physical exercise training on cognition and quality of life in frail older adults. Journals of Gerontology Series B: Psychological Sciences and Social Sciences, 68(3), 400-404.

LaRocca, T.J., Seals, D.R., Pierce, GL. (2012) Leukocyte telomere length is preserved with aging in endurance exercise-trained adults and related to maximal aerobic capacity. Mech. Ageing Dev, 131, 165-167.

Laso, FJ. (2015). Introducción a la medicina clínica. Fisiopatología y semiología. Barcelona, España: Elsevier.

Laufs, U.1., Werner, N., Link, A., Endres, M., Wassmann, S., Jürgens, K., Miche, E., Böhm, M., Nickenig, G. (2004). Physical training increases endothelial progenitor cells, inhibits neointima formation, and enhances angiogenesis. Circulation, 20;109(2):220-6.

Lee, IM., Shiroma, E.J., Lobelo, F., Puska, P., Blair, S.N., Katzmarzyk, P.T. (2012). Impact of Physical Inactivity on the World's Major Non- Communicable Diseases. Lancet, 380:219-29.

Lin, S., Yang, Y., Qi, Q., Wei, L., Jing, N., Jie, Z., Shifu, X. (2019). The Beneficial Effect of Physical Exercise on Cognitive Function in a Non-dementia Aging Chinese Population. Frontiers in aging neuroscience, 11, 238.

Lin, X., Zhou, J., Dong, B. (2019). Effect of different levels of exercise on telomere length: A systematic review and meta-analysis. J Rehabil Med, 8;51 (7):473-78.

Livingston, G., Sommerlad, A., Orgeta, V., Costafreda, SG., Huntley, J., Ames, D., et al. (2017). Dementia prevention, intervention, and care. Lancet 390 2673-2734.

Lobo, A., Ezquerra, J., Bugarda, F.G., et al. (1979). El Mini Examen Cognoscitivo. Un test sencillo y práctico para detectar alteraciones intelectuales en pacientes médicos. Act Luso Esp Neurol Psiquiatr Cienc Afines, 7:198-202. 
López-Otín, C., Blasco, M.A., Partridge, L., Serrano, M., Kroemer, G., (2013). The hallmarksof aging. Cell 153, 1194-1217.

Ludlow, AT, Roth, SM. (2011). Physical activity and telomere biology:exploring the link with aging-related disease prevention, J Aging Res, 790378.

Ludlow, A.T., Zimmerman, J. B., Witkowski, S., Hearn, J. W., Hatfield, B. D., Roth, S. M. (2008) Relationship between physical activity level, telomere length, and telomerase activity. Med. Sci. Sports Exerc, 40, 1764-1771.

Ma, H., Zhou, Z., Wei, S., Liu, Z., Pooley, K.A., Dunning, A.M., Svenson, U., Roos, G., Hos-good 3rd, H.D., Shen, M., Wei, Q., (2011). Shortened telomere length is associated with increased risk of cancer: a meta-analysis. PLoS ONE 6, e20466

Maillot, P., Perrot, A., Hartley, A. (2012). Effects of interactive physical-activity videogame training on physical and cognitive function in older adults. Psychol. Aging 27, 589-600.

Mastaloudis, A., Leonard, S. W., Traber, M. G. (2001) Oxidative stress in athletes during extreme endurance exercise. Free Radic. Biol. Med, 31, 911-922.

Mastaloudis, A., Yu, T. W., O’Donnell, R. P., Frei, B., Dashwood, R. H., Traber, M. G. (2004). Endurance exercise results in DNA damage as detected by the comet assay. Free Radic. Biol. Med, 36, 966-975.

Mathur, S., Ardestani, A., Parker, B., Cappizzi, J., Polk, D., Thompson, P. D. (2013) Telomere length and cardiorespiratory fitness in marathon runners. J. Investig. Med. 61, 613-615.

Mekari, S., Dupuy, O., Martins, R., Evans, K., Kimmerly, DS ., Fraser, S., Neyedli, HF. (2019). The effects of cardiorespiratory fitness on executive function and prefrontal oxygenation in older adults. Geroscience, 15.

Mirabello, L., Huang, W. Y., Wong, J. Y., Chatterjee, N., Reding, D., Crawford, E. D., De Vivo, I., Hayes, R. B., Savage S. A. (2009) The association between leukocyte telomere length and cigarette smoking, dietary and physical variables, and risk of prostate cancer. Aging Cell, 8, 405-413.

Moffat, S. D. (2009). Aging and spatial navigation: what do we know and where do we go? Neuropsychology Review, 19(4), 478-489. 
Mundstock, E., Zatti, H., Louzada, F.M., Oliveira, S.G., Guma, F.T., Paris, M.M. (2015). Effects of physical activity in telomere length: Systematic review and meta-analysis. Ageing Res Rev, 22:72-80.

Netz, Y., Dwolatzky, T., Zinker, Y., Argov, E., Agmon, R. (2011). Aerobic fitness and multidomain cognitive function in advanced age. International Psychogeriatrics, (1):114-24

Nilsson, LG. (2003). Memory function in normal aging. Acta Neurologica Scandinavica. Supplementum, 179, 7-13.

Nilsson, L.G., Adolfsson, R., Bäckman, L., de Frias, C.M., Molander, B., Nyberg, L. (2004). Betula: A Prospective Cohort Study on Memory, Health and Aging. Aging, Neuropsychology, and Cognition, 11(2-3), 134-148.

Nitrini, R., Dozzi-Brucki, SM. (2012). Demencia: definición y clasificación. Neuropsicología, Neuropsiquiatría y Neurociencias, 12(1): 75-98.

Northey, JM., Cherbuin, N., Pumpa, KL., Smee, DJ., Rattray, B. (2017).Exercise interventions for cognitive function in adults older than 50: a systematic review with meta-analysis. Br J Sports Med, 0:1-9.

Oberlin, L.E., Verstynen, T.D., Burzynska, A.Z., Voss, M.W., Prakash, R.S., Chaddock-Heyman, L. (2016). White matter microstructure mediates the relationship between cardiorespiratory fitness and spatial working memory in older adults. Neuroimage, (131): 91-101

O'Callaghan, N.J., Fenech, M. (2011). A quantitative PCR method for measuring absolutetelomere length. Biol Proced Online 13, 3.

OMS. Nota Descroptiva del 22 de Julio de 1946.

OMS. Nota Descriptiva del 23 de Febrero de 2018.

OMS. Datos y Cifras del 14 de Mayo de 2019.

ONU. Population Ageing and Development. 2009: New York.

Opresko, P.L., Shay, J.W. (2017). Telomere-associated aging disorders. Ageing Res. Rev, 33, 52-66. 
Ornish, D., Lin, J., Chan, J.M., Epel, E., Kemp, C., Weidner, G. (2013). Effect of comprehensive lifestyle changes on telomerase activity and telomere length in men with biopsy-proven low-risk prostate cancer: 5-year follow-up of a descriptive pilot study. Lancet Oncol, 14(11):1112-20.

Østhus, I. B., Sgura, A., Berardinelli, F. (2012) Telomere length and long-term endurance exercise: does exercise training affect biological age? A pilot study. PLoS One, 7, e52769

Piepoli M.F., Hoes, A.W., Agewall, S., Albus, C., Brotons, C., Catapano, A.L., Cooney, M.T., Corra, U., Cosyns, B., Deaton, C., Graham, I., Hall, M.S., Hobbs, F.D., Lochen, M.L., Lollgen, H., Marques-Vidal, P., Perk, J., Prescott, E., Redon, J., Richter, D.J., Sattar, N., Smulders, Y., Tiberi, M., van der Worp, H.B., van Dis, I., Verschuren, W.M. (2016). European guidelines on cardiovascular disease prevention in clinical practice. Eur Heart J, 37:2315-2381.

Podewils, L.J. (2005). Physical Activity, APOE Genotype, and Dementia Risk: Findings from the Cardiovascular Health Cognition Study. American Journal of Epidemiology, 161(7): 639-651.

Rae, D. E., Vignaud, A., Butler-Browne, G. S., Thornell, L. E., Sinclair-Smith, C., Derman, E.W., Lambert, M. I., Collins, M. (2010) Skeletal muscle telomere length in healthy, experienced, endurance runners. Eur. J. Appl. Physiol, 109, 323-330.

Ramirez, R., Carracedo, J., Jiménez, R., Canela, A., Herrera, E., Aljama, P., Blasco, M.A. (2003). Massive telomere loss is an early event of DNA damage-induced apoptosis. J Biol Chem, 278(2):836-842.

Reichert, S., Froy, H., Boner, W., Burg, T.M., Daunt, F., Gillespie, R., Griffiths, K., Lewis,S., Phillips, R.A., Nussey, D.H., Monaghan, P. (2017). Telomere length measurementby qPCR in birds is affected by storage method of blood samples. Oecologia 184,341-350.

Reitan, R.M. (1992). Trail Making Test. Manual for administration and scoring. Tucson: Reitan Neuropsychology Laboratory 
Reiter, K., Nielson, K.A., Smith, T.J., Weiss, L.R., Alfini, A.J., Smith J.C. (2015). Improved cardiorespiratory fitness is associated with increased cortical thickness in mild cognitive impairment. J Int Neuropsychol Soc, 21:757-767.

Rey, A. (1968). Memorisation d'e une serie de 15 mots en 5 répétitions. L'examen clinique en psychologie. París: PUF.

Robles, A., Del Ser, T., Alom, J., Peña-Casanova, J. (2002). Propuesta de criterios para el diagnóstico clínico del deterioro cognitivo ligero, la demencia y la enfermedad de Alzheimer. Revista de Neurología, 17(1): 17-32.

Rufer, N., Brummendorf, T. H., Kolvraa, S., Bischoff, C., Christensen, K., Wadsworth, L., Schulzer, M., Lansdorp, P. M. (1999). Telomere fluorescence measurements in granulocytes and $\mathrm{T}$ lymphocyte subsets point to a high turnover of hematopoietic stem cells and memory T cells in early childhood. J. Exp. Med, 190, 157-167

Safar, M.E. (2010). Arterial aging-hemodynamic changes and therapeutic optionsn. Nature Publishing Group, 7, 442-449

Salech, F., Michea L. (2012). Cambios fisiológicos asociados al envejecimiento. Revista Médica Clínica Las Condes, 23 (1): 19-29

Salthouse, T. (1996). The processing-speed theory of adult age differences in cognition. Psychological review, 103(3), 403-28.

Savela, S., Saijonmaa, O., Strandberg, TE., Koistinen, P., Strandberg, AY., Tilvis, RS. (2013). Physical activity in midlife and telomere length measured in old age. Cardiovasc J Afr, 48: 81-4.

Sawyer, JR., Roloso, GJ., Bell, JM., Thomas, JR., Teo, C., Chadduck, WM. (1996). Telomeric associations in the progression of chromosome aberrations in pediatric solid tumors. Cancer Genet. Cytogenet, 90: 1-13

Schuler, G., Adams, V., Goto, Y. (2013). Role of exercise in the prevention of cardiovascular disease: results, mechanisms, and new perspectives. Eur Heart J, 34: 1790-99.

Sedivy, JM. (1998). Can ends justify the means? Telomeres and mechanisms of replicative senescence and immortalization in mammalian cells. Proc Natl Acad Sci USA, 95: 9078-81 
Sfeir, A \& de Lange T. (2012). Removal of shelterin reveals the telomere end-protection problem. Science, 336: 593-97.

Sfeir, AJ., Chai, W., Shay, JW., Wright, WE. (2005). Telomere-end processing the terminal nucleotides of human chromosomes. Mol Cell, 18(1):131-138

Shadyab, AH., LaMonte, MJ., Kooperberg, C., Reiner, AP., Carty, CL., Manini, TM. (2017). Leisure-time physical activity and leukocyte telomere length among older women. Exp. Gerontol, 95 141-147

Shay, JW., Werbin, H., Wright, WE. (1996). Telomeres and telomerase in human leukemias. Leukemia, 10: 1255-6

Shiels, P.G., McGlynn, L.M., MacIntyre, A., Johnson, P.C., Batty, G.D., Burns, H.,Cavanagh, J., Deans, K.A., Ford, I., McConnachie, A., McGinty, A., McLean, J.S.,Millar, K., Sattar, N., Tannahill, C., Velupillai, Y.N., Packard, C.J., (2011). Acceler-ated telomere attrition is associated with relative household income, diet andinflammation in the pSoBid cohort. PLoS ONE 6, e22521

Sjögren, P., Fisher, R., Kallings, L., Svenson, U., Roos, G., Hellénius, ML. (2014) Stand up for health-avoiding sedentary behaviour might lengthen your telomeres: secondary outcomes from a physical activity RCT in older people. Br. J. Sports Med., 48, 1407-09

Slagboom, PE., Droog, S., Boomsma, DI. (1994). Genetic determination of telomere size in humans: a twin study of three age groups Am. J. Hum. Genet., 55, 876-882

Slijepcevic, P., Bryant, PE. (1998). Chromosome healing, telomere capture and mechanisms of radiation-induced chromosome breakage. Int J Radiat Biol, 73: 113.

Smith, PJ., Blumenthal, JA., Hoffman, BM., Cooper, H., Strauman, TA., WelshBohmer, K., Sherwood, A. (2010). Aerobic exercise and neurocognitive performance: A meta-analytic review of randomized controlled trials. Psychosomatic Medicine, 72, 239-252. doi:10.1097/PSY.0b013e3181d14633

Spartano, NL., Demissie, S., Himali, JJ., Dukes, KA., Murabito, JM., Vasan, RS., Seshadri, S. (2019). Accelerometer-determined physical activity and cognitive 
function in middle-aged and older adults from two generations of the Framingham Heart Study. Alzheimer's \& dementia (New York, N. Y.), 5, 618-26.

Srinivas, N., Rachakonda, S., Hielscher, T., Calderazzo, S., Rudnai, P., Gurzau, E.,Koppova, K., Fletcher, T., Kumar, R. (2019). Telomere length, arsenic exposure andrisk of basal cell carcinoma of skin. Carcinogenesis, Mol Cell, 18(1):131-138.

Stroop, JR. (1935). Studies of interference in serial verbal reactions. J Exp Psychol, $18: 643$

Stuss, D. (2006). Frontal lobes and attention: processes and networks, fractionation and integration. Journal of the International Neuropsychological Society, 12(02), 261271.

Svenson, U., Nordfjäll, K., Baird, D., Roger, L., Osterman, P., Hellenius, ML., Roos, G. (2011) Blood cell telomere length is a dynamic feature. PLoS One, 6, e21485

Theall, KP., McKasson, S., Mabile, E., Dunaway, LF., Drury, SS. (2013). Early hits and long-term consequences: tracking the lasting impact of prenatal smoke exposure on telomere length in children. Am J Public Health.103 (1):133-5

Thomas, AG., Dennis, A., Rawlings, NB., Stagg, CJ., Matthews, L., Morris, M. (2016). Multi-modal characterization of rapid anterior hippocampalvolume increase associated with aerobic exercise. Neuroimage, 131, 162-170.

Thomas, P., Pesce, A., Cassuto, JP. (1990) ABC de enfermedad de Alzheimer. Barcelona.

Torres, M., Quezada, M., Rioseco, R., Ducci, ME. (2008). Calidad de vida de adultos mayores pobres de viviendas básicas: Estudio comparativo mediante uso de WHOQOL-BREF. Rev Med Chile,136: 325-333.

Unryn, BM., Cook, LS., Riabowol, K.T. (2005). Paternal age is positively linked to telomere length of children. Aging Cell 4, 97-101

Van der Elst, W., Van Boxtel, MP., Van Breukelen, GJ., Jolles, J. (2006). The Stroop color-word test: influence of age, sex, and education; and normative data for a large sample across the adult age range. Assessment, 13(1), 62-79. 
Van Uffelen, JG., Chin, APM., Hopman-Rock, M., van MW. (2008). The effects of exercise on cognition in older adults with and without cognitive decline: a systematic review. Clin J Sport Med. 18(6):486-500.

Véliz, M., Riffo, B., Arancibia, B. (2010). Envejecimiento cognitivo y procesamiento del lenguaje: cuestiones relevantes, 48 (1): 75-103

Vera, E., Bernardes, B., Foronda, M., Flores, J., Blasco, M. (2012). The Rate of Increase of Short Telomeres Predicts Longevity in Mammals. Cells Reports, 2(4); $732-7$

Von Zglinicki, T., Pilger, R., Sitte, N. (2000). Accumulation of single- strand breaks is the major cause of telomere shortening in human fibroblasts. Free Radic Biol Med, 28(1):64-74.

Voss, MW., Prakash, RS., Erickson, KI., Basak, C., Chaddock, L., Kim, JS. (2010) Plasticity of brain networks in a randomized intervention trial of exercise training in older adults. Frontiers in Aging Neuroscience, 2: 1-17.

Warburton, DE., Nicol, CW., Bredin, SS. (2006). Health benefitsof physical activity: The evidence. Can Med Assoc J, 174: 801-09

Werner, C., Fürster, T., Widmann, T., Pöss, J., Roggia, C., Hanhoun, M. (2009). Physical Exercise Prevents Cellular Senescence in Circulating Leukocytes and in the Vessel Wall. Circulation, 120(24):2438-47.

Whittemore, K., Vera, E., Martínez-Nevado, E., Sanpera, C., Blasco, M. (2019). Telomere shortening rate predicts species life span. PNAS, 116 (30) 15122-27.

Williamson, JD., Espeland, M., Kritchevsky, SB., Newman, AB., King, AC., Pahor, M., Guralnik, JM., Pruitt, LA., Miller, ME. (2009). Changes in cognitive function in a randomized trial of physical activity: results of the lifestyle interventions and independence for elders pilot study. J Gerontol A Biol Sci Med Sci, 64(6):688-94.

Woo, J., Tang, N., Leung, J. (2008). No association between physical activity and telomere length in an elderly Chinese population 65 years and older. Arch. Intern. Med.168, 2163-64.

Wolkowitz, O.M., Mellon, S.H., Epel, E.S., Lin, J., Dhabhar, F.S., Su, Y., Reus, V.I., Rosser, R., Burke, H.M., Kupferman, E., Compagnone, M., Nelson, J.C., 
Blackburn,E.H. (2011). Leukocyte telomere length in major depression: correlations withchronicity, inflammation and oxidative stress - preliminary findings. PLoS ONE6, e17837

Wrigth, DL., Jones, EL., Mayer, JF., Oehninger, WE., Lanzendorf, SE. (2001) Characterization of telomerase activity in the human oocyte and preimplantation embryo. Mol Hum Reprod, 7(10):947-55.

Xiufang, L., Jianghua, Z., Birong, D. (2019). Effect of different levels of exercise on telomere length: a systematic review and meta-analysis. J Rehabil Med, 51: 47378.

Yaffe, K., Barnes, D., Nevitt, M., Lui, LY., Covinsky, K. (2001). A prospective study of physical activity and cognitive decline in elderly women: women who walk. Arch Intern Med, 161(14):1703-8.

Yaffe, K., Lindquist, K., Kluse, M., Cawthon, R., Harris, T., Hsueh, WC., Simonsick, EM., Kuller, L., Li, R., Ayonayon, HN. (2011). Telomere length and cognitive function in community-dwelling elders: findings from the Health $\mathrm{ABC}$ Study. Neurobiol Aging, 32 (11):2055-2060

Yun, A. (2019). How,Does Obesity and Physical Activity Affect Aging?: Focused on Telomere as a Biomarker of Aging. Journal of Obesity \& Metabolic Syndrome, 28: $92-104$

Zakian, Va. (1995). Telomeres: beginning to understand the end. Science, 270: 1601-7

Zhao, J., Miao, K., Wang, H., Ding, H., Wang, D.W. (2013). Association between telom-ere length and type 2 diabetes mellitus: a meta-analysis. PLOS ONE 8, e79993.

Zhang, L., Hu, X.Z., Li, X., Li, H., Smerin, S., Russell, D., Ursano, R.J., (2014). Telomere length - a cellular aging marker for depression and post-traumatic stressdisorder. Med. Hypotheses 83, 182-5. 
ANEXO 


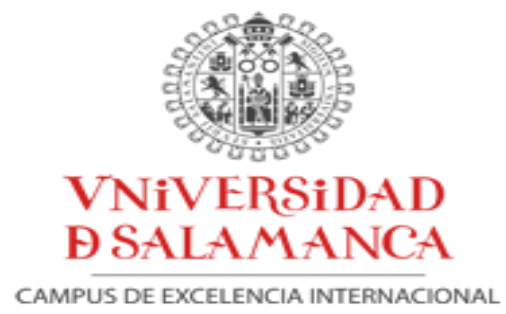

ÁREA DE FISIOTERAPIA

CAMPUS DE EXCELENCIA INTERNACIONAL

\section{ANEXO I.}

\section{LEA ESTA HOJA DETENIDAMENTE}

Objetivo del estudio: Se le ha invitado a participar en un estudio que tiene como objetivo principal valorar los efectos del Programa de Revitalización Geriátrica (PREGE) en el rendimiento de las funciones cognitivas como los procesos atencionales (atención), las funciones mnésicas (memoria) y las funciones ejecutivas (rapidez de procesamiento) con respecto a un grupo de población que no participa en dicho programa. Los sujetos no participantes en el PREGE serán sujetos que participen en algunas de las actividades que oferta el Ayuntamiento de Salamanca (taller de informática, de bricolaje etc...). Además, otro de los objetivos del estudio será comparar la longitud de sus telómeros (uno de los principales biomarcadores causantes del envejecimiento) entre ambos grupos de población.

Beneficios del estudio: Los beneficios esperados de este estudio consisten en mejorar el rendimiento neuropsicológico de las diversas tareas evaluadas.

Procedimientos del estudio: En caso de aceptar participar en el estudio se le pasaran una serie cuestionarios y test de evaluación. Estos test no les causaran daño alguno y manteniendo el anonimato completo de las identidades de los sujetos incluidos en el estudio. La investigación tendrá una duración de 6 meses y los cuestionarios se repetirán al inicio y al finalizar. Además, se les realizará una anamnesis detallada donde se recogerán datos como edad, talla, peso, medicación y tensión arterial. Para determinar la longitud de los telómeros en ambos grupos de población se hará a través de una muestra de saliva (medición no invasiva). 
La evaluación biológica de los telómeros será realizada por el Dr. D. Rogelio González Sarmiento a través de pruebas de saliva (procedimiento no invasivo), en un sólo momento de toma para ambos grupos para posteriormente medir las diferencias entre ambos grupos

Riesgos asociados al estudio: No existen riesgos añadidos por participar en el estudio.

\section{Aclaraciones:}

- No tendrá ninguna consecuencia negativa en caso de no participar en la investigación.

- Si decide participar, podrá retirarse en el momento que desee sin tener que dar ningún tipo de explicación.

- Su participación en la investigación no supondrá coste económico alguno para usted.

- Su participación es voluntaria sin ningún tipo de retribución económica.

- La información personal de cada paciente será mantenida en estricta confidencialidad por el grupo de investigadores, pudiendo ser utilizados los datos obtenidos en el estudio. En caso de considerarlo necesario por parte del equipo de investigación o a petición propia de los participantes nos comprometemos a informarle de los resultados obtenidos. 


\section{Declaración de consentimiento}

Yo, Don/Dña. con D.N.I. he leído el documento de consentimiento informado que me ha sido entregado, he comprendido las explicaciones en él facilitadas y he podido resolver todas las dudas y preguntas que he planteado al respecto. También comprendo que, en cualquier momento y sin necesidad de dar ninguna explicación, puedo revocar el consentimiento que ahora presento. También he sido informado/a de que mis datos personales serán protegidos y serán utilizados únicamente con fines de formación y desarrollo profesional para el equipo de investigación. Tomando todo ello en consideración y en tales condiciones, CONSIENTO participar en dicha investigación y que los datos que se deriven de mi participación sean utilizados para cubrir los objetivos especificados en el documento.

En Salamanca, a........ de de 2018

Firmado:

Don/Dña. (El/la usuario/a) 